Does Fiscal Policy Benefit the Poor and Reduce Inequality in Namibia?

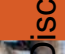
(y) Man. (y) (N) Ning

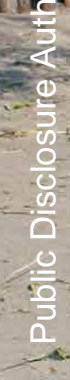

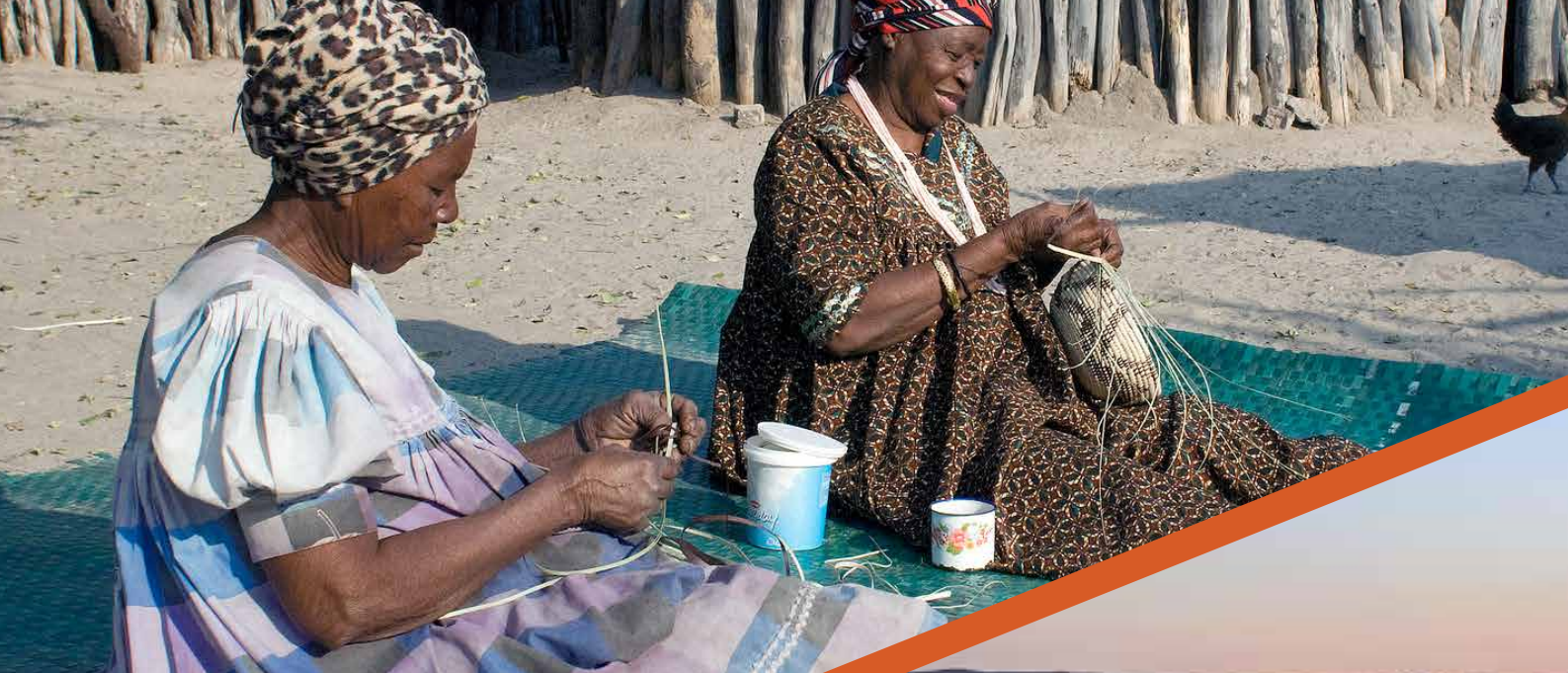

3
$\frac{1}{1}$
$\frac{1}{0}$
0
0
0
0
$\frac{0}{0}$
0
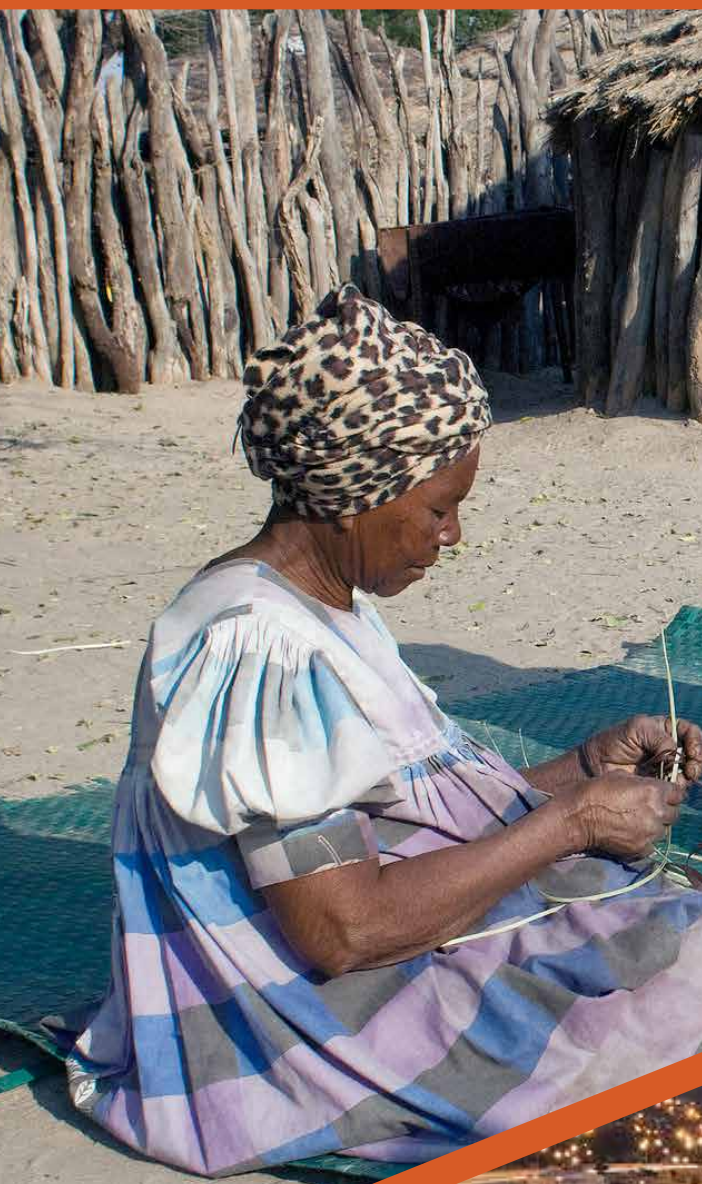

(3)

(2)

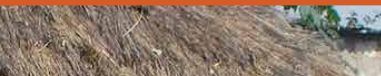

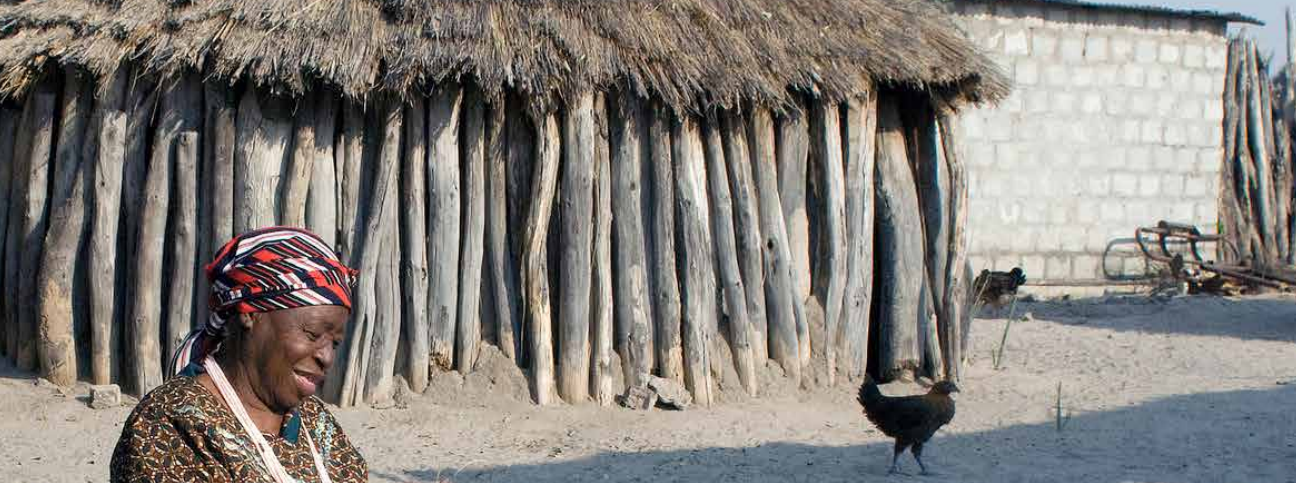

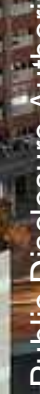

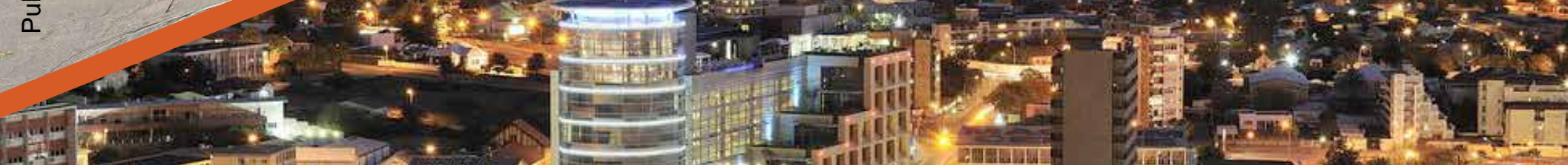

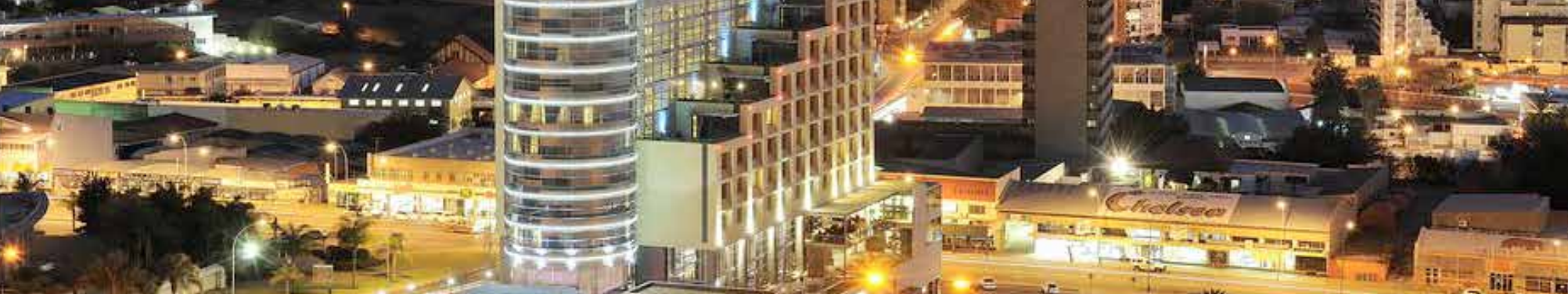

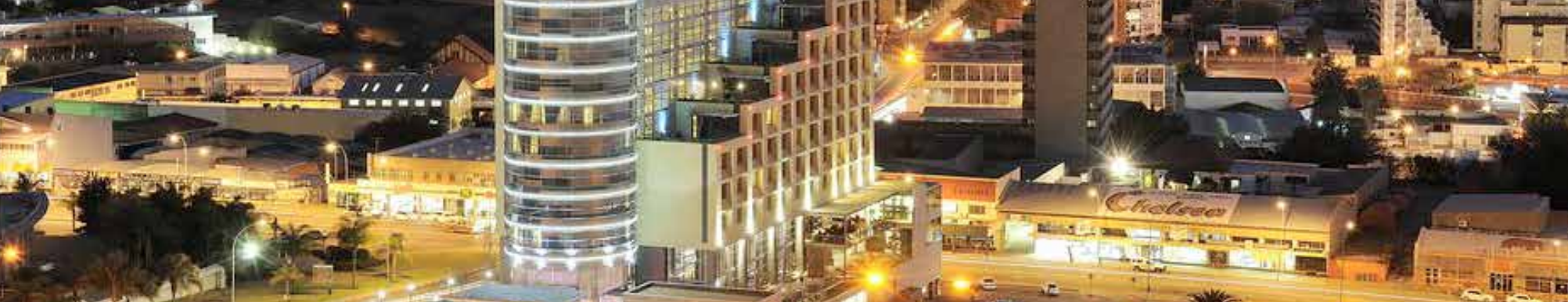

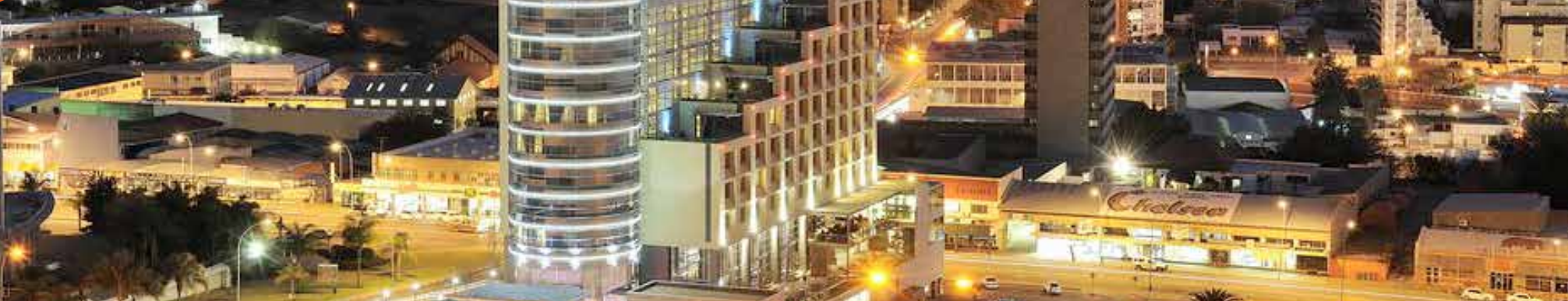

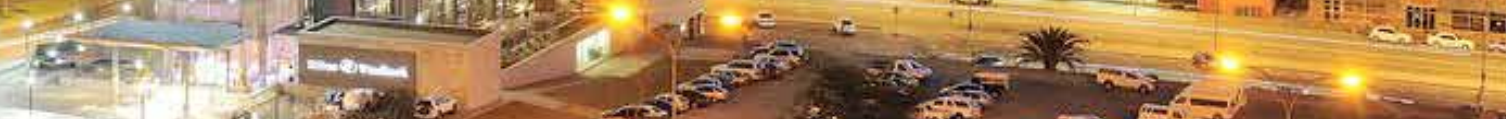

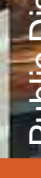

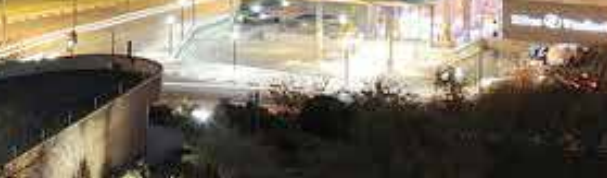
S. Sossos: 

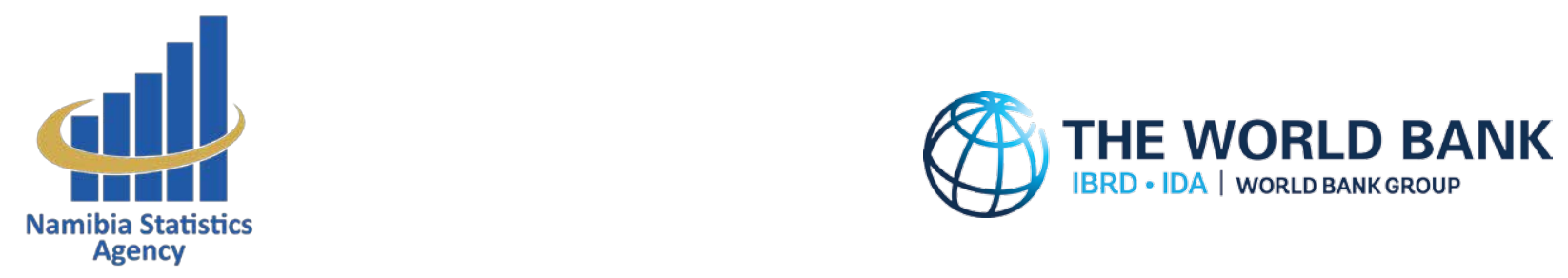

\section{Does Fiscal Policy Benefit the Poor and Reduce Inequality in Namibia?}

\section{The Distributional Impact of Fiscal Policy in Namibia}


(C) 2017 International Bank for Reconstruction and Development / The World Bank 1818 H Street NW

Washington DC 20433

Telephone: 202-473-1000

Internet: www.worldbank.org

This work is a product of the staff of The World Bank in close collaboration with staff of the Namibia Statistics Agency. The findings, interpretations, and conclusions expressed in this work do not necessarily reflect the views of The World Bank, its Board of Executive Directors, or the governments they represent. The World Bank does not guarantee the accuracy of the data included in this work. The boundaries, colors, denominations, and other information shown on any map in this work do not imply any judgment on the part of The World Bank concerning the legal status of any territory or the endorsement or acceptance of such boundaries.

\section{Rights and Permissions}

The material in this work is subject to copyright. Because The World Bank encourages dissemination of its knowledge, this work may be reproduced, in whole or in part, for noncommercial purposes as long as full attribution to this work is given.

Any queries on rights and licenses, including subsidiary rights, should be addressed to World Bank Publications, The World Bank Group, 1818 H Street NW, Washington, DC 20433, USA; fax: 202-522-2625; e-mail: pubrights@worldbank.org.

Front cover, top: Basket weavers in Ongula, Northern Namibia @Philip Schuler / World Bank

Front cover, bottom: Hilton Windhoek Hotel - Studio One, Photography Markus Weiss

Back photo: Ev Thomas/Shutterstock.com

The report was designed and typeset by Shereno Printers, Gauteng, South Africa. 


\section{Contents}

Preface vi vi vi

Foreword vii

Acknowledgements viii

Executive Summary 1

Chapter 1: Poverty and Inequality Context in Namibia $\quad \mathbf{4}$

A. Why this study? 4

B. Setting the stage: Namibia's development challenges 4

C. Responding to the challenges of poverty and inequality 9

D. Why now? 11

E. Content of the report 13

Chapter 2: Namibia's Tax and Public Benefits System 14

A. Structure of taxes 14

B. Public social benefits system 18

C. Non-social spending benefits (indirect subsidies) assessed in this study 21

Chapter 3: Methodology and Data $\quad 22$

A. What is fiscal incidence analysis? 22

B. Data, incomes, and income components 27

Chapter 4: Incidence and Progressivity of Taxes $\quad 30$

A. Direct taxes 31

B. Indirect taxes $\quad 32$

C. Progressivity of total taxes (direct and indirect) 33

Chapter 5: Incidence and Efficiency of Social Spending 35

A. Incidence and efficiency of direct transfers 35

B. Incidence and efficiency of indirect subsidies 44

C. Progressivity of in-kind transfers: education and health 45

D. Tying it all together: Progressivity of the fiscal system 48

Chapter 6: Impact of Fiscal Policy on Poverty and Inequality $\quad \mathbf{5 0}$

A. Overall impact of fiscal policy on poverty and inequality 50

B. Marginal contribution of the components to poverty and inequality reduction 54

C. Comparison to other middle-income countries 56

D. Changes in fiscal policy between 2009/10 and 2016 and possible implications 59

Chapter 7: Conclusions and Implications for Policy and Data 61

A. Main findings 61

B. Distributional analysis of taxes 62

C. Transfers and subsidies $\quad 62$

D. In-kind transfers in health and education 63

E. Impact on poverty and inequality 64

Annex 1: What is Fiscal Incidence Analysis $\quad 65$

Annex 2: Classifying targeting methods $\quad 67$

Notes

$\begin{array}{ll}\text { References } & 75\end{array}$ 


\section{Figures}

Figure 1. Poverty has declined substantially since 1993

Figure 2. Poverty is high in Namibia relative to average income per person 5

Figure 3. Namibia has the second-highest Gini index of inequality in the world 6

$\begin{array}{lll}\text { Figure 4. GDP growth has been accelerating } & 7\end{array}$

Figure 5. Unemployment has remained stubbornly high since independence $\quad 7$

Figure 6. Labor force participation is low in Namibia compared to other $\begin{array}{ll}\text { developing countries } & 8\end{array}$

Figure 7. Few poor households benefit from employment income 8

Figure 8. Employment has not shifted into higher productivity activities 9

Figure 9. Employment is falling in industries where productivity is rising 9

Figure 10. Spending on education, health, and other social programs is large $\begin{array}{ll}\text { and has been growing as a share of the economy } & 10\end{array}$

Figure 11. Spending on social grants has been generous 11

Figure 12. Spending and deficits are at record levels 12

$\begin{array}{ll}\text { Figure 13. SACU receipts are declining sharply } & 12\end{array}$

Figure 14. Composition of Total Government Revenues as a share of GDP 16

$\begin{array}{lr}\text { Figure 15. Social spending as a share of GDP } & 19\end{array}$

Figure 16. Definitions of income used in the CEQ fiscal incidence analysis 23

Figure 17. Diagram representing the progressivity of taxes and transfers 24

Figure 18. Income totals by decile (Namibian dollars, trillions) 28

Figure 19. Personal income tax collection total (of total reference income) 29

Figure 20. Tax revenue, cross country comparison (percent of GDP) 30

Figure 21. Concentration curves for PIT (share of total tax paid by reference i ncome deciles) $\quad 31$

Figure 22. Concentration shares: personal income taxes 32

Figure 23. Progressivity of direct tax system: Kakwani coefficient 32

Figure 24. Concentration curves of indirect taxes (share of total tax paid by reference income deciles)

Figure 25. Concentration curves of direct and indirect taxes (share of total tax paid by reference income deciles)

Figure 26. Spending on social protection by country (percent of GDP) 36

Figure 27. Distribution of spending on direct transfers by type of program, 2012/13 36

Figure 28. International comparison: coverage of the transfers (poorest decile) 37

Figure 29. International comparison - targeting efficiency of the transfers

Figure 30: Progressivity of direct cash transfers by category: concentration curves for transfers and Lorenz curves for market incomes, Namibia and South Africa 38

Figure 31. Targeting accuracy, coverage, and generosity - all direct transfers 39

Figure 32. Progressivity of all direct transfers 39

Figure 33. Targeting accuracy, coverage, and generosity of each direct transfer 41

Figure 34. PMT conditional cash transfers in Indonesia - concentration curves for transfers

Figure 35. Concentration curves for subsidies 
Figure 36. Concentration curves, education 46

Figure 37. Percent of households utilizing public education, by reference income decile 47

Figure 38. Concentration curves, health and all in-kind 48

Figure 39. Progressivity of the fiscal instruments (Kakwani Index) 49

Figure 40. Poverty and inequality indicators at each income concept 51

Figure 41. Amounts by which incomes exceed market income (as a share of market income)

Figure 42. The impact of fiscal policy on inequality worldwide, circa 2009/2010 (measured in Gini points) 57

Figure 43. Change in poverty headcount ratio (\%) from market to consumable income, US\$2.50 PPP per day poverty line, circa 2009/2010

\section{Tables}

Table 1. Namibia government revenue collections $\quad 15$

$\begin{array}{ll}\text { Table 2. Income tax rates in } 2009 & 17\end{array}$

Table 3. Namibia general government expenditure, percent of GDP 18

Table 4. Coverage (targeting efficiency) of direct transfers 39

Table 5. Poverty and inequality indicators for each income concept 52

Table 6. Fiscal impoverishment at a \$1.25 PPP per day poverty line 53

Table 7. Marginal contribution of indirect subsidies and direct transfers to poverty 54

Table 8. Marginal contribution of indirect subsidies and direct transfers to inequality 55

Table 9. Gini coefficient at each income concept 56

Table 10. Poverty headcount ratio for the US\$2.50 PPP a day for each income concept 58

Table 11. Income tax rates in 2009 and 2013

\section{Boxes}

Box 1. Caveats of the CEQ analyses and data limitations 26

Box 2. Main indicators of performance and targeting efficiency of direct transfers 35

Box 3. Advantages of proxy means tests for targeting social programs: the case of Indonesia 


\section{Preface}

I am pleased to present the report: Does Fiscal Policy Benefit the Poor and Reduce Inequality in Namibia?, jointly prepared by the World Bank and the Namibia Statistics Agency. I seize this opportunity to express my gratitude to the Namibia Statistics Agency, particularly John Steytler (former and founding Statistician-General, Namibia Statistics Agency (NSA)) who initiated this study and to Alex Shimuafeni, StatisticianGeneral (NSA), for his leadership during the preparation of this report. This report goes to the heart of Namibia's most pressing challenges of poverty and inequality - as articulated in Vision 2030, the country's guiding development strategy. The report is also fully aligned with the World Bank Group's twin goals to help client countries eliminate extreme poverty and boost shared prosperity by 2030 .

Despite progress made in addressing development challenges since independence in 1990, challenges for poverty and inequality reduction remain. The economy's steady growth has not generated enough jobs, resulting in sluggish reduction in poverty, inequality, and unemployment. Poverty rates are relatively high for an upper middle income country. World Bank estimates show that 16.9 percent of the population lived on less than US $\$ 1.90$ a day in 2015 . Inequality is among the highest in the world and unemployment remains relatively high. The persistence of the triple challenge of poverty, inequality and unemployment despite the high allocation of public resources to address them calls for an in-depth assessment of whether the government is making the best possible use of fiscal policy to reduce poverty and inequality. This report contributes to such analyses by assessing the contribution of fiscal instruments to reducing poverty headcounts and the Gini coefficient while drawing comparison from experiences of other countries. This way, the report provides evidence that can shape public debates over government spending and overall design of social programs.

The main conclusion is threefold: firstly, Namibia's generous fiscal policy does reduce poverty and inequality, but its impact is relatively modest in comparison to other high inequality countries. Secondly, the overall income tax system in Namibia is mildly progressive with the income tax burden falling on the top income earners and the poor hardly paying income taxes, yet indirect taxes tend to be rather neutral. Thirdly, generous and progressive social spending benefits the low income earners and the poor, but its coverage and efficiency could be further improved. The most progressive programs are direct transfers, especially the child support grants and old age pension.

To further reduce poverty and inequality, this report suggests that Namibia will need further improvements in the efficiency of social spending through for example better targeting efficiency and consolidation of social programs, and reducing leakages of existing programs. Ultimately, higher and more inclusive economic growth that creates more jobs for the poorest members of society is needed.

It is my hope that this evidence-based analysis will enhance ongoing public debates on fiscal policies that are suitable and effective to tackle poverty and inequality while also ensuring that existing policies are implemented more efficiently and effectively.

Paul Noumba Um

Country Director for Namibia

World Bank 


\section{Foreword}

Poverty and inequality remain two of Namibia's pressing challenges. Though falling, poverty and inequality remains relatively high especially considering the amount of resources the government has invested in addressing these challenges. As Namibia takes steps towards accelerating development and eradicating poverty, new analytical studies are vital to generating knowledge, expertise, innovations, and new thinking on how to address these long standing challenges. Effective partnerships in analytical studies aimed at reducing inequality and poverty through comprehensive and rigorous tax and benefit incidence analysis, and active engagement with the policy community are highly welcome. This report uses this framework to answer two main questions: To what extent do taxes and spending in Namibia redistribute income between the rich and poor households? What is the impact of taxes and spending on poverty and inequality levels in Namibia?

In answering these questions, the report contributes to policy introspection on whether the Government is making the best possible use of fiscal policy to reduce poverty and inequality. It uses an innovative approach that combines administrative fiscal data with the Namibia Household Income and Expenditure Survey (NHIES) data to analyze the impact of the tax and benefit system (fiscal policy) on poverty and inequality in Namibia. An international perspective is given by comparing the results from Namibia to those of other countries.

Namibia's fiscal policy is found to reduce both poverty and inequality although inequality is still among the highest in the world and is reducing at a slow pace. The report emphasizes the limits of what redistributive fiscal measures alone can accomplish. It stresses the need to promote job creation as a sustainable way to reduce poverty and inequality.

This work was initiated by John Steytler (former and founding Statistician-General, Namibia Statistics Agency (NSA)). It was prepared by a team at the World Bank in close collaboration with a team in the Household and Welfare Statistics division at the NSA. The NSA would like to express appreciation to the World Bank for its leadership in preparing this report as well as for availing funds to support the preparation of the report. Appreciation also goes to colleagues at the Ministry of Finance who generously provided administrative data needed to carry out this study.

I am confident that the analysis will deepen policy dialogues and debates on policies to tackle the twin challenges of poverty and inequality in Namibia. More specifically, I hope that this report informs policy dialogues on the implementation of the National Development Plan and the Harambee Prosperity Plan.

Alex Shimuafeni

Statistician-General \& CEO

Namibia Statistics Agency 


\section{Acknowledgements}

This report was prepared by a core team comprising Victor Sulla, Precious Zikhali, Philip Schuler, and Jon Jellema (Associate Director, Commitment to Equity Institute). The report was undertaken under the guidance of Andrew Dabalen (Practice Manager), Pablo Fajnzylber (Practice Manager), Paul Noumba Um (Country Director), Guang Zhe Chen (former Country Director), Sebastien Dessus (Program Leader), and Ivan Velev (Country Program Coordinator). The report was prepared in close collaboration with the Social Statistics division at the Namibia Statistics Agency (NSA), led by Daniel Oherein (Manager: Social Statistics).

The team would like to thank John Steytler (former and founding StatisticianGeneral, NSA) for his fruitful collaboration and specifically for initiating the study. The support of Alex Shimuafeni (StatisticianGeneral and CEO, NSA) and Liina Kafidi (Executive: Demographic and Social Statistics, NSA) is greatly appreciated. Special thanks to Penda Ithindi, Ndilimeke lipinge, Robert Kaveto, and Kenneth Haludilu at the Ministry of Finance for generously availing administrative data needed for the analysis. The report benefited from discussions with government officials, particularly in two workshops held in Windhoek in October 2015 and October 2016, development partners and stakeholders outside government.

The peer reviewers for the report were Matthew Grant Wai-Poi and Maria Ana Lugo. The team also thanks Lucilla Maria Bruni (GSP01) for her continued support throughout the preparation of the report. Logistical assistance in the preparation of this report was ably provided by Siele Shifferaw Ketema and Mokgabo Molibeli. Communications support was provided by Zandile Ratshitanga and Maura Leary. Last but not least, the team would like to thank everyone at NSA and the World Bank who contributed to making this a truly collaborative effort. Thank you.

The Commitment to Equity (CEQ) toolkit developed by Tulane University and ADePT Software developed by the World Bank were used to produce most of the statistical outputs in the report. 


\section{Executive Summary}

Reducing poverty and inequality continues to be an important national priority in Namibia. Vision 2030 - the country's guiding development strategy - has a subordinate vision that points to several goals: "Poverty is reduced to the minimum, the existing pattern of income-distribution is equitable and disparity is at the minimum." Vision 2030 is being implemented via a series of five-year National Development Plans, with the current National Development Plan IV (NDP4) covering 2012 through to 2017. NDP4 sets specific numerical targets. One is reducing the incidence of extreme poverty to less than 10 percent of individuals by the end of FY2016/17, measured at the national lower bound poverty line of $\mathrm{N} \$ 277.54$ in 2009/10. Another is reducing the Gini coefficient by 3 percent a year on a path toward achieving Vision 2030's goal of 0.30 .

Political stability, sound economic management, moderate economic growth, and a sustained fiscal commitment to social programs have helped Namibia confront developmental challenges since independence in 1990. More than half of government spending routinely goes to education, health, social security, housing, and other social programs. This has been complemented by a highly progressive income tax schedule and exemptions in the value-added tax for goods consumed by the poor. This has helped achieve notable progress in reducing poverty, although variations persist across the country's 14 regions. The incidence of extreme poverty fell from 58.9 percent of individuals in $1993 / 94$ to 15.3 percent in 2009/10. In addition, the country has made strides in upgrading its human development record by improving citizens' access to basic public services.

Despite the progress, daunting challenges for poverty and inequality reduction remain. The economy's steady growth has not generated enough jobs, resulting in sluggish reductions in poverty, inequality, and unemployment. Though falling, poverty rates are relatively high for an upper middle income country. World Bank calculations show that 16.9 percent of the population lived on less than $\$ 1.90$ a day in 2015 . Inequality is among the highest in the world. In 1993/94, the Gini coefficient stood at 0.646 , declining to 0.60 in $2003 / 04$ and 0.597 in 2009/10. Unemployment has remained stubbornly high. The Labor Force Survey (LFS) reported an unemployment rate of 28.1 percent in 2014, with youth unemployment higher at 39.2 percent (NSA, 2014).

The persistence of the triple challenge of poverty, inequality, and unemployment despite the high allocation of public resources to address them calls for an assessment of whether the government is making the best possible use of fiscal policy to reduce poverty and inequality. This becomes more pertinent now that Namibia has entered a period of fiscal consolidation. This study seeks to help the country assess poverty and inequality reduction programs during a time of budget cuts. It uses the fiscal-incidence methodology developed by the Commitment to Equity (CEQ) ${ }^{1}$ project to assess the poverty reduction and redistributive effects of Namibia's taxes and public benefits. By decomposing the contributions of individual tax and spending measures, the report provides a unified framework for measuring programs' progressivity, generosity, coverage, and final impacts, whether they take the 
form of direct cash grants, indirect subsidies, or in-kind subsidies. This can contribute to the development and monitoring of the NDPs and serve as a tool for improving the targeting efficiency of social spending.

Results show that Namibia's personal income tax (PIT) is progressive, while indirect taxes (fuel levy and value added tax), when taken together, are more or less neutral. Focusing on the tax system as a whole reveals a progressive system, driven by the progressivity of PIT.

An analysis of the incidence and efficiency of direct transfer spending shows that: (i) overall spending on direct transfers is above the average for Sub-Saharan African countries, but comparable to the average for developing countries; (ii) it is progressive in terms of targeting, that is, the poor are more likely to receive the transfers; (iii) the transfers matter for the poor, being generous in that they make up a larger share of total income; and (iv) the targeting accuracy of transfers is low and could be improved.

Taken together, indirect subsidies are progressively targeted, largely because of the water subsidy. This study considered three indirect subsidies: the rural water infrastructure and services program and two housing subsidies, the Build Together Program (BTP) and the National Housing Enterprise (NHE). The progressivity is largely driven by the fact that the water subsidy is allocated only to households in rural areas, where the majority of poor and low income households live. Both the BTP and NHE are active primarily in urban areas and are less likely than the water subsidy to reach a poor household.

Taken together, expenditures on inkind health and education services are approximately neutral. In both education and health, poorer households acquire greater shares of the lower value but more frequently provided public services (primary education and outpatient healthcare). Richer households acquire greater shares of the higher value but not as frequently provided public services (tertiary education and inpatient healthcare). As a result, the distribution of total public expenditures on in-kind health and education services is approximately neutral; each population group receives a share of benefits equal to its share of the population.

Taken separately, spending in public school education is absolutely progressive but the system becomes less progressive as education levels rise - from primary to tertiary. Although education spending matters for everybody, outlays for primary education target the poor better. However, spending on tertiary education is regressive by enrollment rather than program design - the small number of students reaching the tertiary level are disproportionately nonpoor. As a result, near-neutrality of education spending is observed.

Fiscal policy on the whole reduces poverty in Namibia. Severe poverty, defined as the proportion of Namibians living below the lower bound poverty line of $\mathrm{N} \$ 277.54$ per month, falls from 22.2 percent before any fiscal policy measures (i.e., based on market incomes) to 16.7 percent after adding direct transfers and indirect subsidies and subtracting taxes. This translates to a reduction of 24.7 percent in extreme poverty due to fiscal policy. Not only does fiscal policy reduce poverty on the whole, the proportion of individuals made poor by the application of fiscal policy is low.

Direct transfers drive poverty reduction, while the role of taxes and indirect subsidies is less significant. The poor barely pay income taxes and as a result, no change in the poverty rate is observed when personal income taxes are deducted from market incomes. Introduction of direct transfers, however, reduces extreme poverty by 30.6 percent to 
15.4 percent (6.8 percentage points). The introduction of indirect subsidies followed by indirect taxes leads to a 1.3 percentage point increase in poverty.

Internationally, the poverty reduction attributable to fiscal policy in Namibia is on par with South Africa: from the set of individuals who would be poor without fiscal expenditures, approximately 11 percent are in receipt of fiscal transfers that help them escape impoverishment (measured as expenditure of \$PPP 2.50 or less per day).

Fiscal policy on the whole reduces inequality in Namibia, largely because of in-kind transfers. The market income Gini coefficient of 0.635 falls to 0.590 , using post-fiscal income (which does not include a monetized value of health, education, or other public in-kind services received). If taken into consideration, in-kind transfers in health and education would have the highest redistributive effect. Including monetized value of in-kind transfers would further reduce inequality to 0.429 , a 0.206 -point reduction from the Gini coefficient for market incomes. Approximately 78.2 percent of the Gini coefficient reduction from market to final incomes is attributed to in-kind transfers, 16.4 percent to direct transfers, and the remaining 5.4 percent to direct and indirect taxes and subsidies.

This report demonstrates that Namibia's progressive income tax and generous social spending programs substantially reduce poverty and inequality, but the analysis also underscores the limits of what redistributive fiscal measures alone can accomplish. The economy must ultimately create more jobs for the poorest members of society to change the underlying distribution of what might be called "pre-fiscal" income; i.e., the income before households pay taxes and receive benefits from social programs. This will require structural transformation through greater investment in activities that create employment for unskilled workers and offer the potential for continuous productivity increases. 


\section{Chapter 1: Poverty and Inequality Context in Namibia}

\section{A. Why this study?}

Namibia is one of the youngest countries in Africa, having gained its independence from South Africa in 1990. In recent decades, the country has established an enviable track record of political stability, prudent macroeconomic policies, moderate economic growth, and a sustained fiscal commitment to social programs. Per capita income has grown. Financial inclusion is high by regional standards. Poverty has declined substantially. Namibia has achieved these gains while facing constraints imposed by climate, geography, and legacies of apartheid and colonialism.

Daunting challenges remain. Namibia suffers from chronic high unemployment, Human Immune-deficiency Virus (HIV) and Acquired Immune Deficiency Syndrome (AIDS), and a distribution of income that is among the world's most unequal. Only a minority of the population lives in conditions expected in an upper middle income country. Economic growth has not generated jobs because the structure of production and external trade remains essentially unchanged, tied closely to metals, minerals, and other natural resources. In addition, the country faces new risks stemming from global climate change, a growing number of unemployed and poorly educated youth, increased debt exposure, and diminished fiscal space.

Namibia has for years devoted considerable fiscal resources to addressing poverty and inequality. Low income workers are exempt from personal income taxes, which are applied at progressively higher rates on more highly paid individuals. In the past 25 years, Namibia has devoted around half of the government budget to social programs. The government provides a number of cash transfers to vulnerable segments of the population; these are fairly generous compared to similar programs in other developing countries.

This report aims to measure the effectiveness of these efforts and draws comparisons to the experiences of other countries. It estimates how major taxes and social spending programs affect individual incomes. It then assesses who benefits from or bears the burden of each instrument and by how much. This way, the analysis estimates the contribution of each instrument to reducing the poverty headcount and the Gini coefficient, a standard measure of inequality.

The analysis provides evidence that can shape public debates over government spending and the design of social programs. This report is particularly timely in light of the need for deep budget cuts announced by the Minister of Finance in November 2015. It can also contribute to the development and monitoring of new anti-poverty programs and of the next National Development Plan (NDP5), which had the official launch of its formulation process in June 2016.

\section{B. Setting the stage: Namibia's development challenges}

Poverty is falling, but remains high. Since the early 1990s, the incidence of poverty in Namibia has declined substantially. ${ }^{2}$ It fell 
from 58.9 percent of individuals in 1993/94 to 21.9 percent in $2003 / 04$ and then to 15.3 percent in 2009/10, measured at the lower bound national poverty line of $\mathrm{N} \$ 277.54$ in $2009 / 10$ (Figure 1). At the upper bound poverty line of $\mathrm{N} \$ 377.96$ in $2009 / 10$, poverty fell from 69.3 percent in $1993 / 94$ to 37.7 percent in 2003/04 and then to 28.7 percent in 2009/10 (NSA, 2012). Measures of the depth and severity of poverty show similar declines. When compared to other countries, however, Namibia’s poverty remains high relative to its level of national income per person (Figure 2). According to World Bank calculations, 16.9 percent of the population lived on less than $\$ 1.90$ a day in 2015 . At the $\$ 3.10$ a day international poverty line, the rate was 42.8 percent in 2015 .
Figure 1. Poverty has declined substantially since 1993

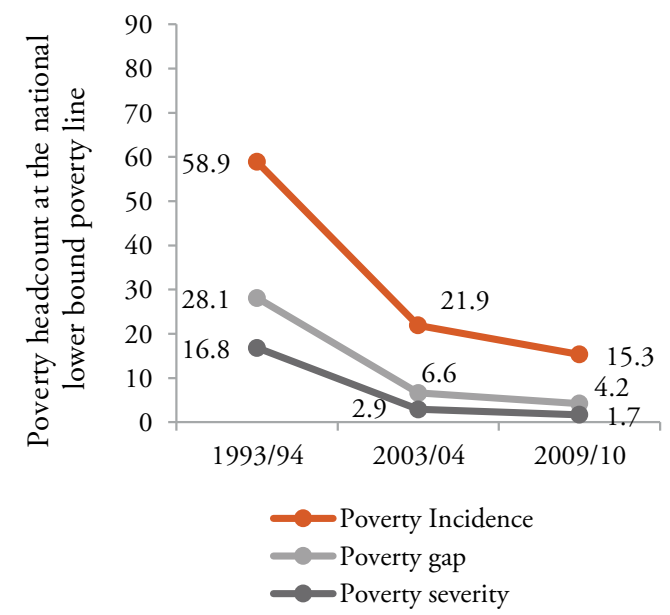

Source: Namibia Statistics Agency.
Figure 2. Poverty is high in Namibia relative to average income per person

\footnotetext{
Poverty has been falling in Namibia, but remains higher than in countries with similar incomes
}

Source: World Development Indicators.

Notes: Values are the most recent available over the past six years.
In 2009/10, the poor were predominantly women, subsistence farmers and pensioners, and Namibians living in rural areas (NSA, 2012). Regional variation is also revealed with the Kavango region recording the highest incidence of poverty. Growth in mean consumption drove the reduction in poverty observed between 2003/04 and 2009/10, while the distributional impact of inequality put a damper on poverty reduction. Improvements in education outcomes supported poverty reduction. In addition, sectoral decomposition of changes in poverty by the main income source shows that although the population share with subsistence farming as the main source of income fell between 2003/04 and 2009/10, poverty reduction among subsistence farmers contributed 2.94 percentage points to the 8.34 percentage point reduction in poverty when the upper bound national poverty line is used (NSA, 2012, pp 31). The proportion of pensioners grew during this period and poverty reduction among pensioners contributed to a decline in poverty by 2.56 percentage points (NSA, 2012, pp 31). The 
GDP grew at an average of 5.6 percent a year between 2010 and 2014 but the growth did not result in significant job creation latter underscores the role of fiscal policy - specifically the Old Age Pension - in supporting poverty reduction.

Inequality is among the highest in the world. A century of colonial rule and apartheid concentrated Namibia's wealth including ownership of land, companies, and financial assets - in the hands of a small minority. The country has taken great strides to expand ownership of these assets by those who were excluded in the past. Nevertheless, income inequality remains quite high. Based on the latest available data, the World Bank estimates that Namibia has the second most unequal distribution of income in the world after South Africa (Figure 3). Unlike the poverty headcount, the Gini coefficient has not declined substantially over the past two decades. In 1993/94, it stood at 0.646, declining to 0.600 in $2003 / 04$ and 0.597 in 2009/10. Inequality remains higher in urban compared to rural areas. In terms of consumption inequality, the Karas region registered the highest inequality.

\section{Figure 3. Namibia has the second-highest Gini index of inequality in the world}

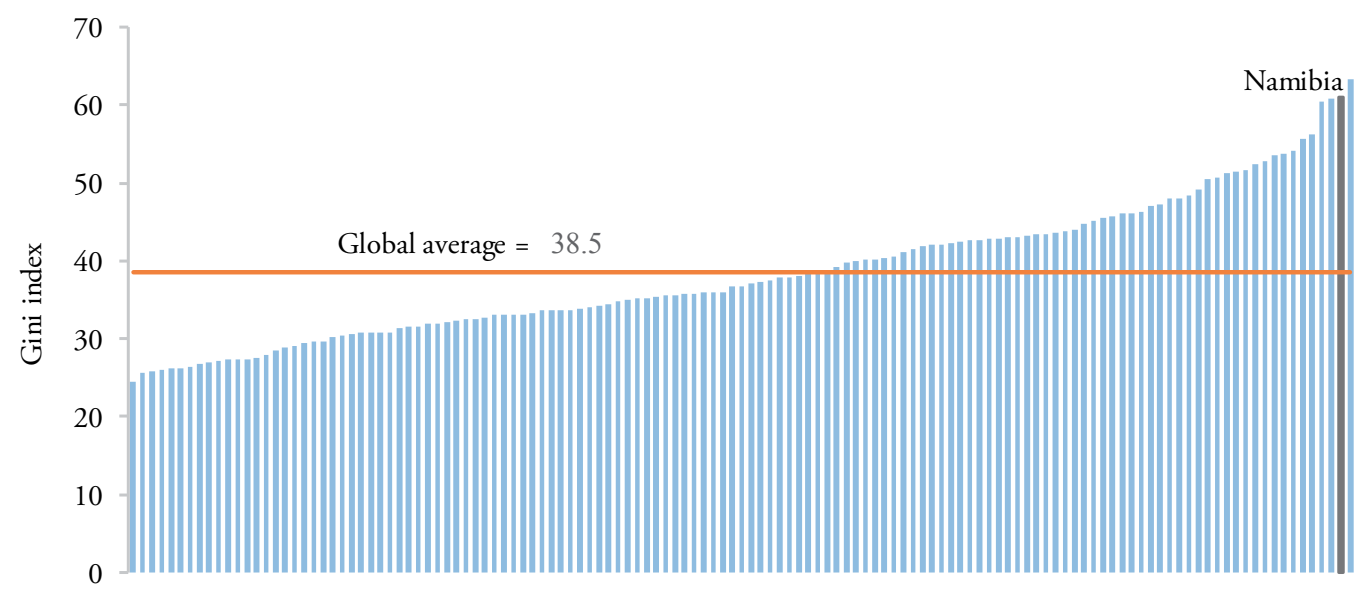

Source: World Bank staff calculations in World Development Indicators.

Jobs are critical for moving out of poverty, but GDP growth has not generated many jobs. GDP has been growing at an accelerating rate since the 1980s (Figure 4). Between 2010 and 2015, it reached an average of 5.6 percent a year. This was supported by historically low real interest rates, fiscal stimulus, rapid private sector credit growth, and foreign investment in several large mining projects. Construction and services industries made the largest contributions to growth in the economy. Steady growth has not put Namibians to work - a key factor behind the sluggish reduction in inequality and the relatively high poverty headcount.

Despite this enviable record of growth, unemployment has remained stubbornly high. Since the early 1990s, the strict unemployment rate has remained at around 20 percent of the labor force (i.e., those with jobs or actively seeking work). When discouraged workers are included, which is the official broad unemployment rate used in Namibia, the jobless rate rises to 30 percent or higher (Figure 5). 


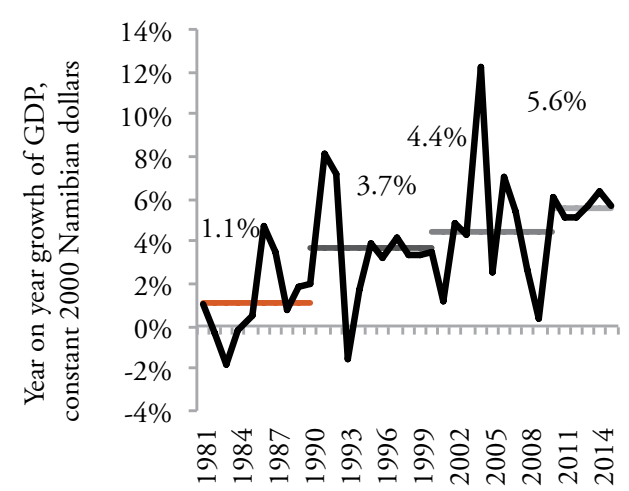

Source: Namibia Statistics Agency.

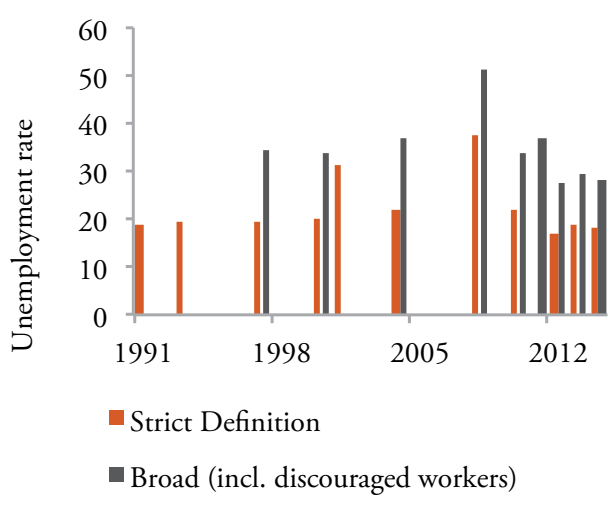

Sources: Namibia Statistics Agency population census (1991, 2001, 2011), household income and expenditure surveys (1993, 2003, 2009), and labor-force surveys (1997, 2000, 2004, 2008, 2012-14).
Not only is unemployment high in Namibia but labor-force participation is low, relative to other developing countries. With less than 60 percent of working-age individuals in the labor force when the strict definition is adopted i.e., either working or actively seeking employment, Namibia falls in the bottom third of developing countries ranked by labor-force participation rates (Figure 6).
Few poor households in Namibia benefit from employment income. In the bottom four income deciles, only 30 percent of households depend on salary, wages, or a pension from previous employment as their primary source of income. Instead, their incomes come mainly from subsistence farming or the receipt of social grants, drought relief, or private transfers (Figure 7). These sources provide little potential for boosting households out of poverty.
Only 30 percent of the bottom 40 percent of households depend on employment income 


\section{Figure 6. Labor force participation} is low in Namibia compared to other developing countries

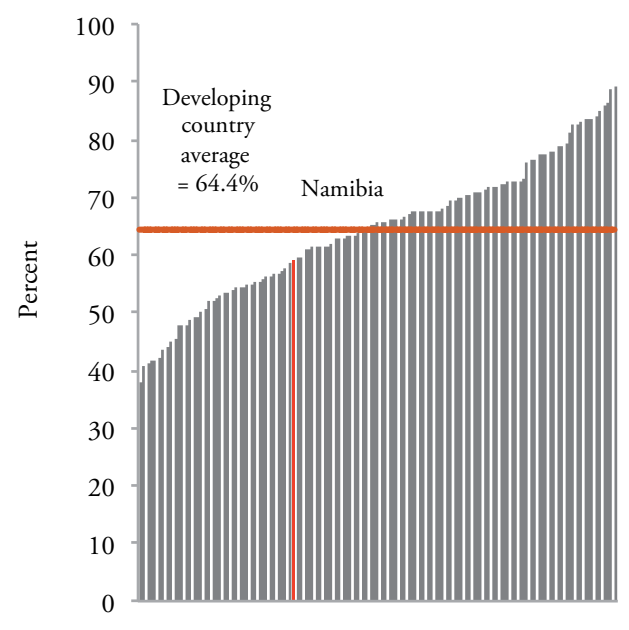

Source: International Labor Organization, 2013 data.
Figure 7. Few poor households benefit from employment income

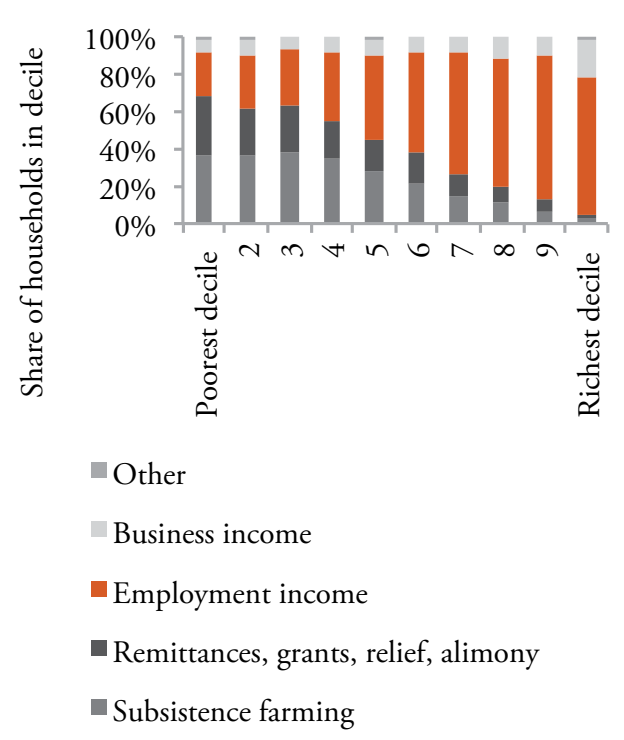

Source: World Bank calculations from the 2009/10 Namibia Household Income and Expenditure Survey.

\section{Employment has not been moving into industries with growing productivity}

The structure of production has changed little over the past several decades. Despite a movement out of subsistence farming (and out of rural areas and into towns), manufacturing's share of employment has declined. In the latest Labor Force Survey, more people were employed in construction than in manufacturing, mining, and public utilities combined (Figure 8). Services that are largely non-tradable-public administration, defense, community services, health, education, and household servicesaccount for 31 percent of total employment. The share of employment in financial, commercial, transportation, professional, and other services that are largely tradable has grown significantly. Some of these may have potential and could generate jobs for relatively unskilled workers (e.g., tourism).

In general, employment has not been moving into industries with growing productivity. Between 2012 and 2014, employment tended to grow mainly in industries with low productivity growth, measured by real value added per worker. It fell in industries with higher productivity growth (Figure 9). Construction has been an exception with gains in both jobs and productivity, but on average, the sector's value added per worker is low compared to other industries. 


\section{Figure 8. Employment has not shifted Figure 9. Employment is falling in}

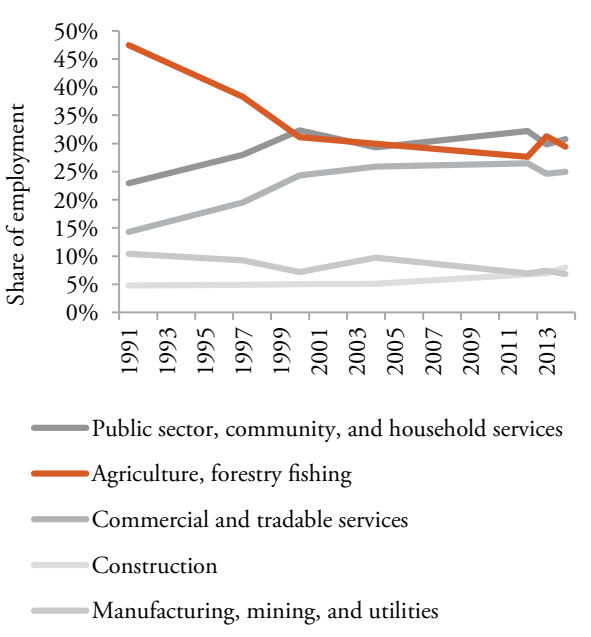

Sources: World Bank calculations from Namibia Statistics Agency Labor Force Surveys (1997, 2000, 2004, 2008, 2012-14) and population census (1991).

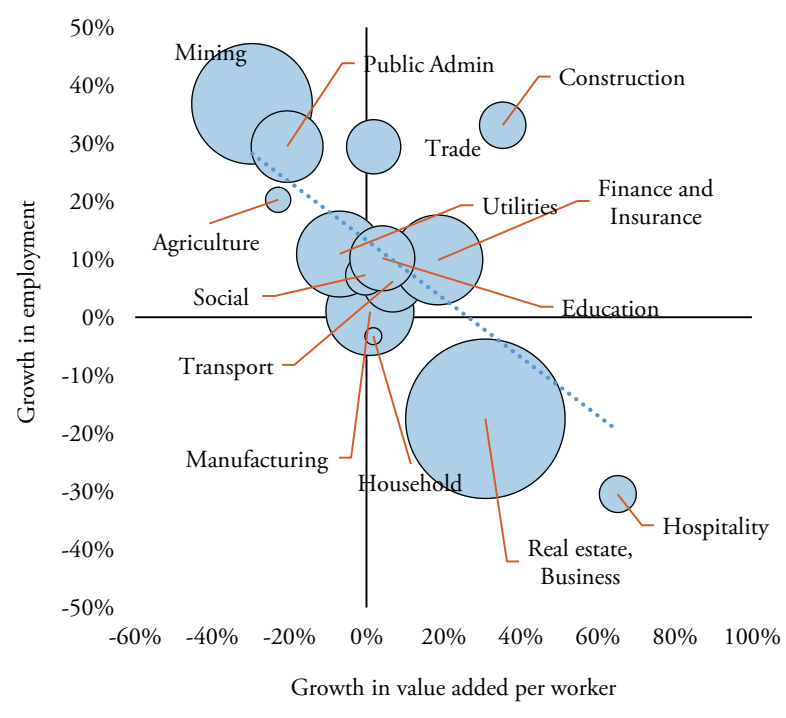

Source: World Bank calculations from NFLS and national accounts data.

Note: The size of bubbles represents 2014 value added per worker (constant 2010 Namibian dollars).

\section{Responding to the challenges of poverty and inequality}

Reducing poverty and inequality remains an important national priority in Namibia. The country's guiding development strategyVision 2030 - sets forth an overriding objective: "A prosperous and industrialized Namibia, developed by her human resources, enjoying peace, harmony and political stability" by the year 2030 (Government of the Republic of Namibia, 2004). Beneath is a subordinate vision: "Poverty is reduced to the minimum, the existing pattern of income distribution is equitable and disparity is at the minimum." Vision 2030 challenges the country to reduce poverty by ensuring that all Namibians enjoy access to safe drinking water, comprehensive health services, housing, sanitation, and other basic services. In addition, it calls for social integration of people with disabilities. Finally, Vision 2030 sets a numerical target of reducing the Gini coefficient to 0.30 by 2030 .
Aseries of five-year National Development Plans is intended to implement Vision 2030. The current National Development Plan IV (NDP4) covers 2012 through 2017. ${ }^{3}$ Unlike the previous NDPs, it is narrowly focused on a few overall goals, supported by a small set of subordinate objectives. The three overall goals are high and sustained economic growth, employment creation, and increased income equality. To reach these goals, NDP4 calls for reducing extreme poverty and for improving the institutional environment, education, health, and public infrastructure. The economic priorities are increasing output for targeted sectors: logistics, tourism, manufacturing, and agriculture.

NDP4 sets a specific numerical target of reducing the incidence of extreme poverty to below 10 percent of individuals by the end of FY2016/17. ${ }^{4}$ Although not setting an explicit target for increasing income equality, NDP4 suggests reducing the Gini coefficient by 3 percent a year on a path toward achieving Vision 2030's goal of 0.30 .
The National Development Plans have emphasized inclusive, sustained and equitable economic growth to realize Vision 2030 
Social spending routinely accounts for more than half of government spending
Since its independence in 1990, Namibia has placed a high priority on using public resources to address poverty, inequality, and other social policy objectives (Figure 10). Education, health, social security, housing, and other social programs routinely receive more than half of government spending. Despite external shocks caused by the global economic downturn since the 1990s, Namibia sharply increased social spending as a share of GDP, bringing spending to record high levels. A highly progressive income tax schedule and value-added tax exemptions for goods the poor consume complement public spending on poverty reduction.

\section{Figure 10. Spending on education, health, and other social programs is large and} has been growing as a share of the economy
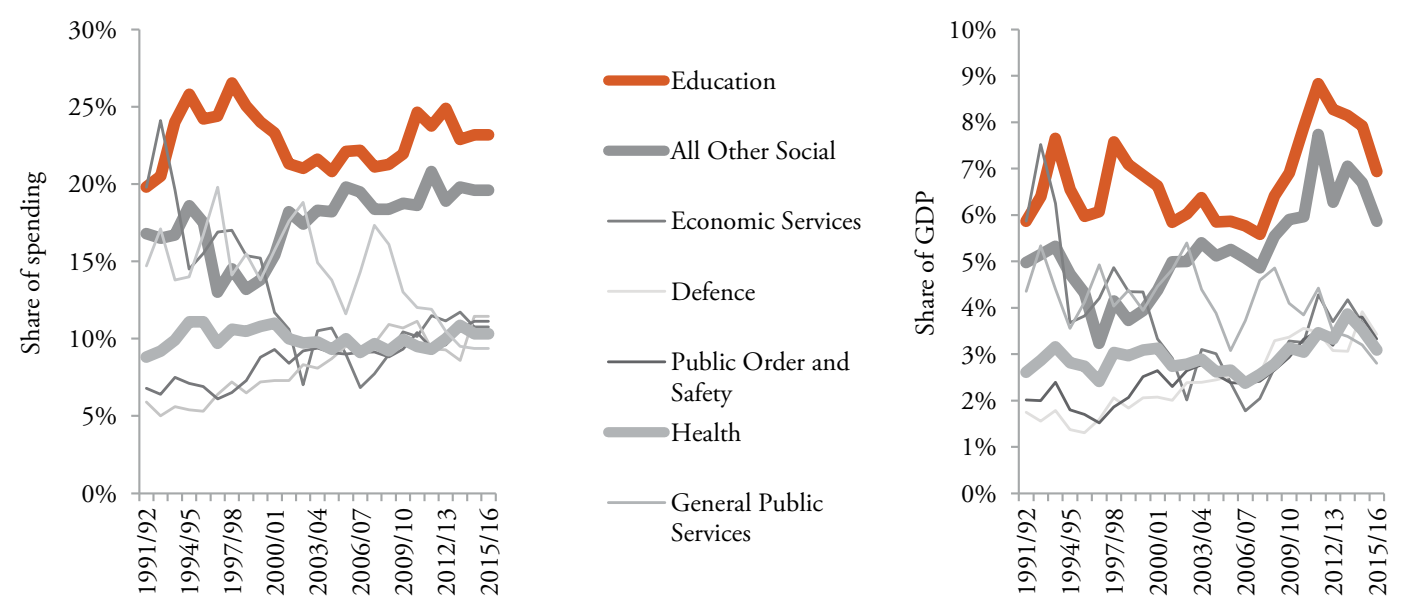

Sources: World Bank calculations using data from the Bank of Namibia (FY1990/91-FY2005/06) and Ministry of Finance (FY2006/07-2014/15).

A well-developed program of cash transfers to vulnerable segments of the population has been a cornerstone of social spending in Namibia. Transfers include a non-contributory pension for all Namibians and grants to families caring for orphans and vulnerable children, disabled children and adults, and war veterans. ${ }^{5}$ Collectively, these accounted for 5 percent of government spending and 2.0 percent of GDP in FY2015/16 (Figure 11). By way of comparison, recent analysis estimates that all developing countries spend an average of 1.6 percent of GDP on social safety nets, and Organization for Economic Co-operation and Development (OECD) countries spend 2.9 percent (Honorati et al., 2015). As the fiscal incidence analysis presented in this report will document, these transfers have made important contributions to reducing poverty and inequality in Namibia. 


\section{Figure 11. Spending on social grants has been generous}

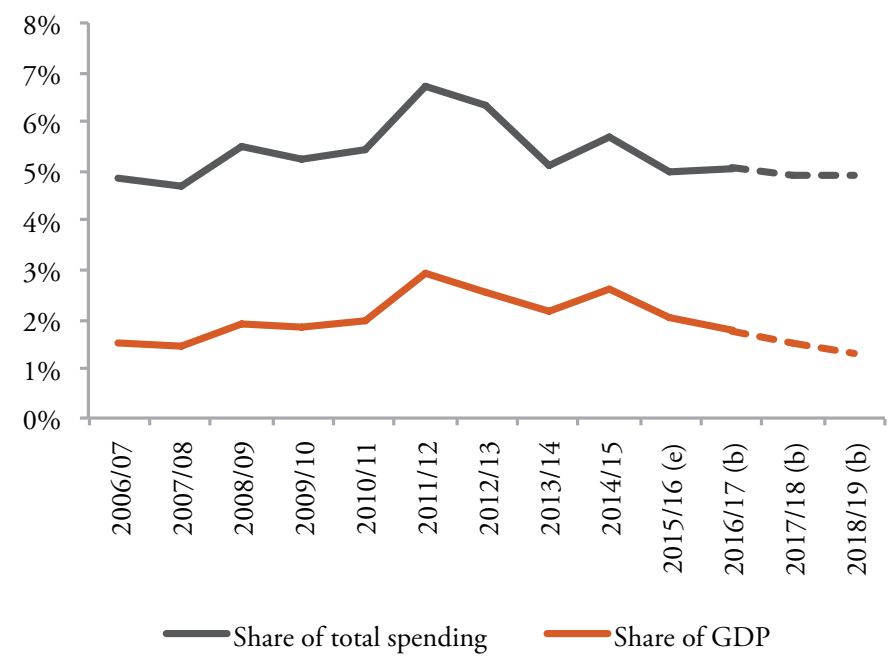

Source: World Bank calculations from Ministry of Finance budget documents.

Note: FY2016/17 onwards are budgeted figures. Programs include grants to the elderly, disabled, orphans and vulnerable children, and veterans.

\section{Why now?}

Namibia has entered a period of fiscal consolidation, and this fiscal incidence analysis can help assess anti-poverty programs during a time of budget cuts. Namibia increased government spending and deficits to record high levels during the past five years (Figure 12). However, Namibia's receipts from the Southern Africa Customs Union's Common Revenue Pool - one of the government's largest revenue sources - are falling sharply due to the downturn in the South African economy. Measured relative to Namibia's
GDP, the decline has been 5.4 percentage points of GDP over two years (Figure 13). The 2016 Fiscal Policy Strategy forcefully makes the case for curtailing spending growth to preserve fiscal sustainability. The Medium-term Expenditure Framework (MTEF) presented in 2016 cuts the budget for FY2016/17 and FY2017/18 by N\$7.5 billion from the projections in the April 2015 MTEF. During this time of fiscal consolidation, it is all the more important to evaluate the success of poverty and inequality reduction measures and to find ways to enhance their effectiveness.
Slower spending growth is needed for fiscal sustainability 


\section{Figure 12. Spending and deficits} are at record levels

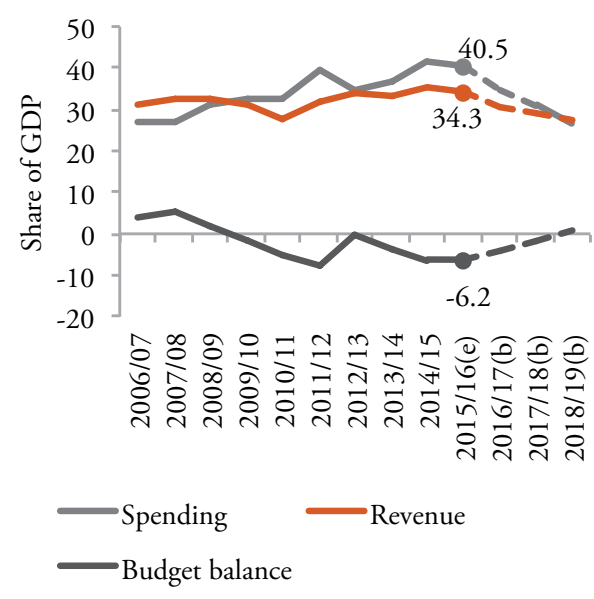

Figure 13. SACU receipts are declining sharply

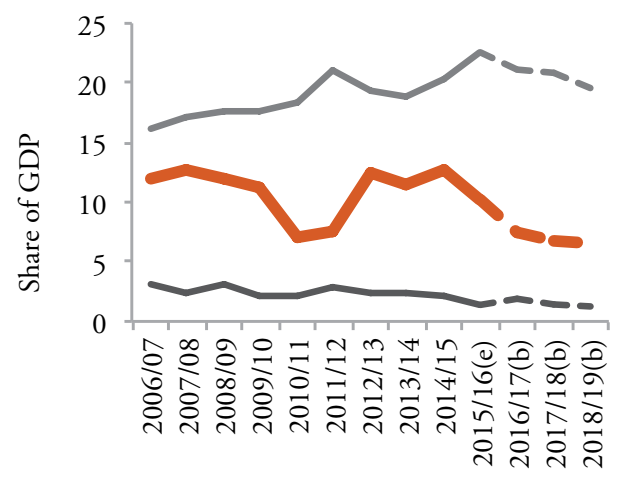

Domestic taxes SACU receipts

Source: World Bank calculations from Ministry of Finance budget documents.

The creation of the

Ministry of Poverty

Eradication and

Social Welfare in

2015 signaled a

renewed commitment

by Government to

tackle poverty and

inequality
This fiscal incidence analysis can also help with the design and implementation of the National Development Plans and initiatives aimed at reducing poverty and inequality. Reducing the levels of poverty and income inequality are two important NDP4 priorities. These are expected to remain priorities in the NDP5, for which the formulation process recently began. In April 2016, President Geingob launched the "Harambee Prosperity Plan, 2016/172019/20: Namibian Government's Action Plan towards Prosperity for All" - a plan to accelerate development via targeted measures to remove bottlenecks and implementation challenges. The plan calls for improving the administration of targeted social safety nets (Government of the Republic of Namibia, 2016). By decomposing the contributions of individual tax and spending measures, the report provides a unified framework for measuring the progressivity, generosity, coverage, and final impact of programs under these initiatives, whether they take the form of direct cash grants, indirect subsidies, or in- kind subsidies.

The creation of the Ministry of Poverty Eradication and Social Welfare in March 2015 signaled a renewed commitment to addressing poverty and inequality. The new ministry has prepared a white paper on poverty reduction and convened the National Conference on Wealth Redistribution and Poverty Reduction to stimulate public debate on existing programs and proposed initiatives, such as a universal basic income grant for all Namibians, a "solidarity" super tax on incomes, and development of new social protection instruments. These consultations are expected to culminate in a blueprint on how to eradicate poverty in Namibia by 2025. In his State of the Nation address in April 2016, President Geingob indicated that the blueprint has been finalized, and it is set to be tabled in Parliament for debate. ${ }^{6}$ The President emphasized that aspects of the blueprint have also been prioritized and incorporated into the Harambee Prosperity Plan. 


\section{E. Content of the report}

The report proceeds as follows: Chapter 2 provides an overview of Namibia's tax and public social benefits system. Chapter 3 presents the fiscal incidence analysis employed to generate results. It includes the methods, data, and the assumptions and choices made as well as the analytical limitations that result when available data was not complete. Chapter 4 examines the progressivity or regressivity of selected taxes in Namibia. Chapter 5 describes the incidence and efficiency of social spending. In Chapter 6, the overall impact of Namibia's fiscal policy on poverty and inequality is estimated. Chapter 7 concludes and discusses possible policy directions for further reduction in poverty and inequality in Namibia.

The Annex provides a more detailed description of the CEQ methodology used in the analysis. It also includes a discussion of different ways of targeting beneficiaries of public benefits, particularly direct transfers.

This report demonstrates that Namibia's progressive income tax and generous social spending programs substantially reduce poverty and inequality. However, the analysis also underscores the limits to what redistributive fiscal measures alone can accomplish. The economy must ultimately create more jobs for the poorest members of society to change the underlying distribution of what might be called "pre-fiscal" income; i.e., the income a household would have before it pays taxes and receives benefits from social programs. This will require a transformation of the structure of the economy through greater investment in activities that create employment for unskilled workers, with a potential for continuous productivity increases. 


\section{Chapter 2: Namibia's Tax and Public Benefits System}

This chapter provides an overview of Namibia's tax and public social benefits, focusing on 2009/10. It also gives an indication of which of these taxes and spending programs are included in this study to assess the redistributive impact of fiscal policy.

\section{A. Structure of taxes}

The majority of Namibia's tax collections in 2009/10 came from direct taxes. Broadly, these included taxes on income and profits as well as property taxes. They made up 54.8 percent of total tax collections and 11.1 percent of GDP (Table 1). ${ }^{7}$ Indirect taxes included value added tax and the fuel levy.
They accounted for around 33.2 percent of total tax collections and 6.7 percent of GDP.

Namibia's tax system shares an important characteristic with most developing economies - dependence on indirect taxes, and international trade comprised of SACU receipts (Besley and Persson, 2013). Taken together, indirect taxes and receipts from the Southern Africa Customs Union (SACU) revenue pool, made up 18.1 percent of GDP in 2009/10, compared to 11.1 percent for direct taxes. Excluding the SACU receipts to capture actual government tax collections show that the country relied more on direct taxes in 2009/10 than it did on indirect domestic taxes on goods and services (Table 1). 


\begin{tabular}{|c|c|c|c|c|}
\hline & $\begin{array}{l}\text { Percent of } \\
\text { GDP }\end{array}$ & $\begin{array}{l}\text { Share of total } \\
\text { Government } \\
\text { revenue and } \\
\text { grants } \\
\text { (percent) }\end{array}$ & $\begin{array}{l}\text { Share of revenue } \\
\text { collected by } \\
\text { the GRN (i.e. } \\
\text { excluding SACU } \\
\text { receipts and } \\
\text { grants)(percent) }\end{array}$ & $\begin{array}{c}\text { Incidence } \\
\text { analysis } \\
\text { (percent } \\
\text { of GDP) }\end{array}$ \\
\hline $\begin{array}{l}\text { Total Government revenue } \\
\text { and grants }\end{array}$ & 32.0 & & & \\
\hline Taxes & 29.5 & 92.2 & & 5.1 \\
\hline Direct taxes & 11.1 & 34.8 & 54.8 & 2.3 \\
\hline Personal income tax & 6.8 & 21.1 & 33.3 & 2.3 \\
\hline Corporate income tax & 3.8 & 11.9 & 18.7 & \\
\hline Other direct taxes & 0.6 & 1.8 & 2.8 & \\
\hline Indirect taxes ${ }^{*}$ & 6.7 & 21.0 & 33.2 & 2.8 \\
\hline Value added tax & 6.6 & 20.7 & 32.6 & 2.7 \\
\hline Fuel levy & 0.1 & 0.3 & 0.5 & 0.1 \\
\hline$S A C U$ receipts & 11.4 & 35.7 & & \\
\hline Stamp duties & 0.2 & 0.7 & 1.1 & \\
\hline Non-tax revenue & 2.5 & 7.8 & 12.3 & \\
\hline Grants & 0.3 & 0.8 & 1.3 & \\
\hline Current & 0.3 & 0.8 & 1.3 & \\
\hline Capital & 0.0 & 0.0 & 0.0 & \\
\hline Other revenue & 2.2 & 7.0 & 11.0 & \\
\hline
\end{tabular}

Only 2.3 percent of GDP worth of direct taxes is identified in the analysis compared to 11.1 percent of GDP indicated by administrative data. This is largely due to two main reasons. First, the study does not include corporate income tax which stands at 3.8 percent of GDP. This decision was driven by lack of an appropriate methodology that makes it possible to comprehensively identify households that pay corporate income tax. Second, PIT is the only direct tax that is analyzed in the study. The challenge, as will be elaborated later, is that the number of (observed) taxpayers and tax revenue reported by households in the NHIES data are far less than comparable data from budget reporting documents and secondary sources.

Direct taxes in Namibia are larger than most regional or income-level comparators (Figure 14). Relative to other revenue sources, direct taxes in Namibia are also larger than comparator countries. For example, only in Georgia and South Africa do direct taxes represent greater shares of total revenues than in Namibia and only in Namibia, South Africa and Mexico do direct taxes represent a greater share of total revenues than indirect taxes. 


\section{Figure 14. Composition of Total Government Revenues as a share of GDP}

(ranked by GNI per capita (2011 PPP) - right-hand side)

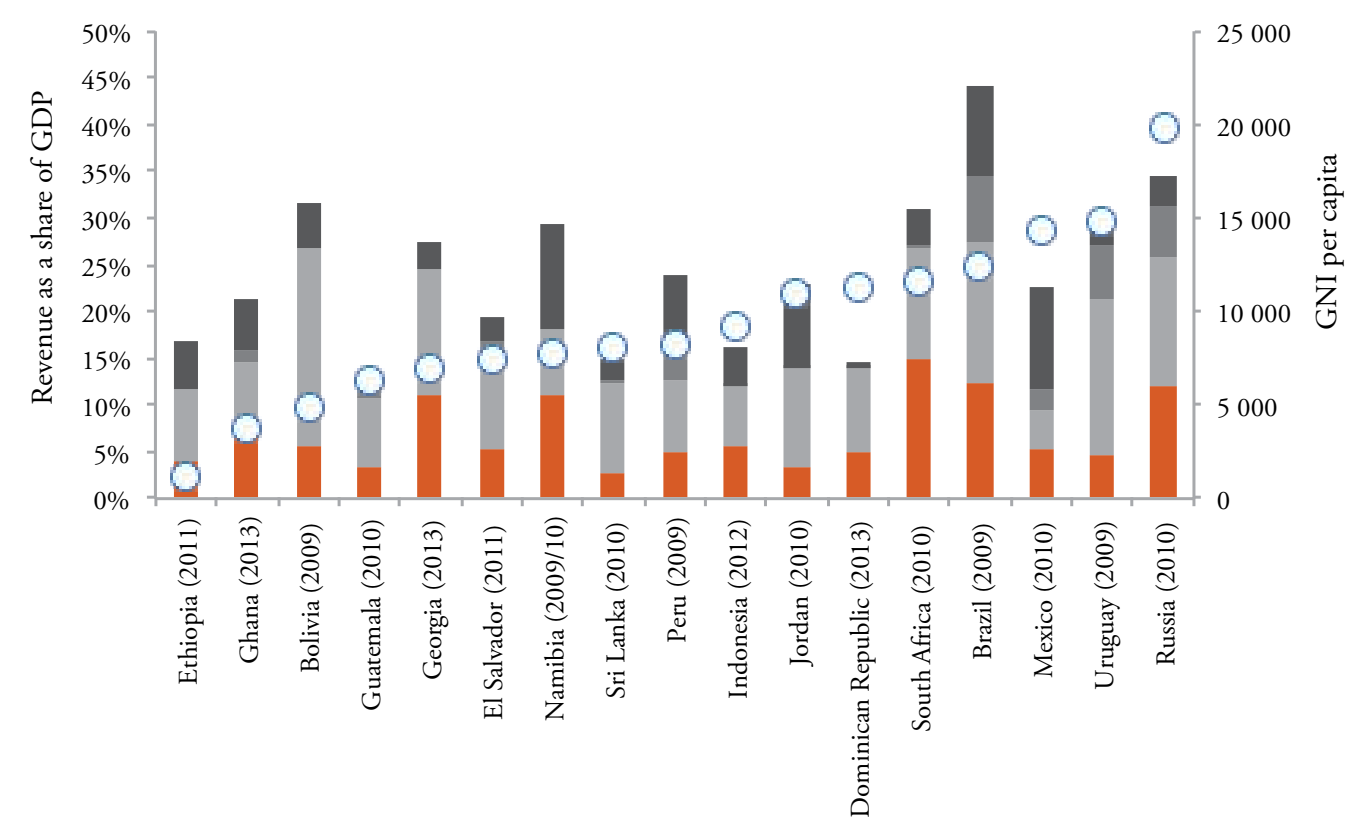

Direct Taxes Indirect and Other Taxes $\square$ Social Security Contributions $\square$ Other Revenues O GNI per capita (2011 PPP)

The majority of

Namibia's tax

collections came from

direct taxes. Relative

to other revenue

sources, direct taxes

in Namibia are large

Sources: Namibia: World Bank calculations from Ministry of Finance budget documents. Uruguay (Bucheli et al., 2014). Guatemala (Cabrera et al., 2015), Brazil (Higgins and Pereira, 2014), Peru (Jaramillo, 2014), Bolivia (Paz et al., 2014), Mexico (Scott, 2014), Ghana (Younger et al., 2015), Dominican Republic (Aristy-Escuder et al., 2016), El Salvador (Beneke et al., 2014), Ethiopia, Georgia, Sri Lanka, Indonesia, Jordan, South Africa, Russia (Inchauste and Lustig, forthcoming).

\section{Direct taxes}

The major component of direct taxes is the personal income tax (PIT), which is levied on individuals' taxable income. ${ }^{8}$ Namibia taxes all receipts and accruals originating from a Namibian source. Foreign residents are taxed only on income generated within Namibia. A self-assessment tax regime is employed, and spouses are taxed separately on their incomes. No deductions are provided for married persons or children. Table 2 reports the applicable PIT rates at different income brackets. It illustrates that income is taxed at progressive marginal rates. It can be argued that the PIT schedules might create disincentives to work in the formal sector. While no empirical evidence exists to support that, the fact that the government reduced the marginal tax rate of the bottom bracket to 18 percent in 2013 suggests efforts by government to increase labor force participation and ensure the labor markets support poverty and inequality reduction. Reducing poverty and inequality cannot be done through fiscal policy alone. 


\section{Table 2. Income tax rates in 2009}

Taxable income (N\$)

Up to 40,000

40,001 to 80,000

80,001 to 200,000

200,001 to 750,000

Over 750,000

\section{Marginal rate (percent)}

0

27

32

34

37

Source: Ministry of Finance budget documents.

The PIT system includes provisions for withholding tax and certain deductions. With regard to salaries or (formal sector) employment income, employers are responsible for registering employees for the PIT and withholding tax under the payas-you-earn system. No capital gains tax exists in Namibia. Deductions limited to N\$40,000 a year in 2009 were allowed for aggregated contributions to approved pension funds, retirement annuity funds, travel expenses, premiums associated with tertiary educational policies, provident funds, and donations to registered welfare organizations or approved educational institutions. There are no deductions for medical expenses or contributions to medical schemes.

The PIT is the only direct tax used in the incidence analysis. In 2009/10, PIT made up 33.3 percent of total tax collections (excluding SACU receipts and grants) and 6.8 percent of GDP. It accounted for 60.8 percent of total direct taxes. We omit from the analysis the company or corporate income tax (CIT), which is levied at 35 percent. The CIT accounted for about 34.1 percent of total direct taxes, 18.7 percent of total tax collections, and 3.8 percent of GDP. The omission is largely due to the lack of a methodology to comprehensively assign the CIT burden to households in the survey.

\section{Indirect taxes}

Two types of indirect taxes are included in the incidence analysis - the value-added tax
(VAT) and the fuel levy. The VAT, introduced in 2000 , is levied at a uniform standard rate of 15 percent of the value of goods and services supplied or imported. However, the VAT system includes items that are zero-rated or exempt. Zero-rated food supplies include mahangu (pearl millet), mahangu meal and maize meal; fresh and dried beans (but not canned or frozen beans); sunflower cooking oil; animal fat used for food preparation; bread flour, cake flour and bread; fresh milk; and white and brown sugar. ${ }^{9}$ In 2009/10, the VAT made up 32.6 percent of total tax collections (excluding SACU receipts and grants), and 6.6 percent of GDP. Interestingly, the country's reliance on the PIT and VAT were almost equal in 2009/10 (6.8 percent of GDP for PIT and 6.6 percent of GDP for VAT). This could compromise the ability of the country's fiscal system to promote equity ${ }^{10}$ because personal income taxes have been shown to be more progressive than consumption taxes. Excise tax revenue is excluded in this analysis. Even though Namibians consume products on which excise taxes are levied (e.g., tobacco, alcohol), most of these products are produced in South Africa, and therefore the South African rather than the Namibian government collects excise taxes on these products. Consequently, excise tax revenue does not appear in the Namibian government budget documents, and it is not possible to estimate excise tax revenue paid by Namibian households.

In $2009 / 10$, the fuel levy made up only
Several exemptions and zero-ratings exist on goods and services consumed mainly by the poor 
Social spending made up 12.7 percent of GDP in 2009/10, higher than other middle income countries for which similar analyses has been done
0.5 percent of total tax collection, and 0.1 percent of GDP. Fuel levies are based on the importation of petrol, diesel, and paraffin into Namibia. The fuel levy finances the Motor Vehicle Accident Fund, established to "provide assistance and benefits to persons injured in motor vehicle accidents and to dependents of persons killed in such accidents; and to provide for incidental matters." It also contributes to the Road Funds Administration for road maintenance.

This report accounts for only a portion of direct and indirect taxes. Table 1 shows the study identifies direct taxes that made up 2.3 percent of GDP in 2009/10, compared to the 11.1 percent indicated in the administrative account. In terms of indirect taxes, the survey accounts for 2.8 percent of GDP compared to 6.7 percent of GDP indicated in administrative records.

\section{B. Public social benefits system}

Namibia has several spending programs that affect poverty and income distribution. These include programs that can be classified as social spending (direct and indirect (or inkind) transfers) and non-social spending ${ }^{11}$ (Table 3). In the social spending component, direct spending includes old age pensions, veterans' grants, children's grants, foster parents' grants, and disability grants for adults and children. Indirect or in-kind transfers include education and health.

\section{Table 3. Namibia general government expenditure, percent of GDP}

\begin{tabular}{|ccc} 
& $\mathbf{2 0 0 9 / 1 0}$ & Incidence analysis \\
Total government spending & $\mathbf{1 4 . 7}$ & $\mathbf{1 1 . 5}$ \\
Primary government spending & $\mathbf{1 4 . 7}$ & $\mathbf{1 1 . 5}$ \\
Social Spending (excludes contributory pensions) & 12.7 & 11.0 \\
Direct Transfers (Total Cash and Near Cash) & 1.6 & 1.6 \\
Old Age Pension & 1.0 & 1.0 \\
Veterans grant & 0.1 & 0.1 \\
Children's grant & 0.2 & 0.2 \\
Foster parents grant & 0.1 & 0.1 \\
Disability grant - adults & 0.2 & 0.2 \\
Disability grant - children & 0.1 & 0.1 \\
Total In-kind Transfers & 10.8 & 9.3 \\
Education & 7.5 & 6.7 \\
Health & 3.3 & 2.6 \\
Other Social Spending & 0.3 & $\ldots$ \\
Non-Social Spending & 0.6 & 0.6 \\
Indirect Subsidies & 0.6 & 0.6 \\
Build Together Program & 0.1 & 0.1 \\
National Housing Enterprise & 0.1 & 0.1 \\
Water Subsidy & 0.4 & 0.4 \\
Source: World Bank calculations from Ministry of Finance budget documents. & \\
\hline & & \\
\hline
\end{tabular}


Social spending in Namibia compares favorably to other countries for which CEQ studies have been undertaken ${ }^{12}$ (Figure 15). At 12.7 percent of GDP, Namibia's social spending in 2009/10 was higher than other middle-income countries, including Indonesia (4.9 percent), Peru (8.4 percent), and Mexico (10.0 percent). At 16.2 percent of GDP in 2009, Brazil recorded the highest social spending among the countries in Figure 15. In-kind transfers in the form of education made the bulk of social spending in Namibia, accounting for 7.5 percent of GDP in $2009 / 10$. This is followed by health
- another form of in-kind transfer - with spending of 3.3 percent of GDP. Direct cash transfers to individuals were only 1.6 percent of GDP. Despite the different magnitudes in overall expenditures, the structure of social spending is similar across all countries in Figure 15 - education constitutes the bulk of social spending, followed by health and then direct transfers. Unlike many countries, Namibia has no contributory national pension (or social security) scheme, nor does it have a national contributory health insurance scheme.

\section{Figure 15. Social spending as a share of GDP}

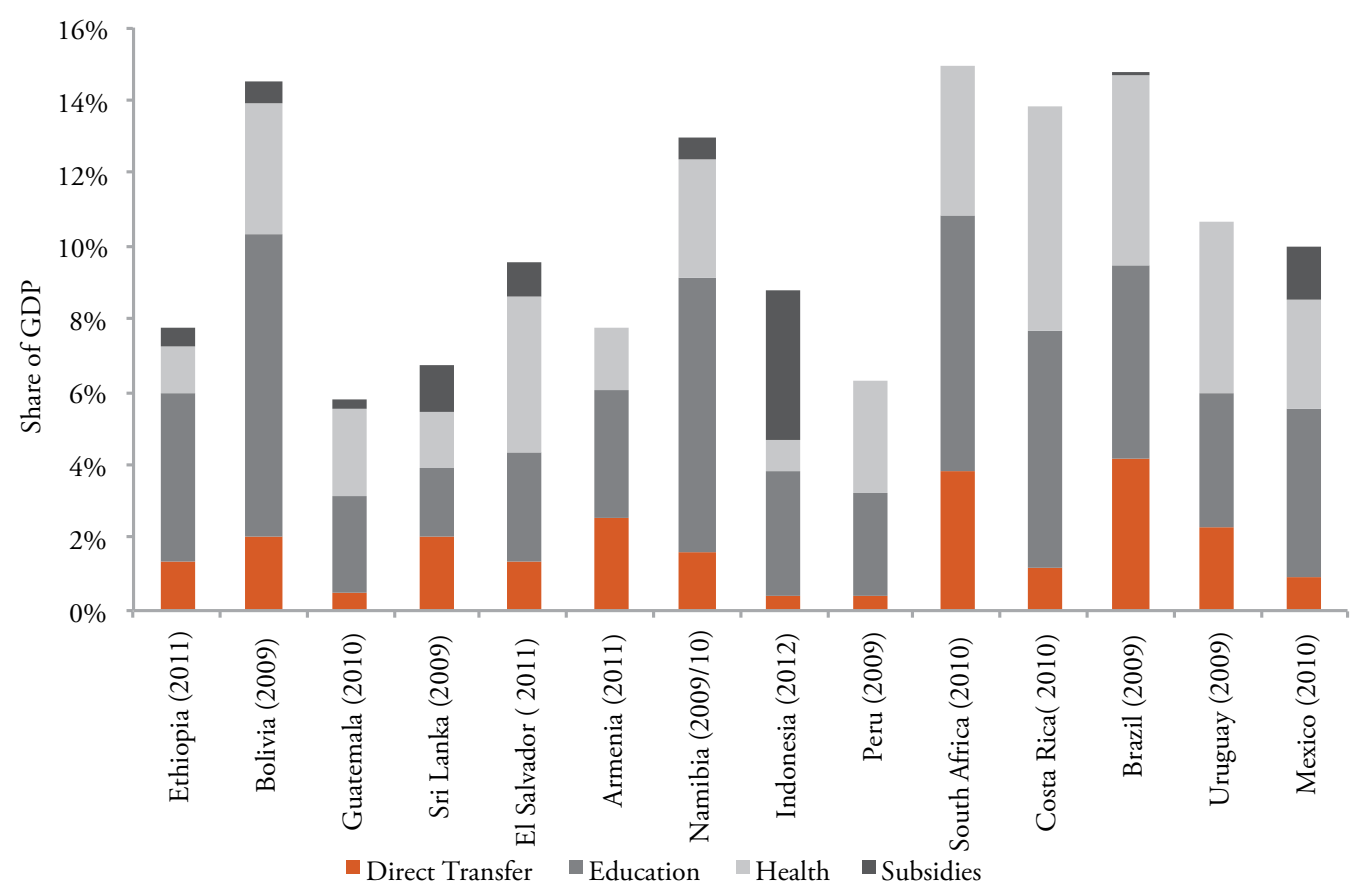


Namibia has a

number of cash

transfers for

vulnerable groups

including the elderly,

war veterans, the

disabled, orphaned

children, and

other children in

need. These are

complemented by in-

kind transfers largely

towards health and

education as well as

indirect subsidies
This study's incidence analysis focuses on direct cash transfers and in-kind transfers for health and education as components of social spending. These items are discussed in greater detail below. Collectively, they accounted for 84.3 percent of total government spending and 97.7 percent of social spending in 2009/10. Other components of social spending are excluded due to data limitations.

\section{Direct transfers (cash transfer programs)}

The Old Age Pension (also referred to as the basic pension) is accessible to all Namibians over the age of 60 , residing in the country. ${ }^{13}$ No means test is required. A means test is a method for establishing whether, based on an indicator of means or financial ability, an individual or household is eligible for specific government assistance (see Annex 2 for a discussion of different methods used). The number of beneficiaries has been growing, increasing from around 110,000 in 2003 to 143,000 in 2013. Close to 92.2 percent of eligible Namibians received the pension by 2011.

War veterans and their dependents are eligible for the veterans' subvention. This targets any person who "was a member of the liberation forces; consistently and persistently participated or engaged in any political, diplomatic or underground activity in furtherance of the liberation struggle; or owing to his or her participation in the liberation struggle was convicted, whether in Namibia or elsewhere, of any offence closely connected to the struggle and sentenced to imprisonment."

This is means tested in the sense that veterans must either not be employed or, if employed, receive less than a prescribed income. At $\mathrm{N} \$ 2,200$ a month, the veterans' subvention has the highest value of the social grants by far.

The Child Maintenance Grant provides support to children with either a disabled parent, a parent receiving an Old Age Pension grant, or a parent who is absent due to death or imprisonment. This is a means tested grant, with the threshold for an applying parent set at less than a gross income of N\$1,000 a month.

The Foster Care Grant targets children who the courts have placed in the temporary care of foster parents. The grant's value in 2010 was N\$200 for the first foster child and N\$100 for any additional foster children. There is no upper limit on the number of children per applicant.

Namibians, 16 years and older, who are either confirmed by a state doctor to be temporarily or permanently disabled (including the blind) or have full-blown AIDS are eligible for the disability grant ("disability grant A" for adults). A special maintenance grant for children under the age of 16 who are living with disabilities is also available ("disability grant C" for children).

\section{In-kind transfers}

\section{Education}

An average of 20 percent of the national budget goes to education, a reflection of the high priority which the Namibian government places on education. In 2009/10, spending on education amounted to 7.5 percent of GDP. The importance of education is recognized in the Namibian Constitution. The Education Act of 2001 further underscores the need to provide for an accessible, equitable, qualitative and democratic national education service.

The NHIES 2009/10 revealed that 11.6 percent of children between the age of 6 and 13 had never been to school. To deal with this challenge and promote primary school enrollment among poor children, Namibia introduced a no-fee primary education (Universal Primary Education) in 2013. ${ }^{14}$ The plan called for the government to cover 
school fees until students completed primary school or reached age $16 .{ }^{15}$ Free secondary school began at the start of 2016.

Financial support is available for higher education. The programs include the Namibia Students Financial Assistance Fund (NSFAF), a loan/grant scheme that supports students in specific priority areas of study.

\section{Health}

Public spending on health is relatively large. Through the Ministry of Health and Social Services (MHSS), the state is the main provider of health care services in Namibia. The system is funded via general taxation and serves 85 percent of Namibians. MHSS expenditures were close to $\mathrm{N} \$ 2.5$ billion in 2009/10, accounting for around 9.8 percent of total public spending. A vibrant private health sector funded largely through employee and employer contributions exists, parallel to the public sector.

Although user charges apply to public health facilities, primary healthcare is subsidized to ensure access by many households. Despite the public subsidies, user charges still serve as a barrier to access to health services by the poor.

\section{Non-social spending benefits (indirect subsidies) assessed in this study}

In addition to direct transfers and in-kind transfers in the form of education and health, the incidence analysis considers indirect subsidies. Specifically, it looks at housing and water subsidies. The two housing programs in the analysis target low- and mediumincome households: the National Housing Enterprise (NHE) and the Build Together Program (BTP).

The NHE targets households with monthly incomes between $\mathrm{N} \$ 5,000$ and
$\$ 20,000$, or a maximum joint income of $\mathrm{N} \$ 30,000$ per month. Collateral of 20 percent or a deposit of 5 percent is required, which means poor households are less likely to benefit from the initiative. The NHE obtains its funds from the capital markets. From 1990 until 2011, the Government gave subsidies of $\mathrm{N} \$ 56.7$ million to the NHE. Additional income was generated through the development and financing of houses and other loan products.

The Build Together Program targets households earning less than $\mathrm{N} \$ 3,000$ per month. It consists of four elements: (a) the urban/rural housing loans scheme; (b) the social housing scheme; (c) the single quarter transformation scheme; and (d) the informal settlement upgrading scheme. Under the urban/rural housing loans scheme, households with low or very low incomes receive assistance to build their own houses. The program is administered by the Ministry of Regional, Local Government, Housing and Rural Development (MRLGHRD).

The rural water infrastructure and services program provides a proxy for water subsidies. The program, administered by the Directorate of Rural Water Supply in the Ministry of Agriculture, Water and Forestry (MAWF), benefits only rural residents with access to an improved water source. Namibia is regularly afflicted by droughts, and large rivers are far from the population centers and large water users in manufacturing and mining establishments. To overcome water shortages, the country has built dams, pipelines, potable water re-use systems, and seawater desalination plants. Broadly, Namibia has given control of water supply and sanitation to the Department for Water Resources Management and the Department for Rural Water and Sanitation Coordination in MAWF. 


\section{Chapter 3: Methodology and Data}

The study's primary methodology comes from the Commitment to Equity (CEQ) project (Lustig and Higgins, 2013). The project uses a comprehensive fiscal incidence analysis and a diagnostic framework to assess the poverty reduction and redistributive effects of taxes and public social benefits. This chapter provides an overview of this methodology, describes the data used, and discusses the assumptions made in the context of data limitations.

\section{A. What is fiscal incidence analysis?}

Fiscal incidence analysis examines who ultimately bears the burden of government taxes and who benefits from public spending
Fiscal incidence analysis consists of allocating the burdens of taxes and the benefits of public spending to households or individuals, making it possible to compare incomes before and after taxes and transfers. The CEQ methodology makes the allocations using household level micro-data. Incomes after taxes and transfers may include the monetized value or consumption of free public services. The allocations can be analyzed to determine how a government's revenue-generation and expenditure activities redistribute income among the population. ${ }^{16}$ Using this approach, it is possible to measure the fiscal system's redistributive impact through its effects on poverty and inequality. As long as there is sufficient detail in the household survey, the same allocation can be used to assess the impact of fiscal policy on the welfare of different social groups - for example individuals differentiated by gender, ethnicity, or location. ${ }^{17}$

This report uses the "accounting" approach to fiscal incidence analysis. ${ }^{18}$ It takes place in an ex-post static setting. The analysis begins from a "before" or "pre-fiscal" income and allocates a tax or transfer to each household or individual. If the fiscal intervention is a direct tax (transfer) and the analysis starts from pre-tax (pre-transfer) income, the posttax (post-transfer) income is calculated by subtracting (adding) the tax paid (transfer received). The accounting approach does not take into account behavioral responses that taxes and public spending may trigger in individuals or households.

This report makes both partial and comprehensive assessments of Namibia's current fiscal system. Partial fiscal incidence analysis looks at the impact of one or several fiscal policy interventions - for example, income taxes or the use of public education and health services. Comprehensive fiscal incidence analysis assesses the impact of the revenue and spending sides simultaneously, measuring the overall impact of direct and indirect taxes, cash and in-kind transfers, and indirect subsidies. For taxes, this report estimates actual average incidence and effective average rates (i.e., it uses the average rate of tax collection including possible tax evasion). It values in-kind benefits according to the "government cost" approach, assuming the full cost of a public service is borne by the government.

We follow Lustig and Higgins (2013) and measure per capita income before and after each set of fiscal interventions (Figure 16). The "before" and "after" measures are referred to as income concepts. For example, all earned and unearned income from any 
source is called "market income," a measure of the resources households' control "before" any direct taxes have been applied. "Net market income" subtracts any direct taxes paid, yielding a measure of the resources households control "after" direct taxes but "before" any direct transfers.

\section{Figure 16. Definitions of income used in the CEQ fiscal incidence analysis}

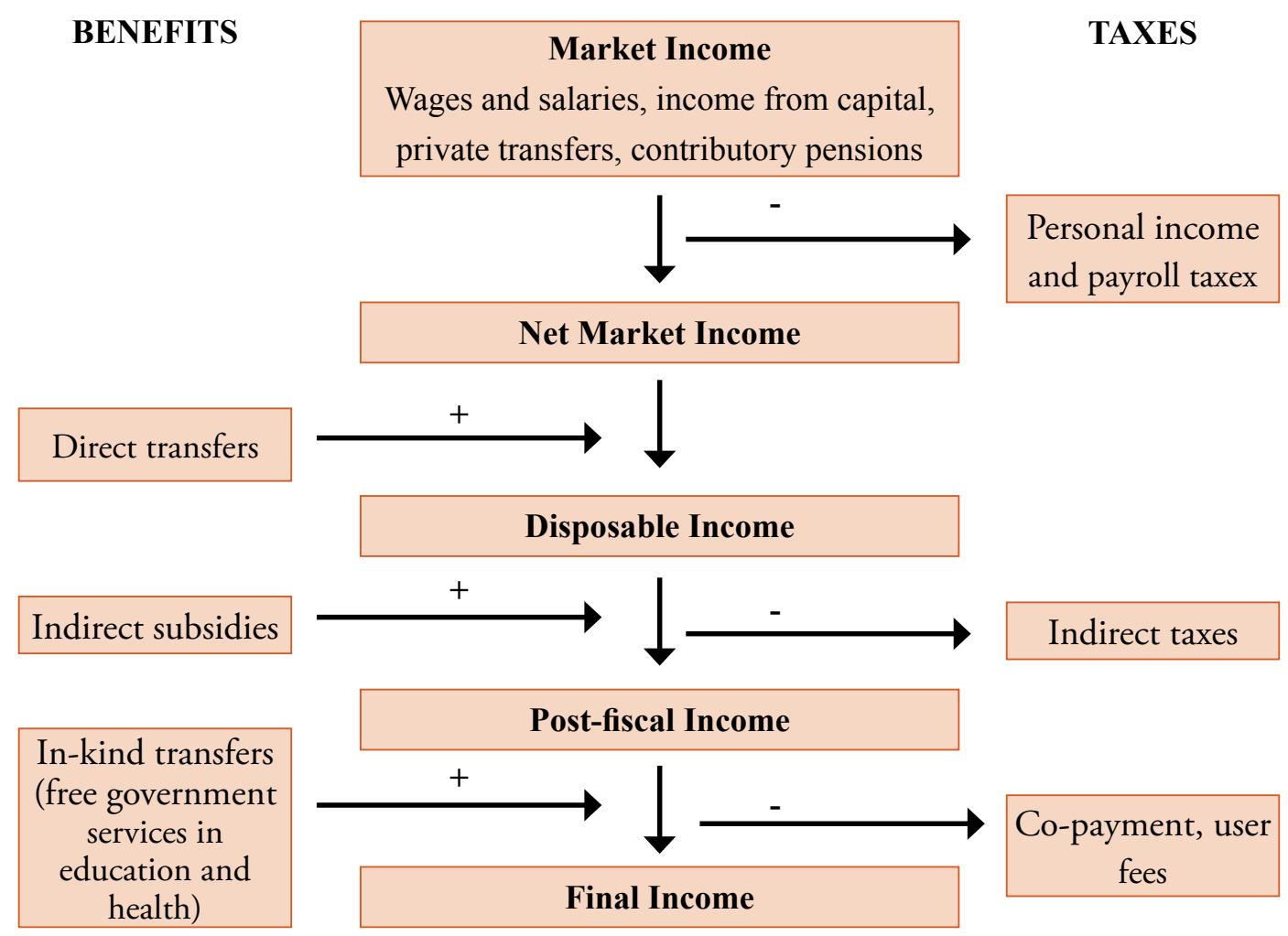

Source: Lustig and Higgins (2013). 
When it comes to poverty and inequality, the impact of any fiscal component depends on two factors: its magnitude and its progressivity. ${ }^{19}$ For any measure of household income, this study measures the progressivity of fiscal policy components (taxes and transfers) by comparing the cumulative distribution and cumulative concentration of the component before and after the component has been received. ${ }^{20}$ The "before" income is called the reference income. A tax (transfer) is progressive when the cumulative share of a tax paid (transfer received) by the bottom or poorest " $\mathrm{x}$ " percent of the population is lower (higher) than that group's share in the pre-tax (pre-transfer) reference income. ${ }^{21}$ If the share of a transfer received by the bottom " $\mathrm{x}$ " percent of the population (ranked by reference income) is higher than its share in the population, a transfer is absolutely progressive. Transfer shares are higher for the poorest populations, and the shares decline as income rises. ${ }^{22}$

To illustrate, Figure 17 presents a Lorenz curve for a reference "market income". Along the horizontal axis, the population is ranked, poorest to richest, according to this reference income. The vertical axis plots the cumulative share of this income. ${ }^{23}$ Using the same ranking of reference income, we can plot on the vertical axis cumulative shares of, for example, taxes paid or transfers received; these are called concentration curves.

\section{Figure 17. Diagram representing the progressivity of taxes and transfers}

The progressivity of taxes can be measured by comparing the share of a specific tax collected from each decile of the population relative to the share of total income each decile receives

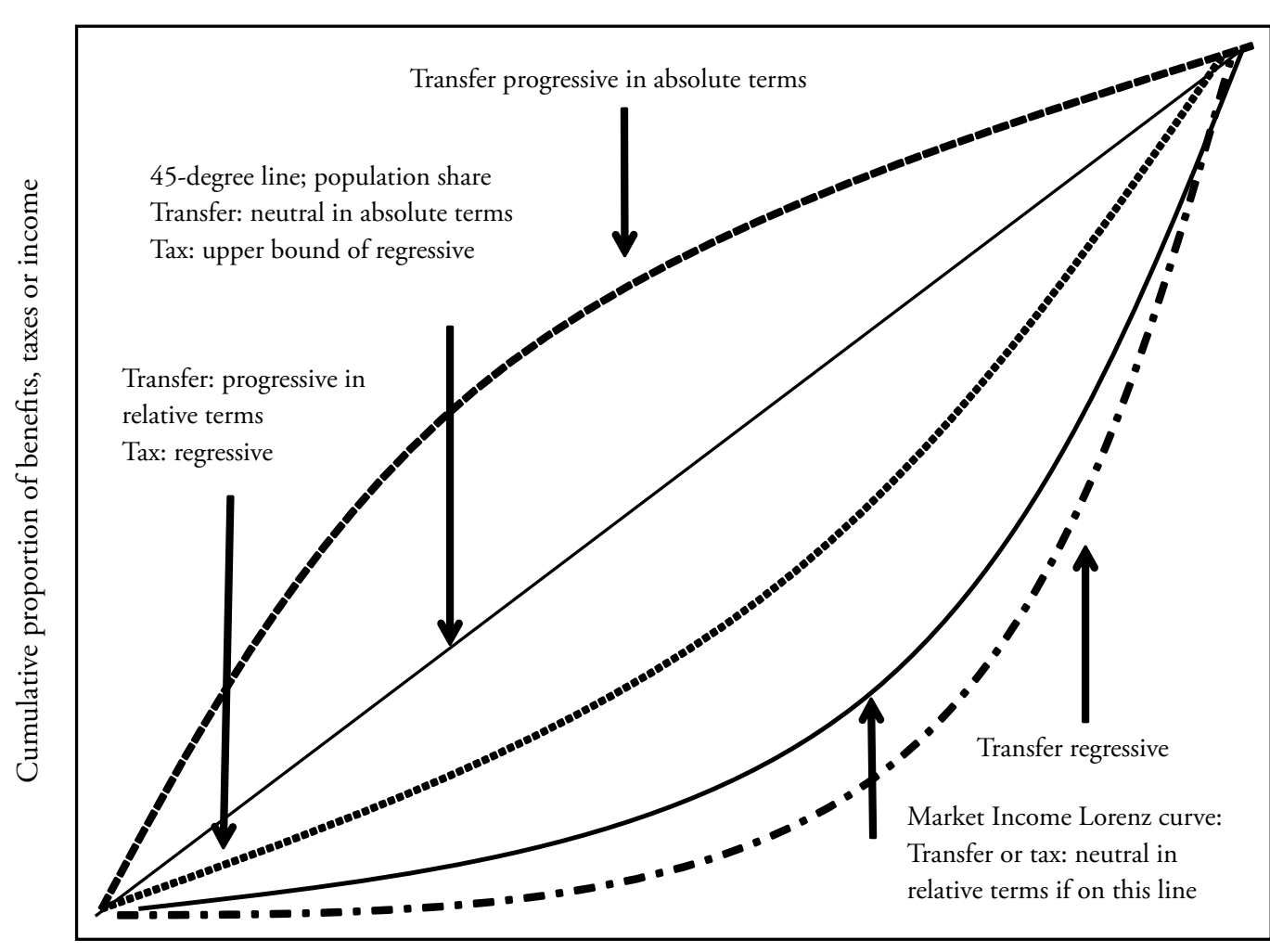

Cumulative proportion of population (ordered by market income)

Source: Lustig and Higgins (2013). 
We use the following descriptions to describe how a fiscal policy component redistributes income:

- Progressive (regressive): A transfer (tax) with a concentration curve above (below) the Lorenz curve for the reference income but below the line of perfect equality (the 45-degree diagonal line). The transfer or tax is progressive only in relative terms. ${ }^{24}$

- Absolute progressive or "pro-poor": When the concentration curve for a spending program is above the line of perfect equality (the 45-degree diagonal line), the transfer is also progressive in absolute terms. The monetary amount received falls as income rises.

- Neutral: A transfer (tax) with a concentration curve that coincides with the Lorenz curve for the reference income is neutral.

- Regressive (progressive): A transfer (tax) with a concentration curve below (above) the Lorenz curve for the reference income. 


\section{Box 1: Caveats of the CEQ analyses and data limitations}

The fiscal incidence analysis applied here has some notable limitations:

- The analysis does not take into account behavioral, lifecycle, or general equilibrium effects and focuses on average incidence rather than incidence at the margin. Our assumptions about tax shifting and labor supply responses are strong because they imply that both consumer demand and labor supply are perfectly inelastic. In practice, they provide a reasonable approximation and they are commonly used.

- The analysis does not take the intra-household distribution of consumption into account.

- The analysis does not explicitly take into account the quality of services delivered by the government. However, when fees for access (in health and education) are taken into account, benefits are adjusted to absorb some of those quality differences that are correlated with funding levels.

- The analysis excludes corporate income, international trade or property taxes and spending categories such as infrastructure investments (including urban services and rural roads).

- The analysis does not capture asset stocks or flows, so the income inequality impacts of savings and investment decisions (and the taxes, subsidies, and fiscal programs that shape those decisions) are not discussed.

- The following limitations emerge from the NHIES data used in the analysis:

- As suggested by very high levels of household indebtedness, market incomes could be misrepresented. The reliability of income data in the survey depends critically on whether the NHIES module includes an exhaustive possible sources of income (including private transfers). This is not necessarily the case.

- As in other countries, the NHIES' ability to capture comprehensive and reliable income information on households at the top of the distribution is limited.

- NHIES coverage limitations are evident in the case of analysis of taxes. Only 2.3 percent of GDP worth of direct taxes are identified compared to 11.1 percent of GDP recorded in administrative records. Even after excluding the corporate taxes, there is a substantial share that is missing. We do not know the distribution of the missing taxes. We assume that under-coverage of the taxes should mostly affect the size of the decline in inequality. 


\section{B. Data, incomes, and income components}

Incidence studies use both national accounts and household survey data, or they rely on incidence indicators from secondary sources, usually micro-data sets. This study uses 2009/10 national accounts and budget reporting data to estimate the magnitudes of the social spending components received by and the revenue collected from Namibian households via different instruments. NHIES 2009/10 is used as a primary microdataset to allocate, household by household, these transfers and taxes. To determine the size of the transfer received or the taxes contributed at each income concept (Figure 16), the taxes and transfers from Namibia's national accounts and administrative fiscal data are allocated to individual households in the NHIES. ${ }^{25}$ The survey contains data on household expenditures, cash transfers, and utilization of educational and health services, collected from approximately 9,656 representative households across the country over 12 months. Per capita values are obtained by dividing the total taxes paid or transfers received by the total number of household members defined as individuals who, during the reference period, were spending at least four nights in a week or at least two of the four weeks of the survey in the household.

For most of the indirect taxes, direct cash transfers, and in-kind transfer items in this analysis, the NHIES allows for direct identification to determine whether a household received a benefit or paid a tax. Simply, the NHIES asks respondents to indicate which transfers were received or which taxable or subsidized items were consumed. ${ }^{26}$ Where the direct identification method is not feasible - for example, for in-kind health transfers and the water and housing subsidies - we use inference, simulation, imputation, and alternative data sources to generate a "best guess" allocation of benefits or taxes paid. ${ }^{27}$

Two important exceptions are the "market income" concept - we use it as the reference income in the analysis - and personal income taxes paid, which when applied to market income, arrives at the "net market income" concept (Figure 16). What follows is a brief summary of assumptions we relied on to generate the reference "market income" and the household level personal income tax burden.

The NHIES applies an income module to all households selected for enumeration. This module contains a (relatively) complete set of possibilities for market income sources: wages and the value of non-wage benefits from employers; income from real estate and other assets; income from insurances and remittances; and income from autoproduction (among others). In the survey, market income from these sources totals about $\mathrm{N} \$ 51$ trillion, or approximately 76 percent of average net national income in $2009 / 10 .^{28}$

Market income from direct identification records indicates relatively high levels of indebtedness among low income households. Figure 18 indicates, for example, that total market income in the poorest 10 percent of households in the NHIES survey is approximately 16 percent of total consumption expenditures. Such an income and expenditure profile implies that some households do not balance their budgets and spend more than what they earn and receive in transfers. 


\section{Figure 18. Income totals by decile (Namibian dollars, trillions)}

A. All deciles

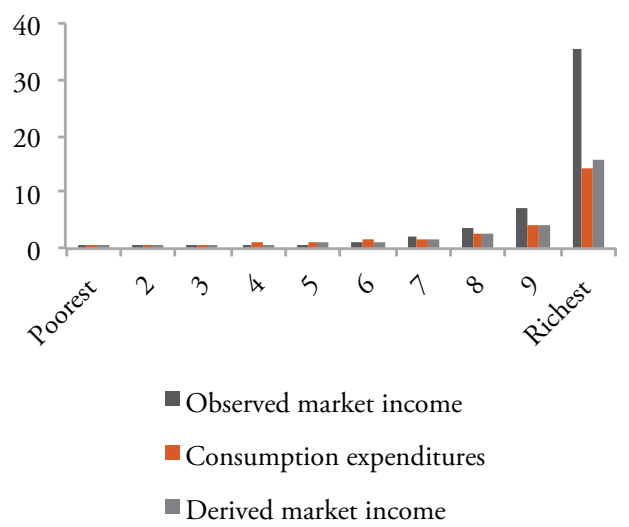

B. First 6 deciles only, re-scaled

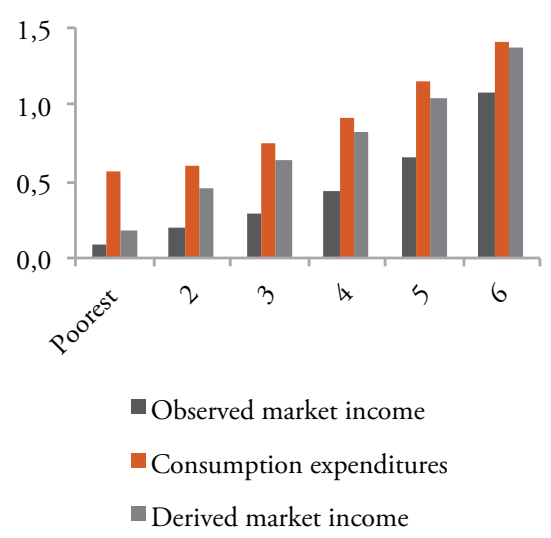

Source: Authors' calculations based on NHIES 2009/10.

For this reason, the baseline incidence analysis takes as the reference income measure, a derived market income created by working backwards from total consumption expenditures. ${ }^{29}$ In other words, we ignore what households indicate they are earning and begin with what they recall spending. From total expenditures we subtract out the value of direct transfers (social grants) received - these can be directly identified in the NHIES - to identify net market income. To this derived net market income, we add back in personal income taxes paid - also directly identifiable in the NHIES - to derive market income. We add a "balanced budget" condition that does not allow derived market income (or net market income) to be less than zero. Figure 18 indicates that this derived market income measure is approximately 100 percent greater than the observed market income for the poorest 40 percent of the population and approximately half the size of observed market income for the richest 10 percent of the population. Derived market income appears much more equally distributed than observed market income. For derived per capita income, the ratio of the tenth to the first decile is 88 ; for market income, the same ratio for is 390 .

There is a relatively high discrepancy between observed market income and consumption expenditures (Figure 18). It is important to mention that "derived market income" includes the value of autoproduction/auto-consumption. Even so, the difference between derived market income and observed market income is smallest for the poorest decile, the decile with a relatively high share of consumption expenditures coming from auto-consumption/autoproduction. Another concern that could arise with the use of derived market income is that richer households typically save a considerable percentage of their income, implying their incomes will be considerably understated by the derived market income variable. This suggests a need to adjust for savings. A common way to do this is to use the marginal propensity to save (MPS) to adjust the derived market incomes higher, based on other survey estimates of the MPS. However, in this particular context, Figure 18 indicates that the marginal propensity to save is not linear or log-linear particularly in observed income, which means applying a single MPS to the entire income distribution 
might not be adequate. Further, the decision to use derived market income rather than reported incomes was based on discussions with officials at NSA that indicated that consumption expenditures were the better estimate for NHIES 2009/10 enumerated households. The NHIES exhibits several weaknesses when it comes to income reporting and these include underrepresented households (the very rich ones); missing households (survey non-response); under-represented income sources (private within-family transfers, for example); missing sources of income (item nonresponse); recall error or bias, among others. Nonetheless, it is important to acknowledge this methodological limitation as use of derived market income could underestimate the extent of income inequality.

Deriving market income from an expenditure proxy has implications for the measurement of poverty and inequality as well as for fiscal components' impacts on welfare. Take the bottom 20 percent of households ranked by observed market income: about 40 percent rank higher when derived market income is used. In fact, approximately 14 percent appear in the top half of the derived market income distribution. ${ }^{30}$

Fiscal policy instruments exhibit different profiles within the two different reference income distributions that are not rank-preserving. Figure 19 summarizes total personal income taxes paid by decile for both the observed and derived market income distributions. Personal income taxes (PIT) paid generally do increase as incomes rise, but the distribution of the PIT burden falls more heavily on low income households in the derived market income distribution.

\section{Figure 19. Personal income tax collection total (of total reference income)}

\section{A. All deciles}

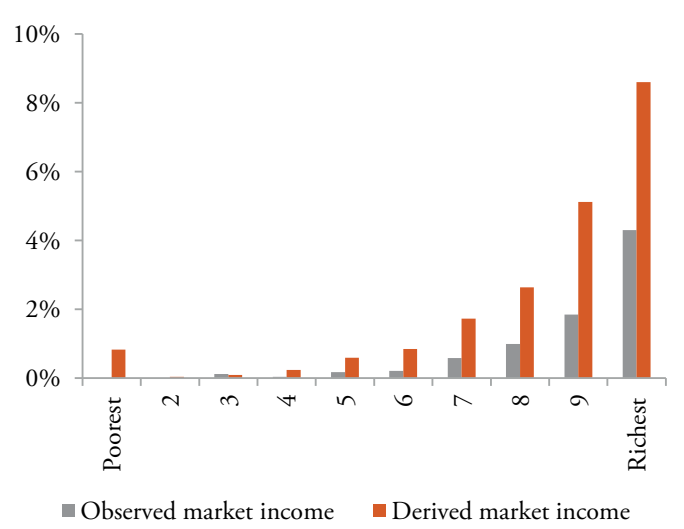

\section{B. First 6 deciles only, re-scaled}

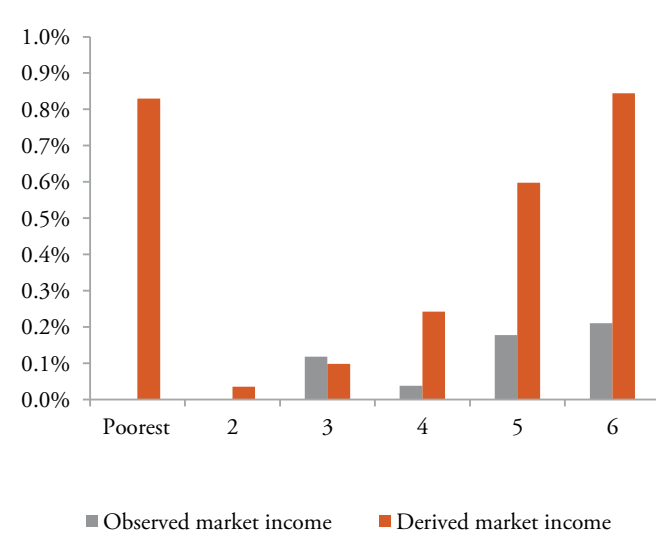

We use the derived market income measure as reference income in the analysis summarized here. The expenditure proxy is likely measured with less error than the observed market income components, especially for those households with less or less reliable - income from the observed market income components. 


\section{Chapter 4: Incidence and Progressivity of Taxes}

This chapter examines the progressivity or regressivity of selected taxes in Namibia. It is important to note that the study's overall objective is to estimate the poverty and redistributive effects of fiscal policy; it does not offer a full analysis of whether specific taxes or expenditures are desirable. Good tax policy will include a range of revenue collection instruments that produce a desired revenue level with minimal distortions and low administration costs. Public spending should aim to provide the minimal functions of a state (such as security) and to invest in public goods (such as infrastructure) that are necessary to ensure prosperity.

The distributional impact of direct and indirect taxes is assessed. The government imposes direct taxes on individuals and organizations - e.g., income taxes, corporate taxes and the like. In the framework of this study, we analyze personal income taxes (PIT) as the main direct tax affecting individuals. Analysis of corporate and wealth taxes are beyond the scope of this analysis. Indirect taxes are applied to the sale of goods and services. Goods and services providers collect VAT and fuel levy taxes from the end user to subsequently pass the proceeds onto the government. Direct and indirect taxes affecting end users are first analyzed separately and then looked at collectively.

\section{Figure 20. Tax revenue, cross country comparison (percent of GDP)}

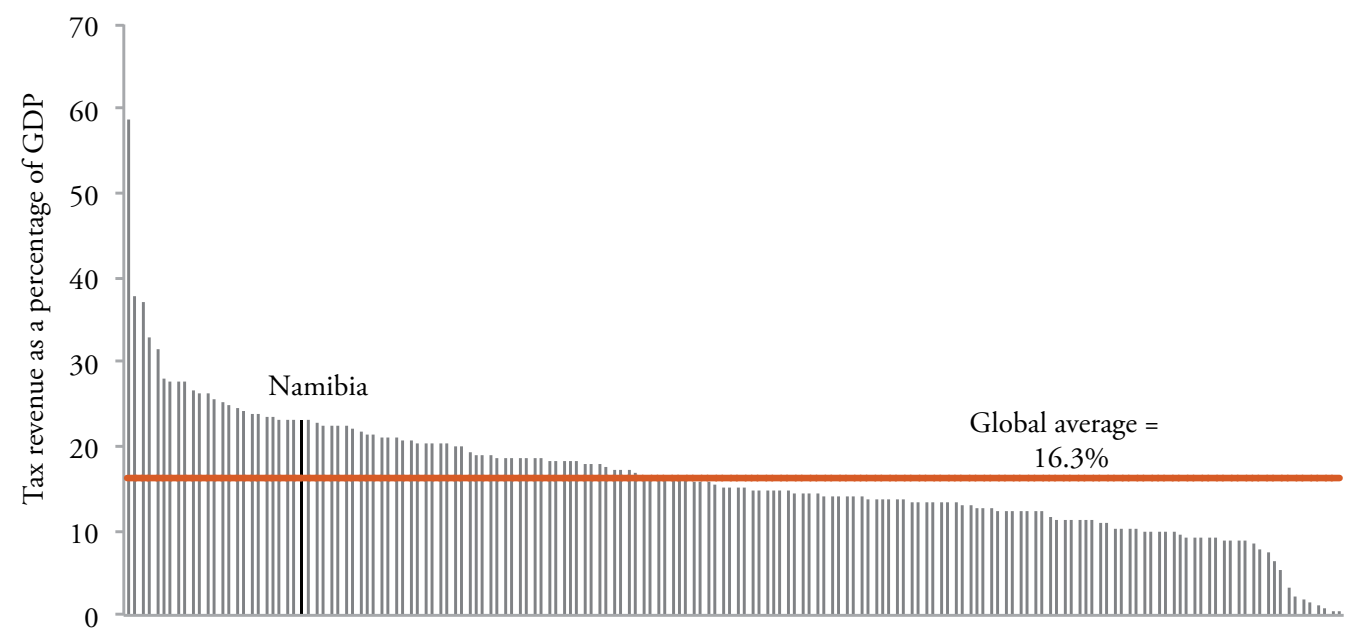


Namibia has relatively high tax-to-GDP ratio in comparison to other developing countries. Wide national variations exist across countries (Figure 20). At the upper end are Lesotho, Algeria and Seychelles, which have a tax-to-GDP ratio above 30 percent, while at the lower end are Middle Eastern economies with less than 5 percent tax-to-GDP ratio. The corresponding average was 16.3 percent in 2010. Namibia tax-toGDP ratio ( 24 percent) was more than 50 percent above the average of the developing countries. ${ }^{31}$ The relatively high share of tax revenues collected by the government in Namibia reflects the relatively wide range of taxes. As Namibia's level of the taxation is relatively high for an average African country, this is the time to analyze incidences of the taxes.

\section{A. Direct taxes ${ }^{32}$}

Incidence analysis shows that the Namibian PIT is progressive - the shares of PIT paid increase with reference income shares. ${ }^{33}$ Figure 21 demonstrates this, using concentration curves. Households are ranked from poorest to richest (according to the reference income) from left to right along the $\mathrm{x}$-axis. The curves are generated by plotting the cumulative share of a tax paid (or a transfer received) accounted for by all the households to the left of any point on the x-axis (see also Chapter 3). Figure 21 shows that the poorest 80 percent of the population (ranked by derived market income plus pensions) accounts for approximately 11 percent of total PIT collections reported in the NHIES. The poorest 90 percent of the population accounts for approximately 30 percent of all PIT collections, leaving about 70 percent of PIT collections within the richest 10 percent.

\section{Figure 21. Concentration curves for PIT (share of total tax paid by reference} income deciles)

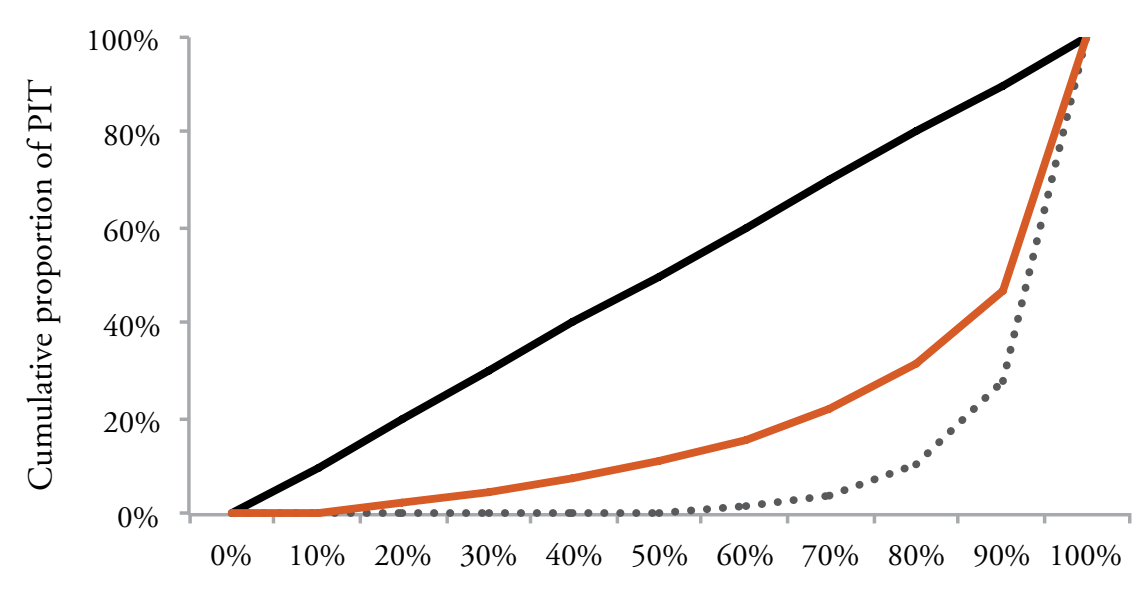

Cumulative proportion of the population

(ranked by market income + pensions)

$$
\text { 45-deg. line } \quad \cdots \text {... PIT } \longrightarrow \text { Market income }+ \text { pensions }
$$

The poorest 90 percent of the Namibian population accounts for about 30 percent of all personal income tax collections 
The progressivity of PIT in Namibia compares favorably to others in the CEQ country set. Figure 22 summarizes the incidence of personal income taxes (and other direct taxes) relative to reference market income for Namibia and four other countries in the CEQ country set. Direct taxes are progressive everywhere, although the share of these taxes in total public revenue varies from country to country. For example, the top decile in South Africa pays over 80 percent of total PIT collected, and total PIT collected represents about 14 percent of GDP. Brazil collects two-thirds of PIT from the top decile, and total PIT receipts represent about 12 percent of GDP.
Figure 22. Concentration shares: personal income taxes (Share of taxes by market income deciles)

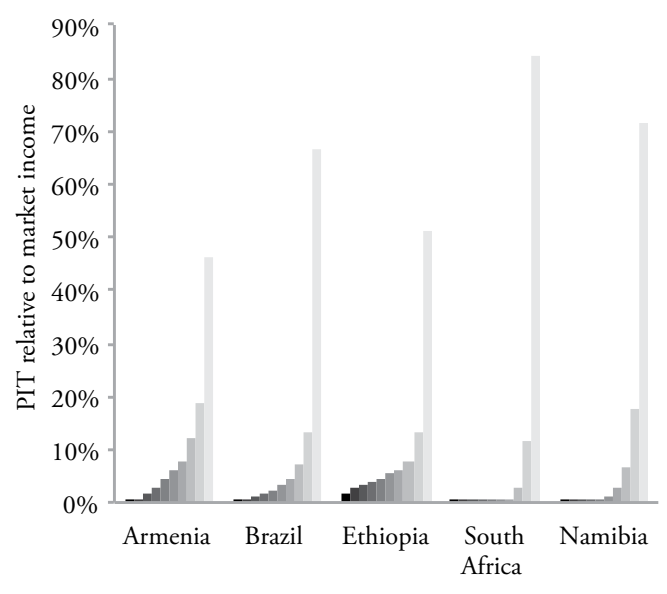

Sources: Armenia (Younger et al., 2014), Brazil (Higgins and Pereira, 2014), South Africa (Inchauste et al., 2015), and Namibia (own calculations based on NHIES 2009/10).

Note: Darker bars at left represent poorer deciles; lighter deciles at right represent richer deciles.

\section{Figure 23. Progressivity of direct tax} system: Kakwani coefficient

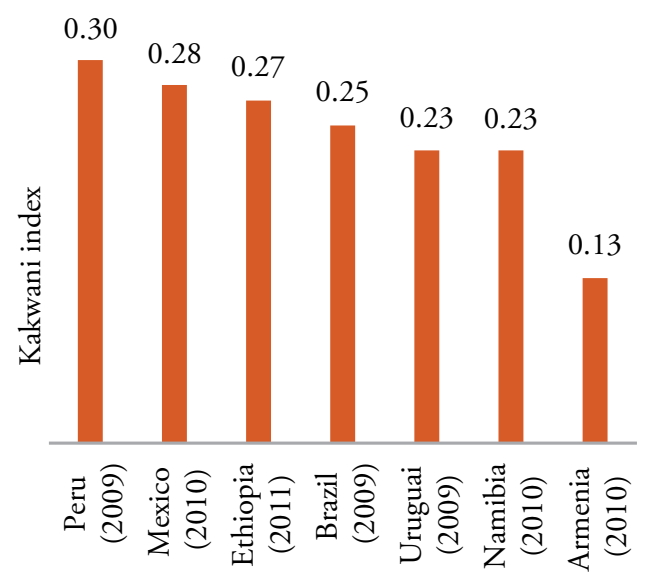

Sources: Armenia (Younger et al., 2014), Brazil (Higgins and Pereira, 2014), South Africa (Inchauste et al., 2015), Ethiopia (Woldehanna et al., forthcoming), Indonesia (Jellema et al., forthcoming), Mexico (Scott, 2014), Peru (Jaramillo, 2014), and Namibia (author' calculations based on NHIES 2009/10).

\section{B. Indirect taxes}

The indirect taxes covered in the study are the VAT and fuel levy. Together, their revenues equal 6.7 percent of GDP. VAT accounted for 32.6 percent of total tax collections in 2009/10 (excluding SACU receipts and grants), and the general fuel levy contributed about 0.5 percent. We assess the incidence of indirect taxes with respect to disposable income, defined as the sum of market income plus direct transfers, net of direct taxes. ${ }^{34}$

Indirect taxes as a whole ${ }^{35}$ are more or less neutral. At the bottom of the income distribution, the cumulative share of total indirect taxes paid is approximately equal to each decile's share of disposable income. For deciles two through six, the share of indirect taxes paid exceeds disposable income shares, meaning only the richest decile pays a share of indirect taxes that is smaller than its share of disposable income (Figure 24). 


\section{Figure 24. Concentration curves of indirect taxes (share of total tax paid by}

reference income deciles)

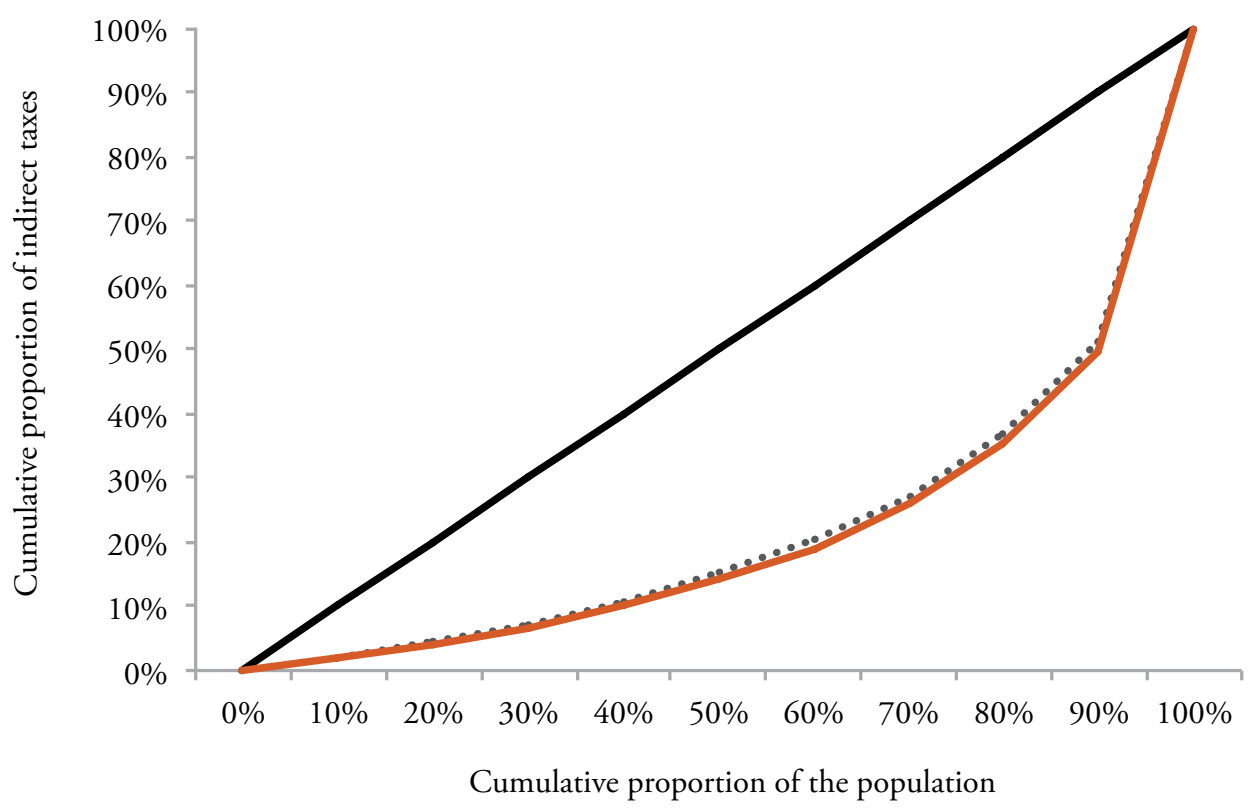

45-deg. line $\quad \cdots .$. VAT + Fuel Levy $\quad \longrightarrow$ Disposable income

\section{Progressivity of total taxes (direct and indirect)}

Combined direct and indirect taxes (excluding SACU receipts) in Namibia are about 17.8 percent of GDP, making it one of the largest total tax burdens of any country with a CEQ assessment. Most countries with a similar-sized indirect tax take (e.g. Ethiopia) have a much smaller direct tax take, and most countries with a similar-sized direct tax take (e.g. South Africa) have a smaller indirect tax take.
The overall incidence of direct and indirect taxes is progressive; i.e., shares of total taxes paid increase with reference income shares. The concentration curve presented in Figure 25 combines information in Figure 21 (PIT) and Figure 24 (indirect taxes). It shows that the poorest 75 percent of the population (ranked by derived market income) accounted for approximately 20 percent of total direct and indirect taxes. The poorest 90 percent of the population accounted for approximately 40 percent of total tax collection, leaving about 60 percent of the total taxes within the richest 10 percent.
The poorest 90 percent of the Namibian population accounts for about 40 percent of all tax collections 


\section{Figure 25. Concentration curves of direct and indirect taxes (share of total tax} paid by reference income deciles)

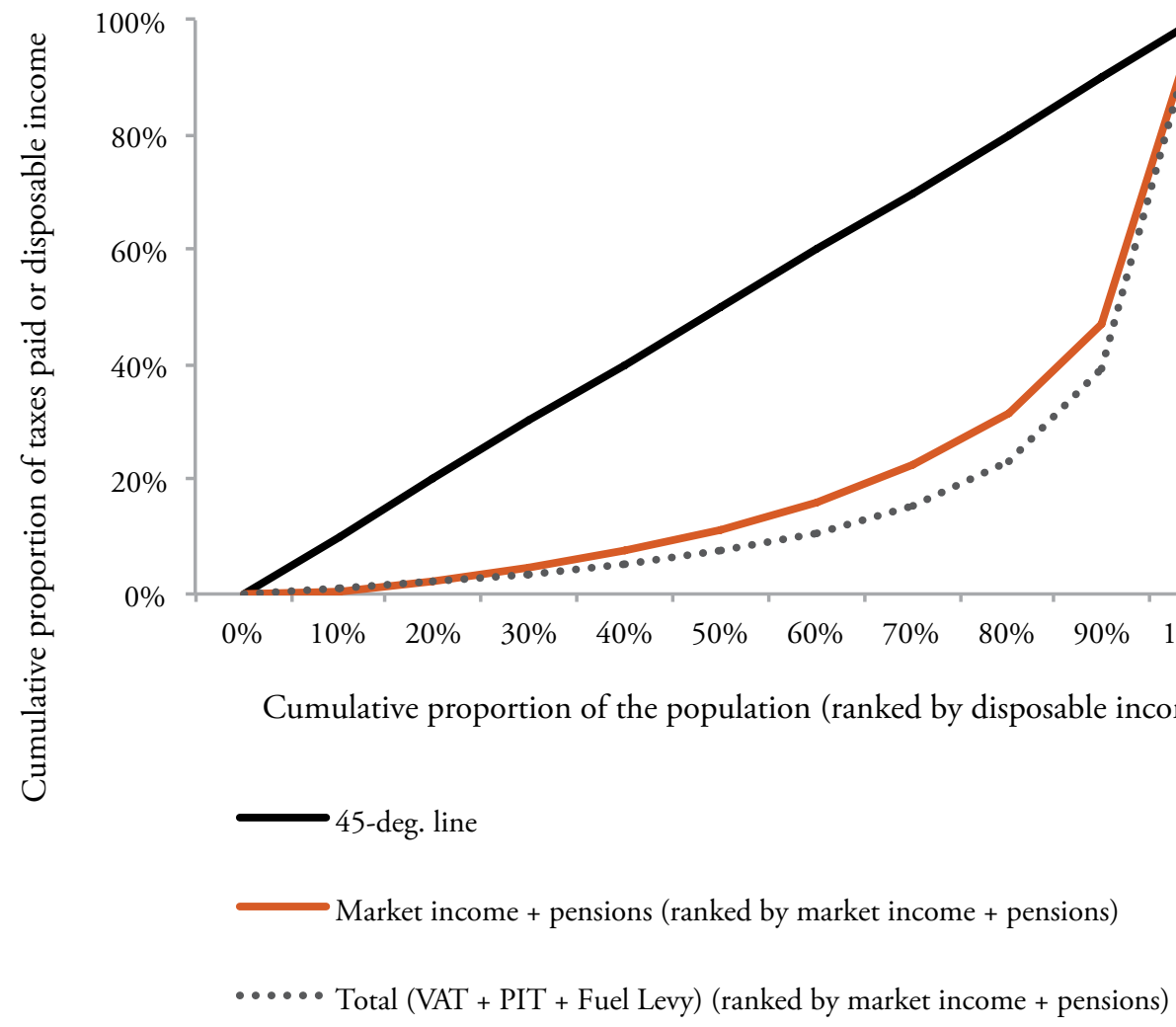




\section{Chapter 5: Incidence and Efficiency of Social Spending}

\section{A. Incidence and efficiency of direct transfers}

The effectiveness of social protection programs in reducing poverty depends on whether they cover a significant number of poor people and whether they are adequate. The key issues are: Do benefits go mostly to the poor? Are they adequate to significantly reduce the consumption gap? Cost effectiveness also depends on the efficiency of administration in terms of identifying beneficiaries and delivering benefits. This section assesses the performance of the direct transfers with respect to: (i) progressivity; (ii) coverage; (iii) targeting accuracy; (iv) the generosity of benefits; and (v) the impact on poverty. Box 2 provides definitions of the performance indicators. ${ }^{36}$

\section{Box 2: Main indicators of performance and targeting efficiency of direct transfers}

Based on the World Bank's study "Targeting of Transfers in Developing Countries"37, economic growth is a necessary but insufficient condition for the alleviation of poverty. The asset base of poor households needs to be built up so that they can participate in the growth process. Growth needs to be more intensive in the sectors in which the poor predominate. Short-term public transfers are required to protect and raise the consumption of the poorest households. Implementation of this agenda for reducing poverty requires methods for reaching the poor. In part, this can be accomplished by spending on items such as universal primary education that reach a wide segment of society, including the poor. It also can be accomplished by providing targeted resources directly to the poor. Targeting is a means of increasing program efficiency by increasing the benefit that the poor can get within a fixed program budget. Several methods exist in the social protection literature which ensure resources are directed to the poor. A brief summary of the individual/household assessment, simple means tests, proxy means tests, community based-targeting, and categorical targeting are described in the Annex 2.

The main indicators of performance of social assistance cash transfers include:

- Coverage: What share of the population receives the transfers, with a focus on the share received by the poorest quintile?

- Targeting accuracy: What share of the transfer goes to each quintile, with particular focus on the share of transfers going to the bottom quintile?

- Generosity: How much is the transfer as a fraction of post-transfer disposable income or consumption? If this fraction is large, it would imply that the household is getting its income primarily from this transfer. 
- Progressivity index: An alternative method to measure progressivity is the Kakwani Index, calculated as twice the area between the market income Lorenz curve and the tax (transfer) concentration curve. If the tax (transfer) concentration curve is below (above) the Lorenz curve, the Kakwani index will be positive, indicating that taxes (transfers) are progressive. If the tax (transfer) concentration curve is above (below) the Lorenz curve, the Kakwani index will be negative, a signal of regressive taxes (transfers).

- Impact of the transfer on poverty and inequality: To what extent does the transfer lift people out of poverty and reduce inequality? To measure this impact, the amount of the transfer is removed from households' consumption, leading to estimates of how many more individuals would be poor in the absence of the transfers and how the inequality would change.

- Under-coverage and leakage: A common approach to evaluating the targeting performance of alternative transfer instruments is to compare under-coverage and leakage rates. Undercoverage is the proportion of poor households that are not included in the program (errors of exclusion). Leakage is the proportion of those who are reached by the program who are classified as non-poor (errors of inclusion).

Namibia exceeds the average spending on public transfers for Sub-Saharan African countries in overall spending on direct transfers. Spending on direct transfers is higher than the average for Sub-Sahara African countries (1.46 percent) (Figure 26). It is comparable to the average for developing countries (1.6 percent). Namibia's spending level is comparable to that of Argentina and Poland, but significantly below that of South Africa (3.5 percent) and Mauritius (3.3 percent). The Old Age Pension (OAP) constitutes 59 percent of spending on direct transfers (Figure 27).
Figure 26: Spending on social protection by country (percent of GDP)
Figure 27: Distribution of spending on direct transfers by type of program, 2012/13
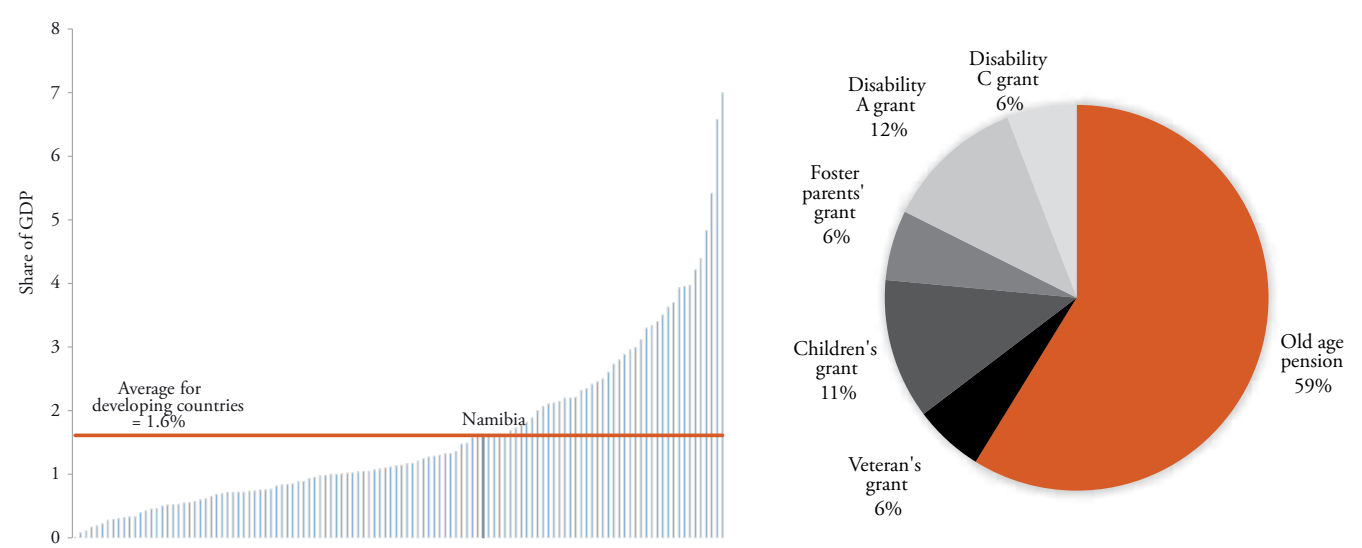

Source: Aspire database, the World Bank and Government of Namibia for Namibia. 
Despite generous spending, the targeting efficiency of direct transfers is relatively low. International comparison suggests that Namibia is below the world average both in terms of coverage of the direct transfers going to the poorest population and in terms of grants' targeting efficiency. Figure 28 presents coverage of the programs going to the poorest quintile of the income distribution for 104 countries worldwide. The coverage for the poorest quintile was 33 percent in Namibia, below the 43.1 percent world average. Figure 29 illustrates the targeting efficiency of direct transfers, expressed as a percentage of the transfers going to the poorest quintile.
Targeting efficiency of direct transfers in Namibia was 16.9 percent compared to the 26.6 percent world average. In other words, despite generally high levels of government spending on grants, both coverage and targeting efficiency are relatively low in Namibia in comparison to other countries. The lack of targeting efficiency of Namibian grants is well illustrated in comparison to South African grants. Both countries spend a significant amount of resources on transfers as a share of GDP, while most of the South African grants are proxy means tested which significantly improves the targeting efficiency of grants.

\section{Figure 28. International comparison: coverage of the transfers (poorest decile)}

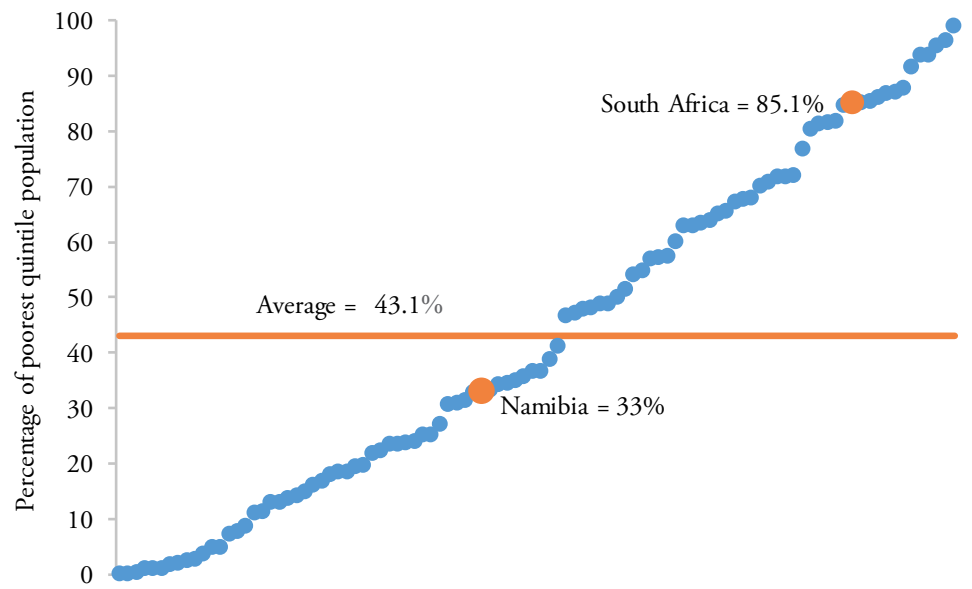

Spending on direct transfers is quite generous but is characterized by relatively low targeting efficiency

\section{Figure 29. International comparison - targeting efficiency of the transfers}

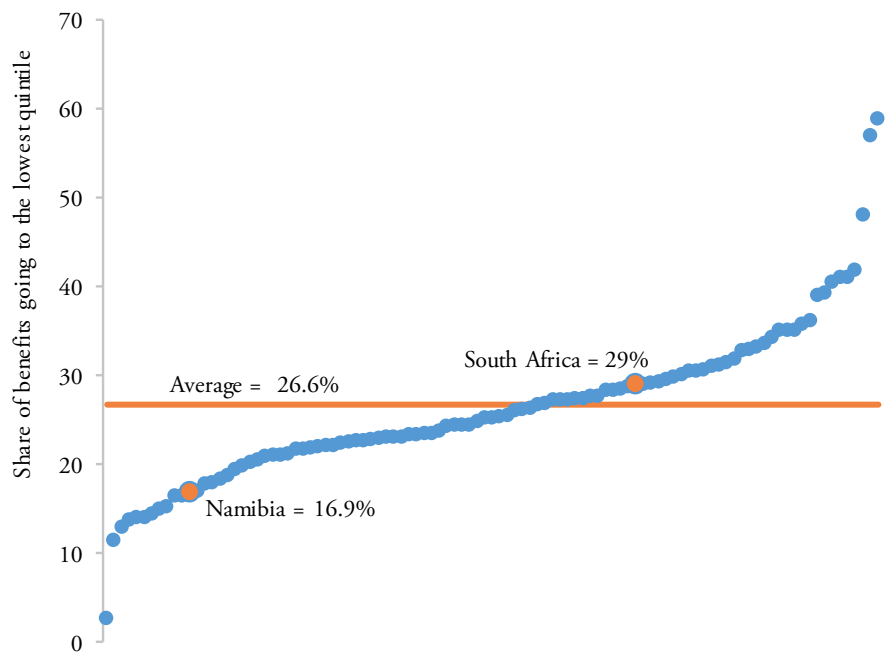

Source: Authors' calculations for Namibia based on NHIES 2009/10. ASPIRE database (The World Bank) for other countries (104 countries). 
Each direct transfer covered in this study is weakly progressive. In the top two panels (A and $B$ ) of Figure 30, the concentration curves present the distribution of the consumption per capita on the far right from the diagonal line of perfect equality. The deep bowing confirms the very high level of inequality in Namibia. However, almost all grants are very close to the 45 -degree equality line. This means that the transfers, analyzed separately, are weakly progressive in relative and in absolute terms (i.e., the transfers represent a larger share of income among lower deciles in relative terms). All the analyzed grants are generally similar in terms of their weak progressivity. However, South African grants are much more progressive.

A comparison to South Africa indicates that the majority of the South African grants are strongly progressive - in contrast to Namibian grants that are merely neutral or slightly progressive (Figure 30, panels C and D). South Africa and Namibia are very similar countries in terms of the high level of income inequality and availability of a wide range of direct transfers. However, South Africa uses proxy means tests for most socialassistance programs, and this could be driving the observed strong progressivity. If so, proxy means tests could be explored in Namibia as a way to improve the progressivity and efficiency of social assistance programs.

\section{Figure 30: Progressivity of direct cash transfers by category: concentration curves for transfers and Lorenz curves for market incomes, Namibia and South Africa}

Panel A: Namibia

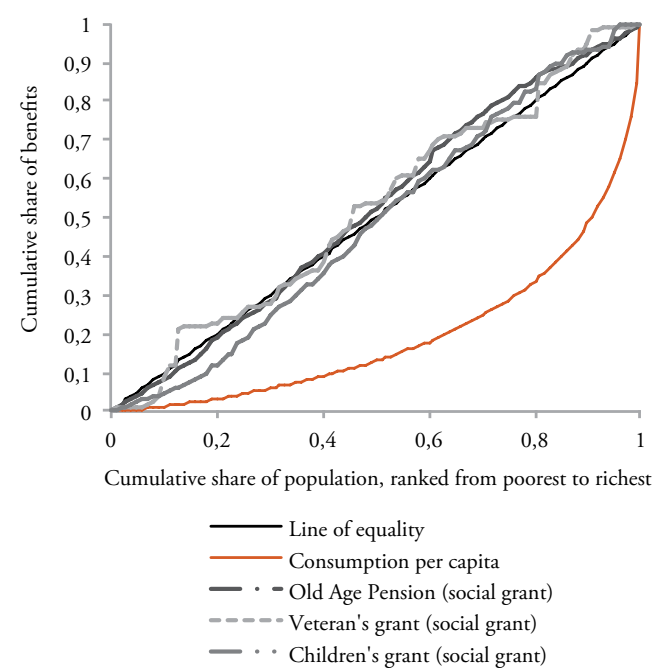

Panel C: South Africa

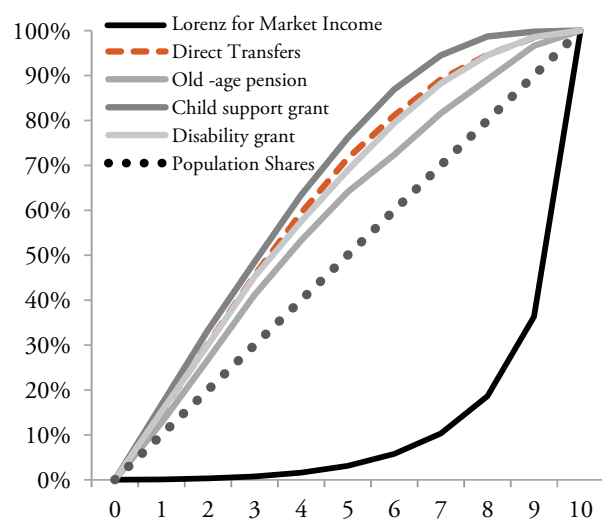

Panel B: Namibia

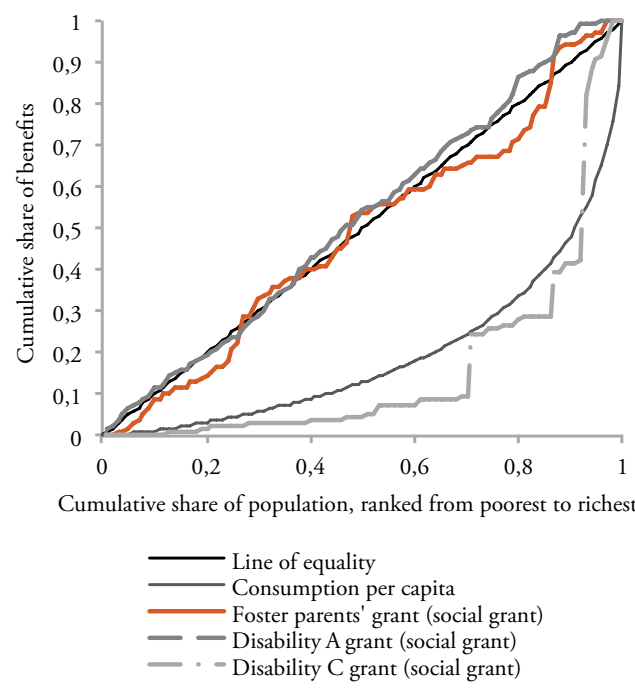

Panel D: South Africa

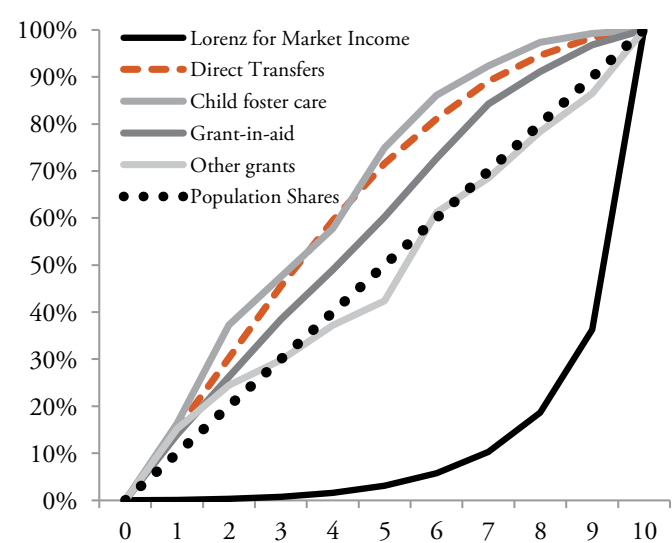


The coverage of direct transfers is slightly progressive in terms of targeting, but they reach a relatively small proportion of the population (Table 4). We define "coverage" as the proportion of people in the respective population group having access to the specific grant or group of grants. Both direct and indirect beneficiaries are included in the analysis - in other words, the whole household is defined as a beneficiary, if any individual in it has access to the grant.
The "all direct grants" category combines all cash transfers; if a household has access to any of the grants, it will be defined as a receiver. Almost one-third of the population (27.2 percent) has either direct or indirect access through family members' access to the transfers. The targeting efficiency indicator is generally progressive: 33 percent of the poorest quintile receive at least one transfer, and coverage declines to 13.1 percent among the top quintile.

\section{Table 4. Coverage (targeting efficiency) of direct transfers}

\begin{tabular}{lcccccc} 
& \multicolumn{7}{c}{ Quintiles of per adult equivalent consumption } \\
\cline { 1 - 3 } & Total & Q1 & Q2 & Q3 & Q4 & Q5 \\
Direct and indirect beneficiaries & & & & & \\
All direct transfers & 27.2 & 33.0 & 35.9 & 31.5 & 22.4 & 13.1 \\
Old Age Pension & 17.2 & 22.2 & 22.6 & 19.6 & 14.7 & 6.8 \\
Children's grant & 6.3 & 6.6 & 9.4 & 7.7 & 5.3 & 2.6 \\
Veterans grant & 1.3 & 2.0 & 1.7 & 1.6 & 0.3 & 1.0 \\
Foster parents grant & 2.0 & 2.3 & 3.3 & 1.3 & 1.2 & 2.0 \\
Disability grant - adult & 4.2 & 6.3 & 5.7 & 4.4 & 3.3 & 1.1 \\
Disability grant - child & 1.3 & 0.7 & 1.3 & 0.6 & 1.8 & 2.2 \\
\hline Source: Authors' calculations based on NHIES $2009 / 10$ for Namibia. & & & &
\end{tabular}

\section{Figure 31. Targeting accuracy, coverage, Figure 32. Progressivity of all direct and generosity - all direct transfers \\ transfers}

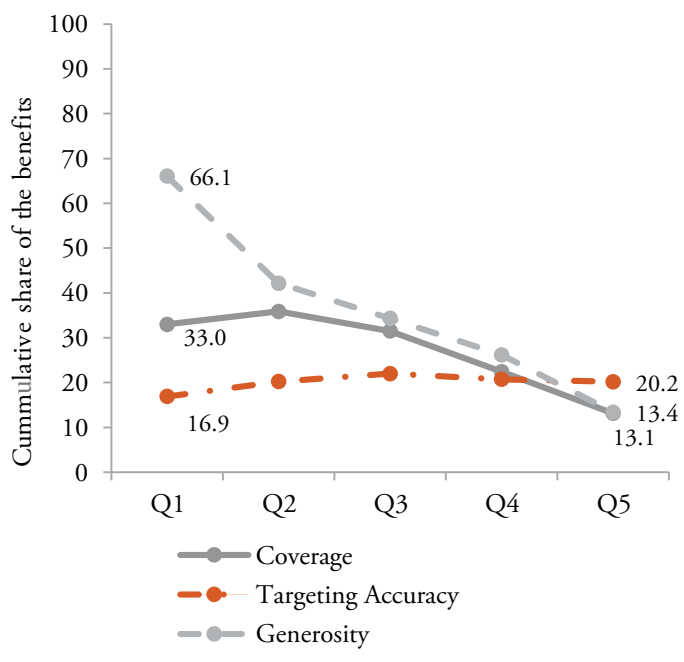

Source: Authors' calculations based on NHIES 2009/10.

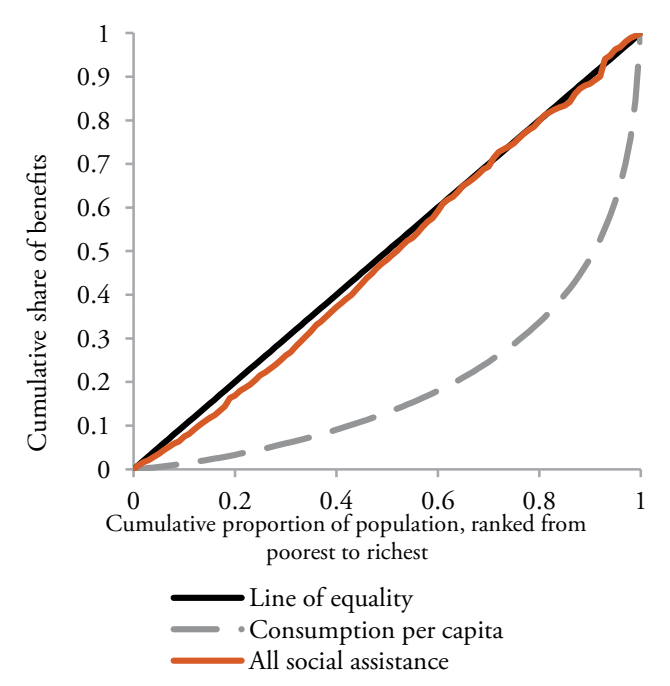

Only close to a third of the population receives direct transfers, directly or indirectly and the poor are more likely to receive direct transfers 
Direct transfers matter for the poor. The coverage and generosity of direct transfers as a whole is slightly progressive (Figure 31). With respect to coverage, progressivity means that the poor were more likely to receive direct transfers in 2009/10. Not only was the coverage progressive, the transfers tended to be generous to the poor, making up a larger share of their total income. Households in the lowest quintiles of the consumption distribution received up to 66.1 percent of their income from direct transfers (generosity); the share was below 20 percent for the top quintile. On average, generosity of direct transfers was 27.2 percent in Namibia in $2009 / 10 .^{38}$

The targeting accuracy of direct transfers is not as progressive despite progressive coverage and generosity as a whole. The targeting accuracy is measured by the share of transfers going to each income quintile. The share of all direct transfers going to the poorest quintile, or targeting accuracy, was 16.9 percent in 2009/10 (Figure 31). The share of benefits going to the richest quintile was 20.2 percent. Direct transfers may matter for the poor in other ways, but their targeting accuracy is low. The finding of regressive targeting accuracy and slightly progressive coverage suggests the value of the transfers is significantly larger among the rich. This is even more evident from the Lorenz curve analysis in Figure 32 where the line for direct transfers nearly lies on the 45-degree line. This differs from the progressive distribution of direct benefits in South Africa, where the poorest quintile received more than 25 percent and richest less than 11 percent (authors' calculation).
The share of all direct transfers going to the poorest quintile, was 16.9 percent in 2009/10 while it was 20.2 percent for the richest quintile 


\section{Figure 33: Targeting accuracy, coverage, and generosity of each direct transfer}
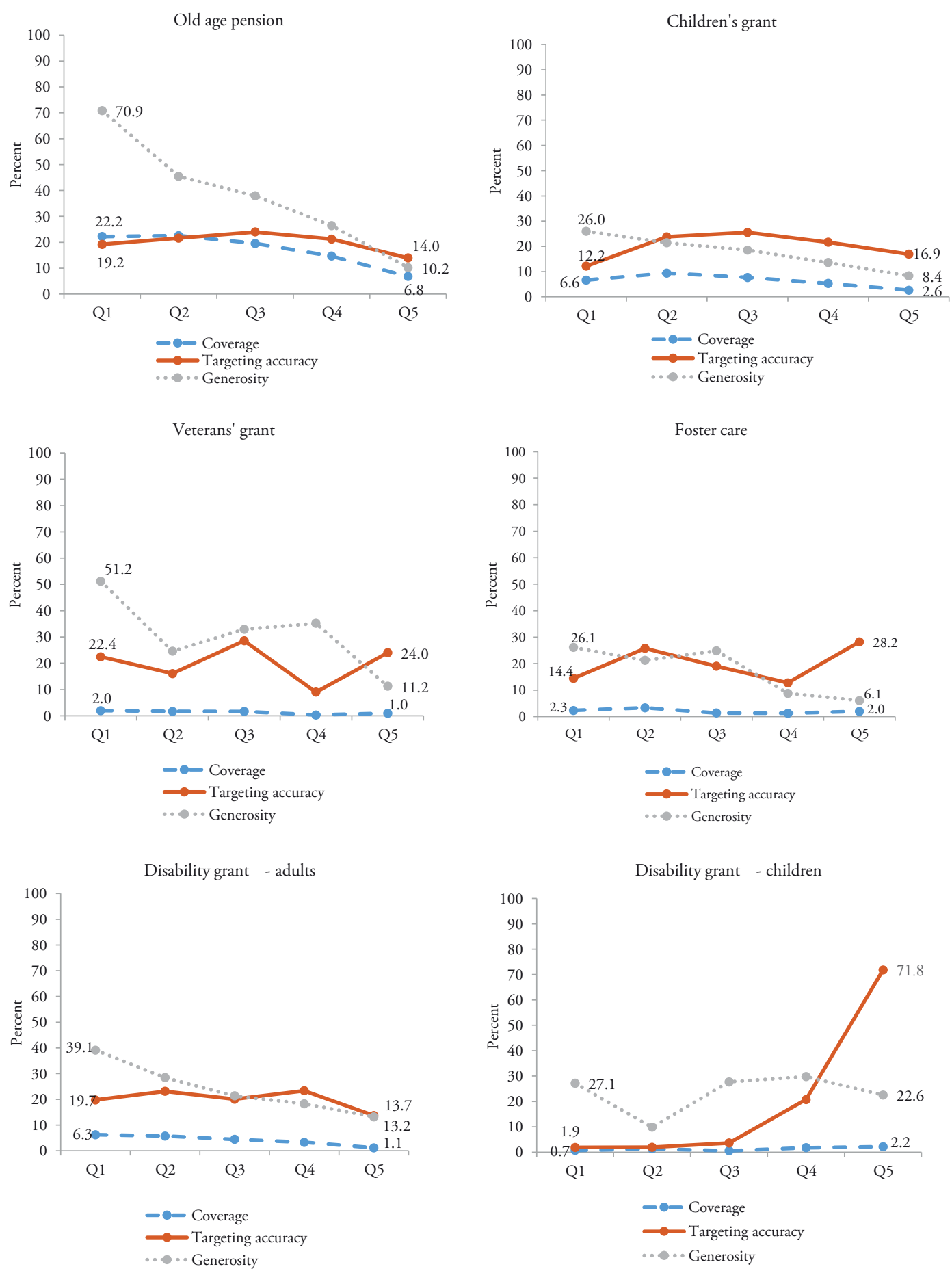

Source: Authors' calculations based on NHIES 2009/10. 
Direct transfers are progressive in terms of coverage and generosity, but their targeting accuracy could be improved
Analyzing the direct transfers, oneby-one, reveals a similar picture. All direct transfers are progressive in terms of coverage and generosity, but their targeting accuracy could be improved (Figure 33).

The Old Age Pension (OAP) has the highest coverage, and it is progressively targeted. An average of nearly 17.2 percent of Namibians receive the OAP. The grant is progressively distributed, going to 22.2 percent of the poorest quintile and 6.8 percent of the top quintile.

Children's grants are given to a relatively small portion of the population, and their targeting efficiency is limited. On average, 6.3 percent of the population receive children's grants, with coverage of 6.6 percent in the poorest quintile and 9.4 percent in the second quintile. However, 2.6 percent of the richest quintile receive the grant. This pattern holds in most countries because child related grants are self-targeting for big families with a lot of children. These households tend to be poorer, making targeting more efficient. With a program coverage size of 6.3 percent, which is relatively small, one would hope that the coverage of the poorest quintile is much higher than any other quintile, but at 6.6 it is barely above the national average, is quite a bit lower than Q2 (9.4) and Q3 (7.7), and is not much higher than Q4 (5.3). These results are not that surprising, given that there is no PMT-style targeting in Namibia.

The veterans, foster care, and disability grants are generally small in terms of coverage and vary in terms of their progressivity. On average, coverage was 1.3 percent of the population for veterans' grants, 2 percent for foster care grants, and 5.5 percent for disability grants. The poor generally are more likely to receive these grants. For example, veterans' grants went to 2 percent of the lowest quintile and 1 percent of the top quintile. For adult disability grants, the corresponding figures were 6.3 percent for the first quintile and 1.1 percent for the top quintile. A similar pattern is observed for foster care grants.

In Namibia, proxy means tested programs could reduce poverty and inequality. Introducing the Proxy Means Test (PMTs) is expected to help Namibia make substantial progress toward achieving the NDP goals as well as offering insights to the strengths and weaknesses of different approaches to poverty and inequality reduction. However, PMTs are operationally complex, requiring considerable investment and institutional capacities. Targeting cash transfer and compliance verification to conditions require highly developed, efficient systems. Box 3 presents the rationale for introducing PMT programs in Namibia, drawing on lessons from PMT in Indonesia. The box also indicates administrative and methodological challenges associated with the introduction of PMT programs. We have not actually compared the PMT based distribution and the current distribution. The basis for thinking that PMT could improve the outcomes is based on cross-country experiences. It is also important to emphasize that a combination of measures should be considered as a long term solution for Namibia. A whole range of targeting mechanisms (community, PMT, self-targeting, etc.) should be further analyzed. Assuming PMT is probably a preferred method, additional research in this area should be undertaken, suggesting appropriate methods that could improve the targeting efficiency of direct transfers in Namibia. 


\section{Box 3: Advantages of proxy means tests for targeting social programs: the case of Indonesia}

Many low- and middle-income countries have introduced conditional cash transfers (CCTs) based on the proxy means testing methodology. Among the countries with good examples of well-designed targeted social protection systems are South Africa, Chile, and Brazil. CEQ analysis indicates progressive patterns of CCTs.

Indonesia has also developed a well-targeted social assistance system. As Indonesia matures into a middle-income country, the government is trying to improve social assistance as part of its efforts to reduce poverty. The country now offers households a number of social assistance programs, including subsidized rice, health-fee waivers, cash transfers for poor students, a pair of CCTs, and a temporary unconditional cash transfer.

Indonesia's government introduced two complementary CCT programs. The household CCT gives quarterly transfers to poor households identified through a PMT system. The community CCT focuses on communities rather than individually targeted households. The PMT methodology estimates household income by associating indicators with household expenditure or consumption. Proxy means testing uses multivariate regression to correlate certain proxies, such as assets and household characteristics, with poverty and income.

The World Bank recently completed a CEQ analysis of the poverty and redistributive impacts of Indonesia's transfers system. Figure 34 presents the results for the proxy means tested conditional transfers to households.

Figure 34: PMT conditional cash transfers in Indonesia - concentration curves for transfers

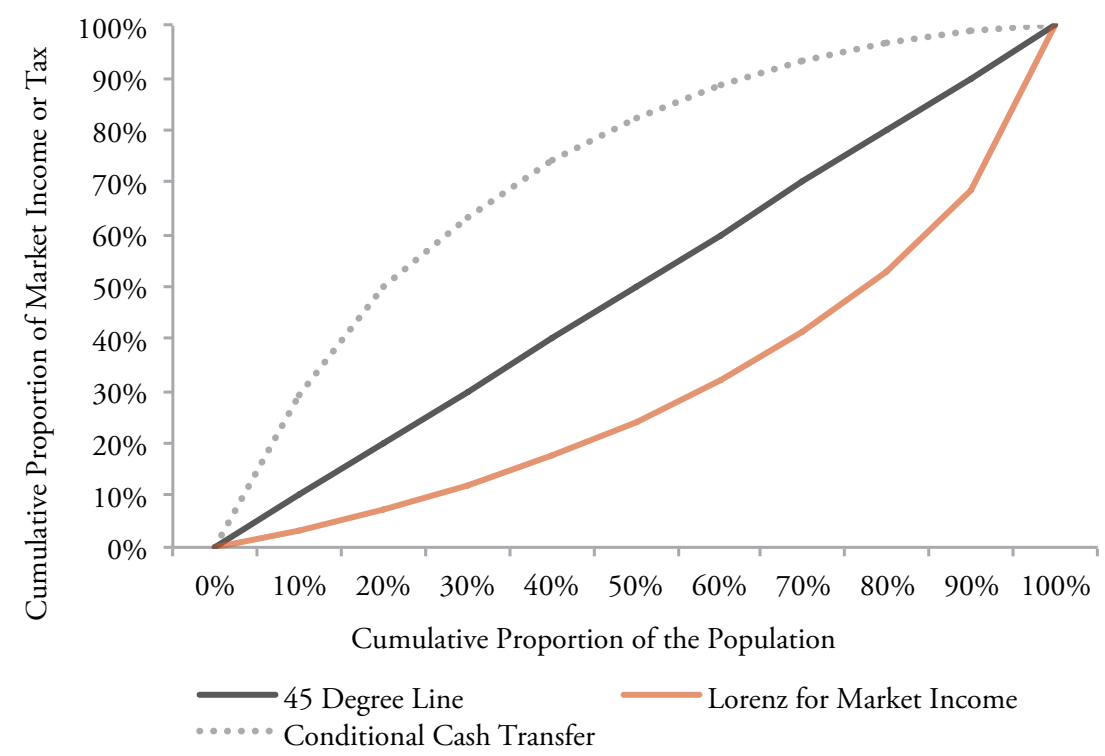

Source: Authors' calculations based on Indonesia National Socio-Economic Survey 2012.

The concentration curve for the CCT is significantly above the 45-degree line of equality, indicating the progressivity of the transfers. The program has a very substantial impact on poverty and income inequality in Indonesia. The transfer raises the income of poor households and increases their consumption, reducing poverty and inequality. PMT transfers are considered more efficient and more effective than other types of government transfers. 
Indirect subsidies are progressively targeted, driven by the water subsidy

Implementing proxy means testing significantly improves targeting of the social protection system, but the method has a number of challenges. Significant administrative costs are associated with introduction and implementation of PMT programs. PMT methodology is based on national household survey data, and the enumerators are not always objective when conducting surveys and do not always have time to verify proxies within households. Some households' characteristics are difficult to verify. The method does not take into consideration financial shocks and distress when households fall in poverty without observing a change in the household characteristics.

To summarize, the foregoing discussion shows that the magnitude of government spending on direct transfers is adequate in Namibia, but targeting efficiency is relatively low. The transfers are important to the beneficiaries, especially to the poor in that they make up a large share of their total income. The targeting accuracy of transfers is low and could be improved by introducing PMT programs. Targeting accuracy is low mostly because the transfers are categorical (elderly for pensions, child grants), which automatically makes richer households eligible. Introduction of PMT schemes could improve targeting efficiency in Namibia, making them more pro-poor. However, it does take time, money and capacity to introduce PMT schemes. For the money the Namibian government spends on social assistance, and given a very ambitious inequality reduction target, the PMT programs would have much better targeting outcomes and greater cost effectiveness.

\section{B. Incidence and efficiency of indirect subsidies}

This section covers three indirect subsidy programs - the rural water infrastructure and services program, the Build Together Program (BTP) housing subsidy, and the National Housing Enterprise (NHE) housing subsidy. Only rural residents with access to an improved water source are eligible for the water infrastructure program. The subsidy amount is defined as the public expenditure on this program in 2009/10, divided by the total number of rural households with access. Both the BTP and NHE are allocated randomly to homeowners within the NHIES dataset who meet the programs' eligibility rules. The value of benefits is defined as the preferential financing subsidy relative to expected market or traditional lender finance rates.

Taken together, the three subsidies are progressively targeted, driven by the water subsidy (Figure 35). The three subsidies have a relative- to absolute-progressive incidence in that the poorest and middleincome households receive subsidy shares that are larger than their shares of disposable income. ${ }^{39}$ However, this overall progressivity is driven by the water subsidy; it accounts for nearly three-quarters of all subsidy expenditures analyzed in the study. The BTP accounts for nearly one-quarter, and the NHE for approximately 2 percent. The water subsidy's absolute progressivity (or "pro poor-ness") are not surprising. The subsidy is allocated only to rural households, and the majority of poor and low income households reside in rural areas. Both the BTP and NHE are active primarily in urban areas. In this incidence analysis, these programs are restricted to urban areas and so are less likely than the water subsidy to be allocated to a poor household. In terms of benefits delivered, the BTP is about 10 times larger than the NHE; it is also more progressively 
distributed than the NHE. BTP targets low income homeowners. All else equal, they present greater credit risks, so the belowmarket financing BTP benefit for a similarly valued house is consequently larger than the one for NHE. The NHE indirectly targets a higher range of incomes by providing the same preferential financing on larger loan values (for more expensive houses).

\section{Figure 35. Concentration curves for subsidies}

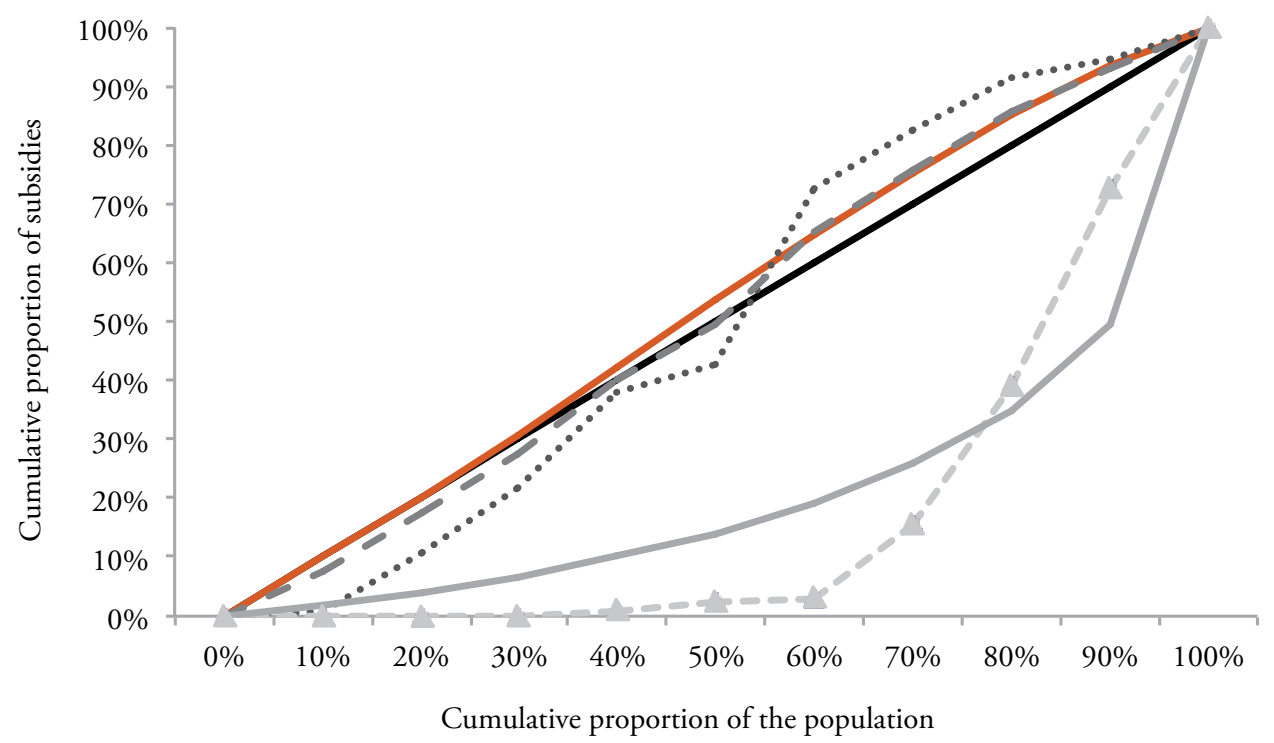

45-deg. line $\longrightarrow$ Water $\cdots . .$. BTP - \pm- NHE - All $\longrightarrow$ Disposable income

The very poorest households (the bottom 10 percent of the disposable income distribution) account for approximately 1 percent of BTP benefits and none of the NHE benefits. The second through to the sixth deciles all have shares of BTP benefits equal to or greater than their population shares (these deciles receive trivial shares of NHE benefits). Therefore, the larger BTP program covers more poor households, but it does not transfer benefits to the poorest of the poor. By virtue of its eligibility criteria and the population it indirectly targets through larger available loans, the NHE program is primarily for middle-income and richer households.

\section{Progressivity of in-kind transfers: education and health}

Government expenditure data on publicly provided education and health services are used to calculate the "unit costs" of services provided - costs per pupil enrolled or cost per outpatient visit, for example. We define the benefit received by individuals to be equal to the amount spent per pupil or per visit. ${ }^{40}$ While health and education services are typically viewed as investments in human capital, we capture only the input side (or the current public sector purchase price) of the provision of these services. In other words, we allocate current public spending on education but not the future returns that such expenditures may generate. 


\section{Progressivity of education}

Spending on public primary schools is absolutely progressive, but the education system becomes less progressive as levels rise from primary to tertiary. Figure 36 shows that enrollment rates in public primary schools are high in all income groups, and that the concentration shares of public primary education expenditures are absolutely progressive, or "pro poor." Low income households receive shares of primary education spending greater than their population shares. ${ }^{41}$ Moving from secondary to tertiary levels, however, the distribution of education benefits becomes first relatively progressive and then regressive at the tertiary level, where the bottom 70 percent of the population receives just 10 percent of all public expenditures. Total public expenditures across all education levels are distributed neutrally. Each group of households receives a benefit share approximately equal to its population share. The benefits of public expenditure on education are conditional on attending school, so it is not surprising that the allocation of education benefits is correlated with enrollment levels.
Spending on public primary schools is absolutely progressive, but the education system becomes less progressive as levels rise from primary to tertiary

\section{Figure 36. Concentration curves, education}

\section{(share benefit received by reference income deciles)}

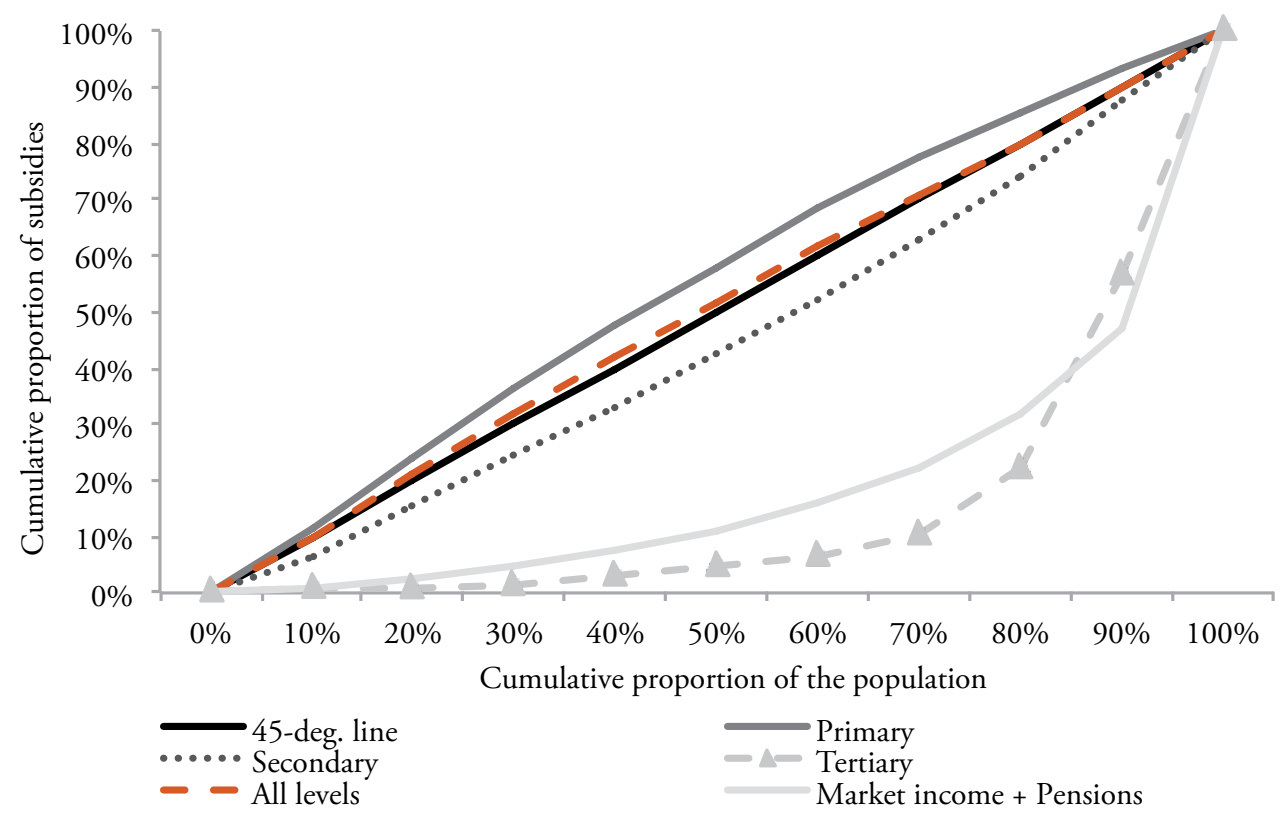

Source: Authors' estimates based on NHIES 2009/10.

Education spending matters for everybody, but spending on primary education has the highest positive impact on utilization rates among the poor. Figure 36 shows that the overall near-neutrality in education spending obscures very unequal access. At the primary level, public education utilization ${ }^{42}$ rates are much higher in poorer deciles than richer ones. At the secondary level, utilization rates are approximately equal (and low) in the poorest and richest deciles. While tertiary utilization is low for all household groups, the rate in the richest households is 28 times higher than the rate in the poorest households. ${ }^{43}$ Figure 37 demonstrates that primary enrollment is nearly universal in Namibia. The observed high primary enrollment rates among 
the poor could be suggesting that poorer households have more kids. Further, this could be reflecting the fact that wealthier households opt for private schools given that, with notable exceptions, Namibian private schools are considered to be of better quality than public schools. The standard
CEQ approach used in this analysis is based on government cost of providing education and does not take into consideration issues of quality or the value that education provides to households. It is, therefore, possible that public spending is pro-poor but not as beneficial to the recipients.

\section{Figure 37. Percent of households utilizing public education, by reference income}

decile

- poorest decile $\quad$ richest decile

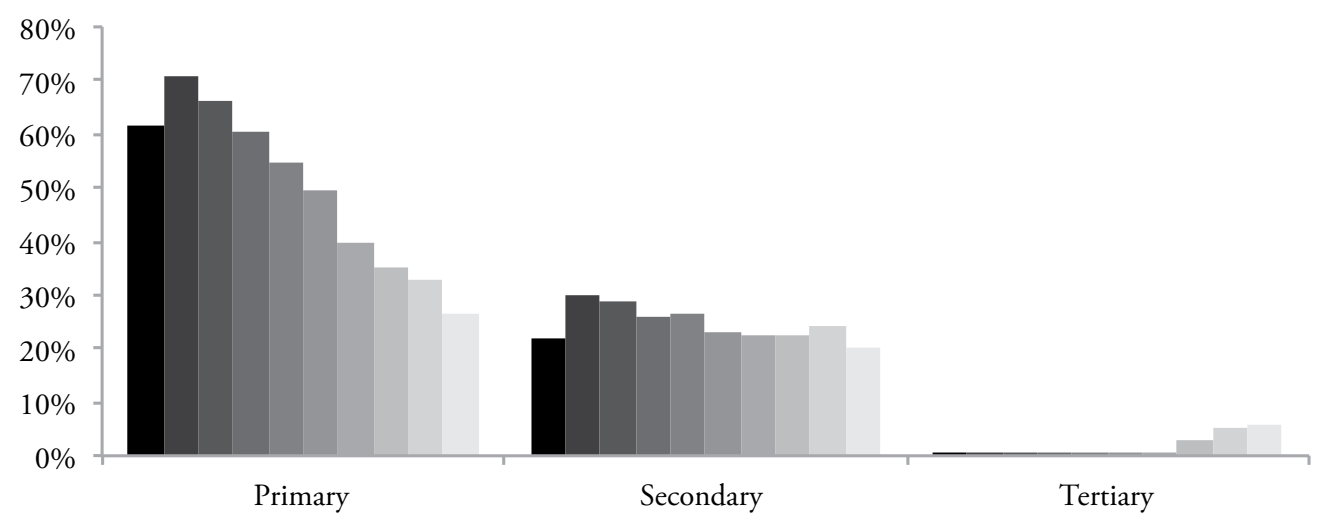

Source: Authors' calculations based on NHIES 2009/10.

\section{Progressivity of health}

Benefitting from public healthcare-related expenditures requires access to healthcare service providers and, as in education, utilization rates drive the progressivity of public health expenditures in Namibia. The NHIES 2009/10 does not include enough detailed healthcare-related questions to allow an estimate of household- or individuallevel utilization rates. An alternate survey - the Namibia Demographic and Health survey, or DHS - was used to estimate an expected household level propensity to utilize publicly provided healthcare services. Total verified expenditures on public inpatient and outpatient healthcare services were allocated according to these propensities. ${ }^{44}$

Health spending is slightly progressive while middle class households benefit most often from the public healthcare system (in expectation). In the bottom 80 percent of the population ranked by market income, the expected shares of health spending received (through expected utilization) are nearly equal to population shares - slightly smaller than population shares in deciles one through to five and slightly higher in deciles six through to eight. Based on administrative data on total spending by facilities and total patients served by facilities, the per-visit public cost for inpatient care is approximately seven times higher than an outpatient visit. ${ }^{45}$ Richer households generally have lower propensities to choose publicly provided healthcare services. ${ }^{46}$

Taken together, expenditures on inkind education and health services are approximately neutral. In both, poorer households acquire greater shares of the low valued but more frequently provided
Health spending is slightly progressive while middle class households benefit most often from the public healthcare system 
public services (primary education and outpatient healthcare). Richer households acquire greater shares of the high valued but not as frequently provided public services (tertiary education and inpatient healthcare). The result is that the distribution of total public expenditures on in-kind health and education services is approximately neutral. Each population group receives a share of benefits equal to its population share (Figure $38)$.

\section{Figure 38. Concentration curves, health and all in-kind}

(share benefit received by reference income deciles)

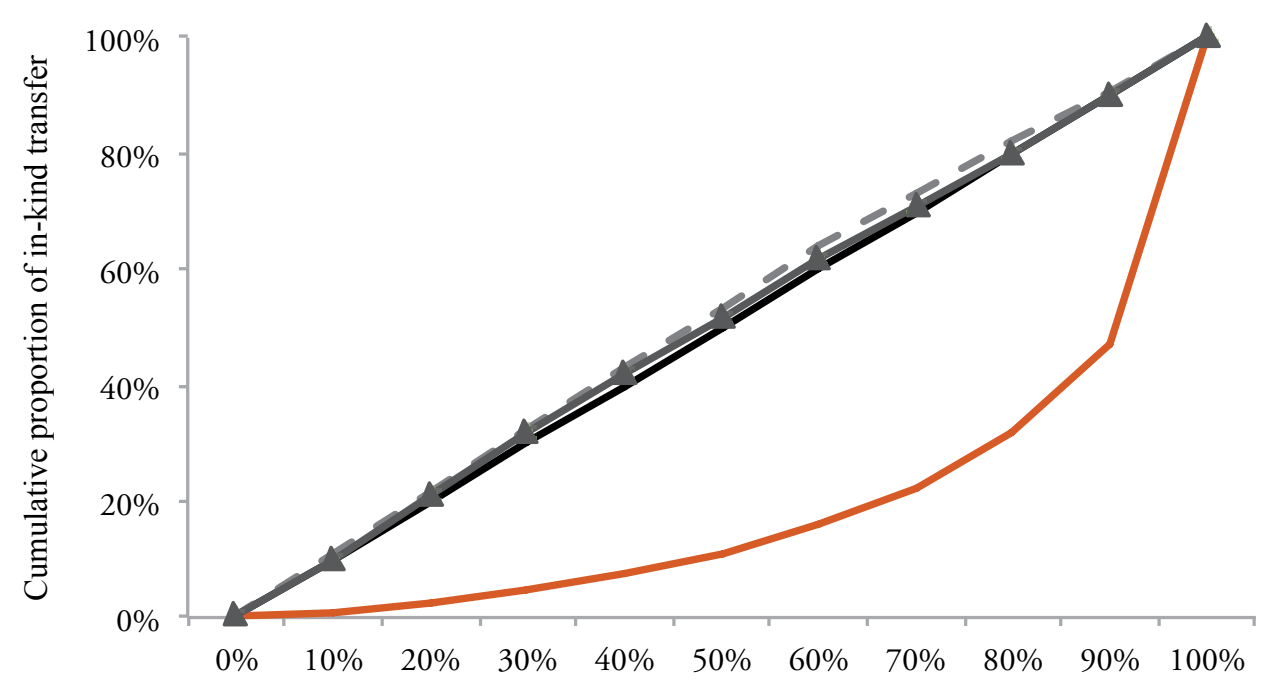

Cumulative proportion of the population (ranked by market income + pensions)

45-deg. line -- Health $\longrightarrow$ Market income + pensions $\longrightarrow$ All in-kind

\section{Tying it all together: Progres- sivity of the fiscal system}

This section summarizes progressivity of the fiscal system (taxes and expenditures) based on the Kakwani index, a measure of progressivity of programs. A negative index suggests regressive programs. The higher the index, the more progressive the programs. Figure 39 shows the Kakwani progressivity index for taxes and transfers. ${ }^{47}$

The majority of the fiscal components are progressive in Namibia. Consistent with what has already been discussed, Figure 39 identifies only two regressive items among the fiscal instruments included in the analysis - the VAT system and tertiary education spending. Tertiary education's regressivity is driven by enrollment rather than program design - the very small number of students reaching the tertiary level are disproportionately nonpoor. Cash transfers (the social grants), inkind transfers (except for tertiary education), and water and housing subsidies (except for the NHE program) are all progressively distributed. Therefore, the bulk of fiscal policy is progressively distributed. 


\section{Figure 39. Progressivity of the fiscal instruments (Kakwani Index)}

Disability grant - children Disability grant - adults

Old age pension

Direct transfers

Veteran's grant

Children's grant

Foster care grant

Primary school

Water subsidy

All transfers and subsidies (excl. pensions)

Health spending

Education, total spending

BTP housing subsidy

Secondary school

Personal income taxes (imputed)

Fuel Levy

NHE housing subsidy

Tertiary education $-0,04$

VAT $-0,07$

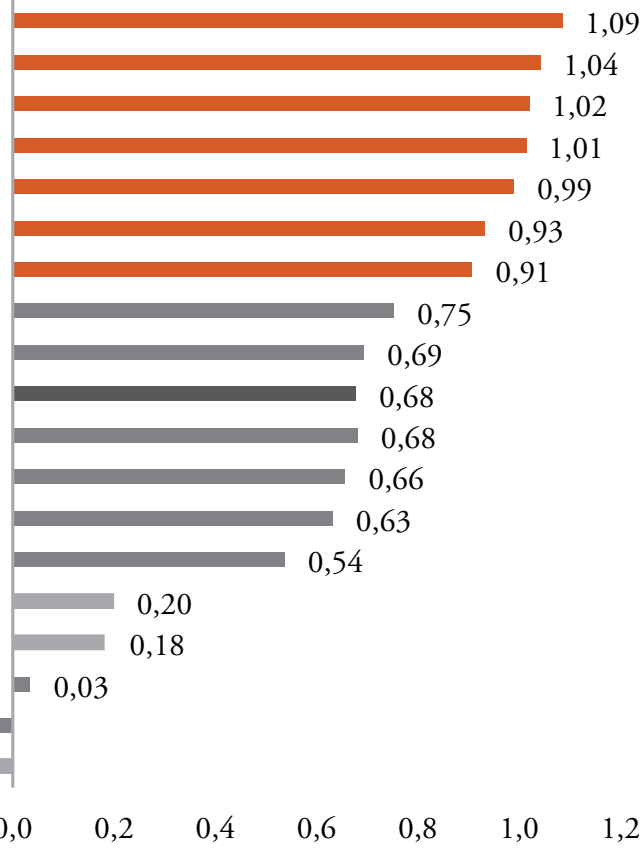

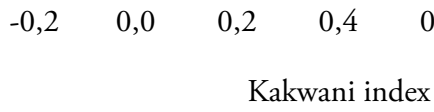




\section{Chapter 6: Impact of Fiscal Policy on Poverty and Inequality}

\section{A. Overall impact of fiscal policy on poverty and inequality}

This chapter estimates the overall impact of Namibia's fiscal policy on poverty and inequality, using the accounting approach described in Chapter 3. This entails first comparing a household's market income the level before payment of taxes and receipt of benefits - to its income after all direct taxes have been paid (net market income). Market income is then compared to the income after direct taxes have been paid and direct transfers have been received (disposable income). Including indirect taxes and indirect subsidies gives post-fiscal income. Adding inkind benefits to households for education and health yields final income, which takes into account all direct and indirect taxes paid as well as all benefits received.

On the whole, fiscal policy reduces poverty in Namibia. ${ }^{48}$ Fiscal policy's impact on poverty and inequality is analyzed at each income concept. Figure 40 summarizes the changes using national extreme poverty levels ${ }^{49}$ (estimated at the national lower bound poverty line of $\mathrm{N} \$ 277.54$ per month in 2009/10 prices) and the Gini coefficient for inequality. Table 5 expands the assessment to alternative indicators of poverty and inequality. Extreme poverty falls from 22.2 percent before the introduction of any fiscal policy measure (market incomes) to 16.7 percent after adding direct transfers and indirect subsidies and subtracting taxes (post-fiscal incomes). This translates to a reduction of 24.7 percent in extreme poverty due to fiscal policy. In-kind transfers are not generally included in poverty calculations because households do not see a monetary contribution.

Direct transfers drive poverty reduction, while the role of taxes and indirect subsidies is less significant. The headcount ratio at the national extreme poverty line shows that the percentage of people below the poverty line decreases by 6.8 percentage points by moving from market income (22.2 percent) to disposable income (15.4 percent)..$^{50}$ The poor pay very little in income taxes, which explains stagnation in poverty due to introduction of direct taxes to market incomes. Indirect taxes and indirect subsidies together do not impact poverty for disposable incomes.

Fiscal policy on the whole reduces inequality in Namibia, largely because of inkind transfers. The Gini coefficient falls from 0.635 for market incomes to 0.590 for postfiscal incomes. If taken into consideration, in-kind transfers in health and education would have the highest redistributive effect. Including the monetized value of in-kind transfers would further reduce the Gini coefficient to 0.429 . Approximately 78.2 percent of the Gini coefficient reduction from market to final incomes is attributed to in-kind transfers, 16.4 percent to direct transfers, and the remaining 5.4 percent to direct and indirect taxes and subsidies. 


\section{Figure 40: Poverty and inequality indicators at each income concept}

Inequality

(Gini index)

BENEFITS

Market Income

Wages and salaries, income from capital, private transfers, contributory pensions

0.635

\section{Direct} transfers

0.594

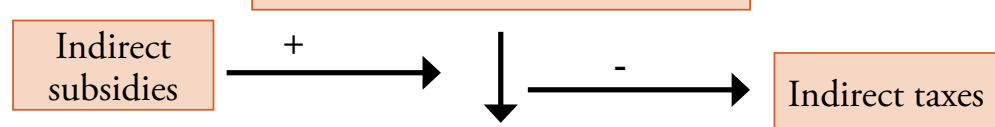

0.590

In-kind transfers (free government services in

0.429 education and health)

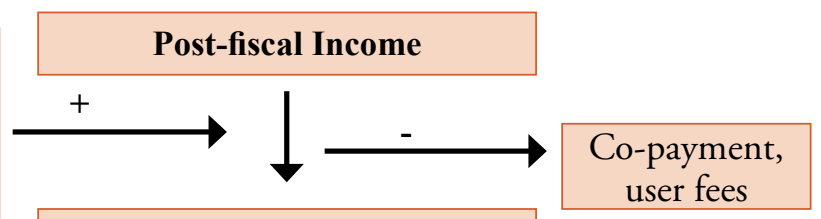

22.2

Personal income and payroll taxex

Net Market Income

15.4

16.7
Poverty

\%)

Final Income 


\section{Table 5. Poverty and inequality indicators for each income concept}

\begin{tabular}{|c|c|c|c|c|c|}
\hline & $\begin{array}{l}\text { Market } \\
\text { Income } \\
\quad+ \\
\text { Pensions }\end{array}$ & $\begin{array}{c}\text { Net } \\
\text { Market } \\
\text { Income }\end{array}$ & $\begin{array}{c}\text { Dis- } \\
\text { posable } \\
\text { Income }\end{array}$ & $\begin{array}{l}\text { Post- } \\
\text { fiscal } \\
\text { Income }\end{array}$ & $\begin{array}{c}\text { Final } \\
\text { Income }\end{array}$ \\
\hline \multicolumn{6}{|l|}{ Inequality indicators } \\
\hline Gini coefficient & 0.635 & 0.628 & 0.594 & 0.590 & 0.429 \\
\hline Theil Index & 0.830 & 0.819 & 0.760 & 0.750 & 0.385 \\
\hline $90 / 10^{1}$ & 16.8 & 15.4 & 10.8 & 10.6 & 5.9 \\
\hline \multicolumn{6}{|l|}{ Headcount poverty indicators } \\
\hline $\begin{array}{l}\text { National extreme poverty } \\
\text { (lower bound poverty) }\end{array}$ & 22.2 & 22.2 & 15.4 & 16.7 & \\
\hline $\begin{array}{l}\text { National poverty } \\
\text { (upper bound poverty) })^{2}\end{array}$ & 34.7 & 34.9 & 28.8 & 31.6 & \\
\hline$\$ 1.90$ PPP 2011 & 22.0 & 22.1 & 15.3 & 16.6 & \\
\hline \multicolumn{6}{|c|}{$\begin{array}{l}\text { Source: All data points based on own estimates based on NHIES 2009/10. Final incomes include in-kind transfers in health and } \\
\text { education that are not included in the poverty calculations. }\end{array}$} \\
\hline \multicolumn{6}{|c|}{${ }^{1}$ The ratio of the average adult equivalent consumption of the 90 th percentile and the average of the 10 th percentile. } \\
\hline \multicolumn{6}{|c|}{$\begin{array}{l}{ }^{2} \text { The official national poverty rate estimated at the upper bound poverty line of } \mathrm{N} \$ 377.96 \text { is } 28.7 \text { percent. However, the } \\
\text { present CEQ calculations find a rate of } 28.8 \text { percent at the disposable income concept. The difference - which is marginal - is } \\
\text { statistical and due to households that were not included in the disposable income calculation because they did not record } \\
\text { answers to all the other NHIES questions necessary to create the other income concepts. }\end{array}$} \\
\hline
\end{tabular}

60 percent of the population are net recipients of public transfers
Most Namibians are net recipients of government transfers. Figure 41 shows that fiscal policy makes a positive contribution to market incomes up to the sixth percentile. In other words, 60 percent of the population are net recipients of public transfers. The ratio of net recipients to net payers/contributors is much larger in many other countries. At final income concept, Namibia's fiscal policy provides net positive transfers (on average) for all but the very richest households. The share of net contributors is generally much higher in other countries. In Armenia (2011), Bolivia (2009), Uruguay (2009), and Ethiopia (2011), for example, third-decile households are already net contributors to public revenues (and all wealthier deciles remain net contributors). For Sri Lanka (2009) and Peru (2009), second-decile households are already net contributors. 


\section{Figure 41: Amounts by which incomes exceed market income (as a share of market}

income)

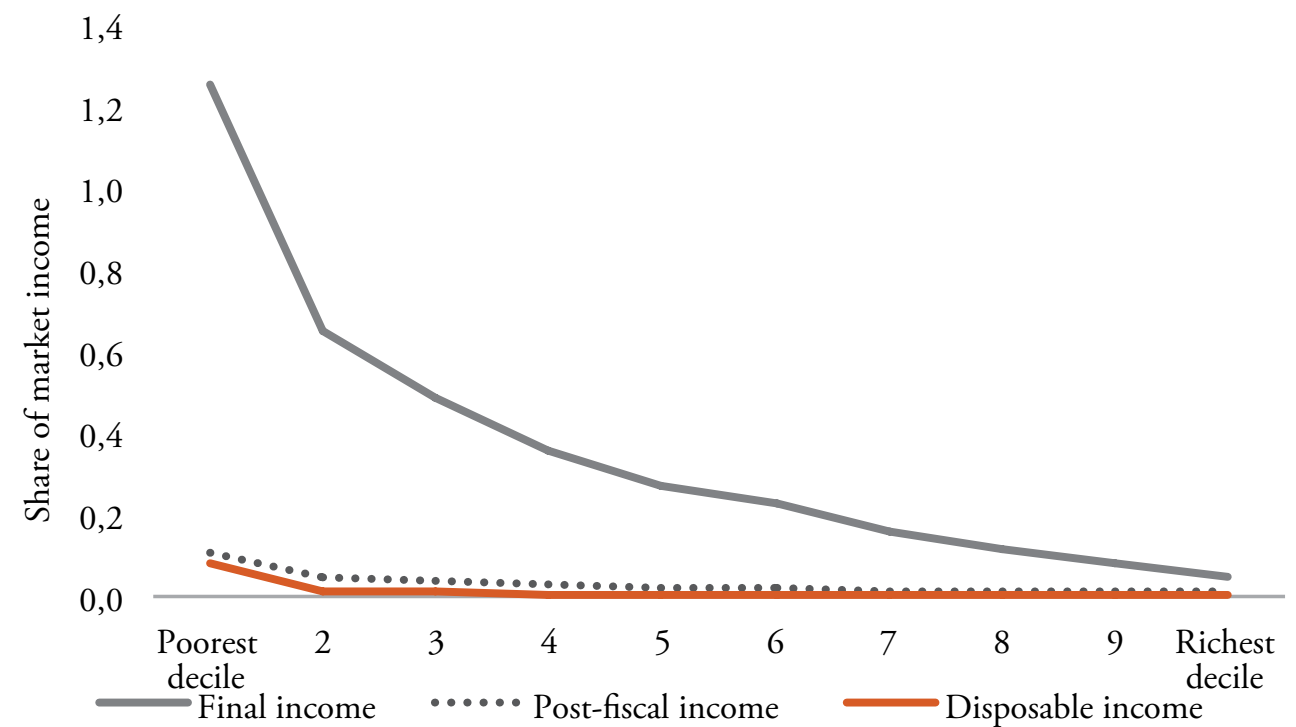

The proportion of individuals made poor by the application of fiscal policy is low. Table 6 summarizes "fiscal mobility," or the movement of individuals across income brackets, between market income and postfiscal income. The standard is the international poverty rate of US\$1.25 PPP per day. After applying all the fiscal instruments in this analysis, less than 4 percent of individuals with market incomes between US\$1.25 and US\$2.50 PPP per day slipped into poverty (i.e., had post-fiscal incomes of less than
US\$1.25 PPP per day). No one with market income above US\$2.50 PPP per day was impoverished. Table 6 also indicates that there are more net "losers" from fiscal policy than net "winners" in every market-income group other than the poorest. However, the amount "winners" gain is greater than the amount "losers" lose for all but the very richest 14 percent of the population (those who start with market incomes above US $\$ 10$ PPP per day).

\section{Table 6. Fiscal impoverishment at a \$1.25 PPP per day poverty line}

\begin{tabular}{l|c|c|c|c|c|c} 
& & & \multicolumn{2}{|c|}{ Post-fiscal < market } & \multicolumn{2}{c}{ Post-fiscal > market } \\
\cline { 4 - 7 } $\begin{array}{l}\text { Market Income } \\
\begin{array}{l}\text { Group (\$ PPP per } \\
\text { day) }\end{array}\end{array}$ & $\begin{array}{c}\text { Popula- } \\
\text { tion (\%) }\end{array}$ & $\begin{array}{c}\text { Made } \\
\text { poor (\%) }\end{array}$ & $\%$ & $\begin{array}{c}\text { Average } \\
\text { loss (of } \\
\text { market } \\
\text { income) }\end{array}$ & $\%$ & $\begin{array}{c}\text { Average gain } \\
\text { (of market } \\
\text { income) }\end{array}$ \\
$\mathrm{y}<1.25$ & 21 & $\ldots$ & 29 & -5.2 & 71 & 293 \\
$1.25<=\mathrm{y}<2.50$ & 28 & 3.9 & 62 & -6.5 & 38 & 29.9 \\
$2.50<=\mathrm{y}<4.00$ & 16 & 0.0 & 79 & -8.1 & 21 & 22.3 \\
$4.00<=\mathrm{y}<10.00$ & 22 & 0.0 & 90 & -10.7 & 10 & 15.7 \\
$10.00<=\mathrm{y}<50.00$ & 12 & 0.0 & 97 & -15.4 & 3 & 10.9 \\
$50.00<=\mathrm{y}$ & 2 & 0.0 & 99 & -17.4 & 1 & 2.9 \\
Source: Author' calculations based on NHIES $2009 / 10$. & & & &
\end{tabular}




\section{B. Marginal contribution of the components to poverty and inequality reduction}

This section analyzes the marginal contribution of each direct transfer and indirect subsidy to poverty and inequality in Namibia. A transfer's marginal contribution is calculated by taking the difference between the inequality indicator without the transfer and with it. For example, the marginal contribution of direct transfers is the difference between the poverty headcounts for disposable income and net market income. ${ }^{51}$ The comparison is carried out on the basis of the poverty rates and coefficients for disposable incomes. This is done to compare the increase and decrease in observed poverty rates. A similar analysis could be done taking into consideration indicators based on market incomes.

\section{Table 7. Marginal contribution of indirect subsidies and direct transfers to} poverty

\begin{tabular}{|c|c|c|c|c|c|c|}
\hline & \multicolumn{3}{|c|}{ Poverty measure } & \multicolumn{3}{|c|}{ Increase in poverty $(\%)$} \\
\hline & 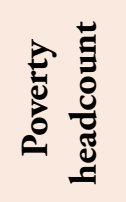 & 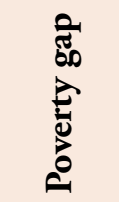 & 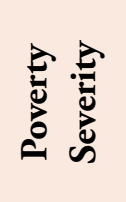 & 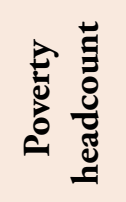 & 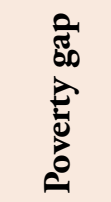 & 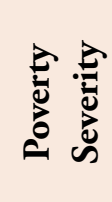 \\
\hline & FGT0 & FGT1 & FGT2 & FGT0 & FGT1 & FGT2 \\
\hline $\begin{array}{l}\text { Poverty indicator (based on } \\
\text { disposable income) }\end{array}$ & 0.154 & 0.042 & 0.017 & & & \\
\hline \multicolumn{7}{|c|}{ Indicator without listed transfer } \\
\hline Direct and indirect transfers & 0.245 & 0.107 & 0.069 & 58.4 & 156.6 & 312.2 \\
\hline Indirect Subsidies & 0.173 & 0.052 & 0.023 & 12 & 23.8 & 39 \\
\hline Build Together Program & 0.158 & 0.045 & 0.019 & 2.2 & 7.9 & 17 \\
\hline National Housing Enterprise & 0.154 & 0.042 & 0.017 & 0 & 0 & 0 \\
\hline Water Subsidy (rural) & 0.169 & 0.048 & 0.02 & 9.6 & 15.8 & 21.4 \\
\hline Direct transfers & 0.225 & 0.094 & 0.059 & 45.8 & 125.6 & 251.6 \\
\hline Old Age Pension & 0.205 & 0.078 & 0.045 & 32.8 & 87 & 169.8 \\
\hline Veterans grant & 0.156 & 0.043 & 0.018 & 1.2 & 4.2 & 8.8 \\
\hline Children's grant & 0.165 & 0.045 & 0.019 & 6.7 & 8.6 & 12 \\
\hline Foster parents grant & 0.157 & 0.043 & 0.018 & 1.8 & 3.7 & 6.2 \\
\hline Disability grant - adults & 0.162 & 0.047 & 0.021 & 5.2 & 12.8 & 25.2 \\
\hline Disability grant - children & 0.156 & 0.043 & 0.017 & 1 & 2.2 & 4.8 \\
\hline \multicolumn{7}{|c|}{ Source: Author' calculations based on NHIES 2009/10. } \\
\hline
\end{tabular}


Severe poverty would be higher in the absence of direct and indirect transfers. Table 7 presents the increases in the poverty headcount, poverty gap, and squared poverty gaps (severity) in the absence of direct and indirect transfers, together and separately. The poverty headcount would rise by 58.4 percent higher without the transfers, the poverty gap would be 156.6 percent higher, and the squared poverty gap would increase by 312.2 percent. The impact is thus greater on the depth and severity of poverty than on the poverty headcount.

Direct transfers reduce poverty more than indirect transfers (subsidies), with the Old Age Pension being the most important contributor. In the absence of the OAP, the rest of the transfers and subsidies each play a relatively small role in poverty reduction. This could suggest poor targeting of most transfers in terms of poverty reduction.

\section{Table 8. Marginal contribution of indirect subsidies and direct transfers to}

inequality

\begin{tabular}{lcc} 
& Gini coefficient & $\begin{array}{c}\text { Change in Gini } \\
\text { (percent) }\end{array}$ \\
\hline Gini (based on disposable income) & 0.594 & \\
Direct and indirect transfers & Indicator without listed transfer & 6.7 \\
Indirect Subsidies & 0.634 & 1.4 \\
Build Together Program & 0.602 & 0.3 \\
National Housing Enterprise program & 0.596 & 0 \\
Water Subsidy (rural) & 0.594 & 1 \\
Direct transfers & 0.6 & 5.3 \\
Old Age Pension & 0.625 & 3.7 \\
Veterans grant & 0.616 & 0.2 \\
Children's grant & 0.595 & 0.6 \\
Foster parents grant & 0.597 & 0.2 \\
Disability grant - adult & 0.595 & 0.6 \\
Disability grant - child & 0.597 & 0.1 \\
\hline Sources: Authors' calculations. & 0.594 & \\
\hline
\end{tabular}

The Old Age Pension drives the povertyreducing impact of direct transfers 
The impact of transfers on income inequality is less than the impact on inequality. Table 8 illustrates the increases in the Gini coefficient in the absence of the transfers. Taken together, the transfers reduce inequality only 6.7 percent. As in the poverty analysis, the OAP is the most effective program in reducing poverty.

\section{Comparison to other middle-income countries}

Although income inequality is very high in Namibia, the country performs quite well when compared with other middleincome countries in terms of the impact of fiscal policy on income inequality. As shown in Table 9, the reduction in the Gini coefficient in moving from market income to disposable income is among the highest of the countries included in the CEQ sample. To a large extent, this is associated with direct transfers. In absolute terms, Namibia's Gini coefficient reduction trails only South Africa's. Considering the percentage change, Namibia's reduction remains among the top performers, but the country's level of inequality is still very high.

\section{Table 9. Gini coefficient at each income concept}

Although income inequality is very high in Namibia, the country performs quite well when compared with other middle-income countries in terms of the impact of fiscal policy on income inequality

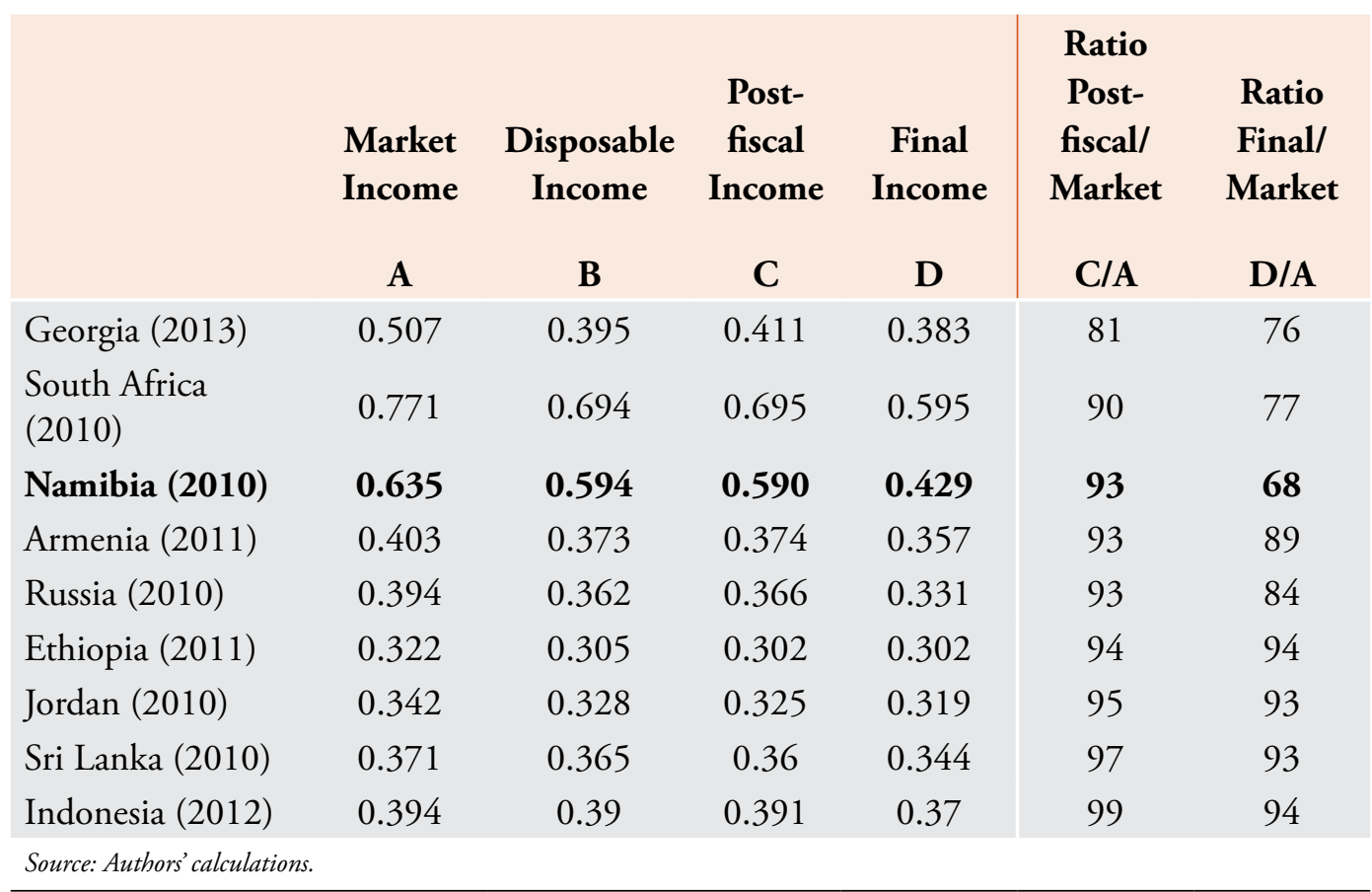


Figure 42: The impact of fiscal policy on inequality worldwide, circa 2009/2010 (measured in Gini points)

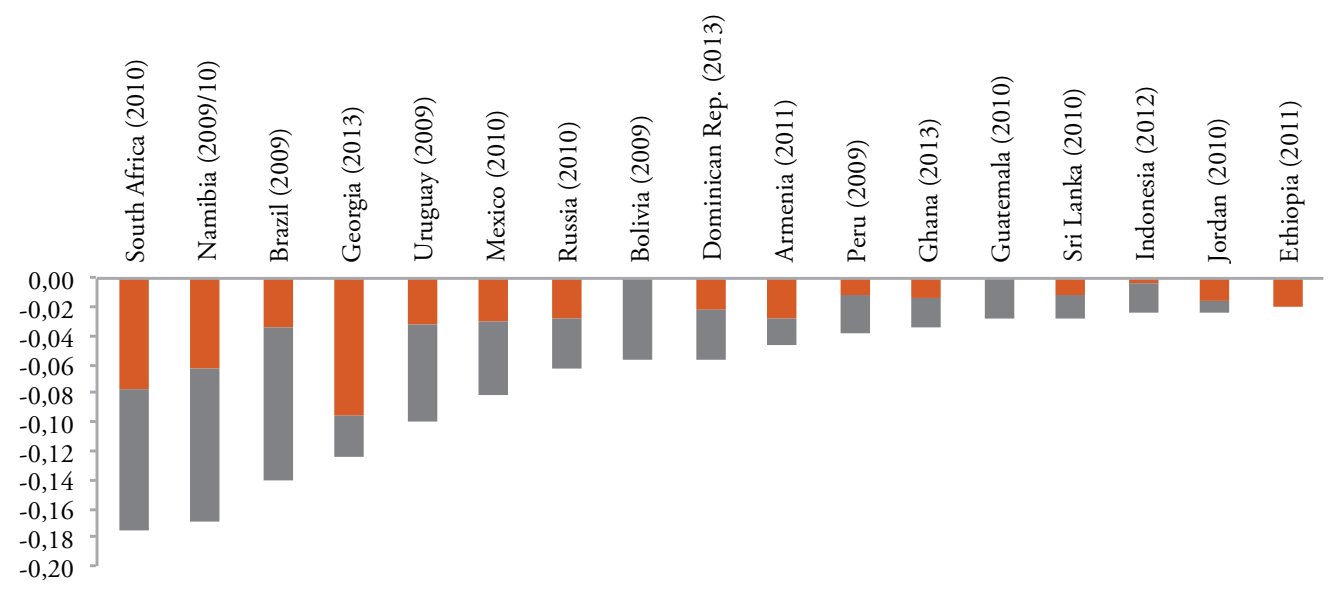

- Taxes and direct transfers $\quad$ In-kind transfers

Sources: Namibia: World Bank calculations from Ministry of Finance budget documents. Uruguay (Bucheli et al., 2014), Guatemala (Cabrera et al., 2015), Brazil (Higgins and Pereira, 2014), Peru (Jaramillo, 2014), Bolivia (Paz et al., 2014), Mexico (Scott, 2014), Ghana (Younger et al., 2015), Dominican Republic (Aristy-Escuder et al., 2016), El Salvador (Beneke et al., 2014), Ethiopia, Georgia, Sri Lanka, Indonesia, Jordan, South Africa, Russia: (Inchauste and Lustig, forthcoming).

Using the international poverty line of $\$ 2.50$ a day, the performance of Namibia's fiscal policy in terms of poverty reduction is generally similar to other CEQ countries. In terms of percentage point poverty reduction, Namibia is in the middle of the distribution
(Table 10). The impact is lower than in South Africa and Mexico but higher than in Armenia, Brazil, and Costa Rica. As in most countries, net indirect consumption taxes increase the poverty headcount in Namibia. 
Table 10. Poverty headcount ratio for the US\$ 2.50 PPP a day for each income concept

$\left.\begin{array}{lcccc} & \text { Market Income } & \begin{array}{c}\text { Net Market } \\ \text { Income }\end{array} & \begin{array}{c}\text { Disposable } \\ \text { Income }\end{array} & \begin{array}{c}\text { Post-fiscal } \\ \text { Income }\end{array} \\ & (1) & (2) & (3) & (4)\end{array}\right)$

Internationally, the poverty reduction attributable to fiscal policy in Namibia is on par with South Africa: from the set of individuals who would be poor without fiscal expenditures, approximately 11 percent are in receipt of fiscal transfers that help them escape impoverishment (measured as expenditure of US\$2.50 PPP or less per day). Across the low- and middle-income countries included in Figure 43, this result is approximately average. 


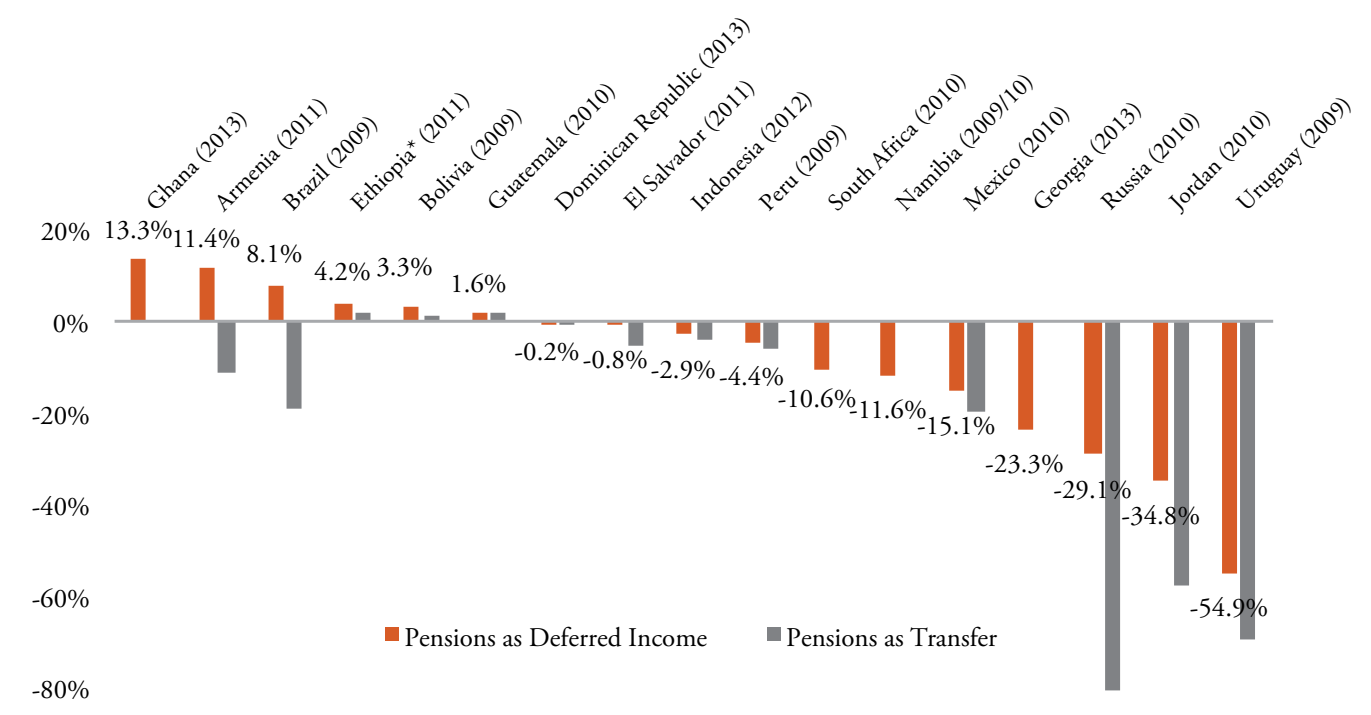

$-100 \%$

Sources: Namibia: World Bank calculations from Ministry of Finance budget documents. Uruguay (Bucheli et al., 2014), Guatemala (Cabrera et al., 2015), Brazil (Higgins and Pereira, 2014), Peru (Jaramillo, 2014), Bolivia (Paz et al., 2014), Mexico (Scott, 2014), Ghana (Younger et al., 2015), Dominican Republic (Aristy-Escuder et al., 2016), El Salvador (Beneke et al., 2014), Ethiopia, Georgia, Sri Lanka, Indonesia, Jordan, South Africa, Russia: (Inchauste and Lustig, forthcoming).

\section{Changes in fiscal policy between 2009/10 and 2016 and possible implications}

Given that this analysis uses data from $2009 / 10$, it is important to highlight changes in fiscal policy that took place between then and now and their possible implication on the incidence of fiscal policy. On the tax side, since 2010 the Ministry of Finance has been reforming inland tax administration through institutional reorganization into functional units (e.g., large taxpayers' office), reengineering of business processes, modernization of IT systems, and increasing the number of staff working on tax collection. The government has also been working to close loopholes in tax policies and to reduce tax avoidance by international companies. These have helped to improve filing rates, improve compliance rates, reduce arrears, etc. This has partly contributed to an increase in domestic taxes. In addition, the personal income tax schedule was changed in 2013 by reducing rates applied at lower levels of income (Table 11). Among other effects, this should encourage Namibians to work in the formal sector. 


\section{Table 11. Income tax rates in 2009 and 2013}

\begin{tabular}{|cc}
\hline Taxable income (N\$) & 2009 \\
Up to 40,000 & Marginal rate (percent) \\
40,001 to 80,000 & 0 \\
80,001 to 200,000 & 32 \\
200,001 to 750,000 & 34 \\
Over 750,000 & 37 \\
& \\
\hline Taxable income (N\$) & Marginal rate (percent) \\
Up to 50,000 & 0 \\
50,001 to 100,000 & 18 \\
100,001 to 300,000 & 25 \\
300,001 to 500,000 & 28 \\
500,001 to 800,000 & 30 \\
800,001 to $1,500,000$ & 32 \\
Over $1,500,000$ & 37 \\
\hline Source: Ministry of Finance budget documents. & \\
\hline
\end{tabular}

Spending on social sectors such as education and health has been growing as a share of GDP (Figure 10). Notably, the government has consistently increased the coverage (number of beneficiaries) and the level of support given to social welfare grant recipients. For example, the OAP grant increased from $\mathrm{N} \$ 500$ in 2010 to $\mathrm{N} \$ 600$ in 2013 and then to $\mathrm{N} \$ 1,000$ in 2015. The 2016/17-2018/19 Mediumterm Expenditure Framework commits to increasing this to $N \$ 1,200$ per month in the next two years. Funds for the funeral benefits of recipients of the OAP and the disability grant were introduced in 2015. Furthermore, new programs targeted at reducing poverty and inequality have been introduced since 2009/10. In June 2016, for example, the first Namibian food bank initiative was launched and targets households whose income falls below $\mathrm{N} \$ 400$ per month.

These abovementioned developments suggest that fiscal policy is likely to have assumed an increased role in poverty and inequality reduction, particularly in light of high unemployment. 


\section{Chapter 7: Conclusions and Implications for Policy and}

Data

\section{A. Main findings}

Namibia's social spending is generous, producing significant impacts on poverty and inequality, but its efficiency can be significantly improved. Namibia dedicates a substantial part of its GDP to direct transfers, and it is one of the few African countries that fully funds these programs out of its own resources. Overall spending on direct transfers is above the average for SubSaharan African countries, but comparable to the average for developing countries. The distribution of social assistance spending is biased toward programs that are not meant to target only the poor. Namibia's 2009/10 fiscal instruments reduced market income poverty through a system of progressive - but only loosely targeted - social spending.

The tax system is merely neutral - taxes are generally paid by the relatively betteroff population and the redistribution effect is low. On the tax side, replenishing fiscal resources (with household contributions) is accomplished directly by taxing incomes and indirectly by taxing certain consumption activities. Consumption taxes are neutral to slightly regressive. Personal income taxes are progressive, but few of these revenues are collected from households that appear in the NHIES. Everyone in Namibia contributes to tax revenues - some through consumption activities at the least, others through income taxes. The government uses these (and other) resources to provide transfers and in-kind spending that raises incomes for the poorest individuals and households as well as a large pool of non-poor households.

Direct transfers and subsidies are important for the poor but not well targeted. Direct transfers are progressive in absolute terms, meaning they more effectively target the poor than in-kind transfers or subsidies. However, they are loosely targeted, and households in all deciles receive some of these transfers. As a result, less than half of all direct transfer expenditures are actually working to reduce existing poverty. Predictably, direct transfers have only a modest impact on measured inequality. The targeting efficiency of selected programs should be improved. Direct transfers and subsidies reduce poverty by 58 percent, with most of the impact coming from the Old Age Pension (OAP) and water programs. The OAP's impact on inequality is minor. Namibia lacks efficiently designed means tested social protection programs.

In-kind transfers are generally larger than direct transfers, but they are received only upon access. While poorer households benefit from both public education and health services; nonetheless, richer households consume enough of the high value services that the overall distribution of in-kind transfers is approximately neutral. A neutral distribution of benefits still produces large inequality reductions because benefits received by poorer households are so large relative to their incomes.

Introduction of proxy means tested (PMT) programs and consolidation of 
programs could improve efficiency of the social protection system. Consolidation could be helpful if the consolidated benefit is given to all current beneficiaries who receive at least one of the six transfers analyzed in this study. To eradicate poverty efficiently, Namibia would need to put in place a good targeting system of identifying the poor and granting them benefits adequate to close their consumption deficits.

\section{B. Distributional analysis of taxes}

A relatively large tax burden falls on the working population. Administrative data shows that taxes (PIT plus indirect taxes, excluding SACU receipts) are about 17.8 percent of GDP. This is a relatively large tax burden among countries that have done CEQ assessments. Most countries with a similar-sized indirect tax take (e.g. Ethiopia) have a much smaller direct tax take, and most countries with a similar-sized direct tax take (e.g. South Africa) have a smaller indirect tax take. Namibia has also a relatively high total tax revenue as a percentage of GDP.

Direct taxes included in the analysis are large but have low coverage. At about 6.8 percent of GDP according to administrative records, direct taxes (PIT) are large relative to the other low- and middle-income countries that have done CEQ assessments. Only Brazil and South Africa have larger direct tax burdens as a percentage of GDP. Direct taxes have low coverage: the household data indicates that 16 percent of households pay PIT. The International Monetary Fund (IMF) sources indicate that the top 0.1 percent of households pay over 45 percent of all PIT, and the top 4.5 percent pay over twothirds of all PIT.

Indirect taxes have high coverage, but they are rather small in comparison to the direct taxes. All households pay some indirect taxes. However, only about one-quarter of households pay any fuel taxes. Indirect taxes are about 6.7 percent of GDP when using administrative records - small relative to the other low and middle-income countries that have done CEQ assessments. Only Indonesia (at 6 percent of GDP) and Mexico (at 4.3 percent of GDP) collect noticeably less than Namibia in indirect taxes.

The overall incidence of direct and indirect taxes is progressive, but the marginal impact of taxes on poverty and inequality is minimal. In Namibia's actual fiscal system, taxes are progressive with respect to market income. Direct taxes do not impact poverty headcount as very few poor or near-poor households pay taxes. Direct taxes, being progressive, slightly reduce inequality. Indirect taxes and subsides, however, are distribution neutral and have almost no effect on inequality, but they increase poverty slightly.

\section{Transfers and subsidies}

Namibia's expenditure on transfers is significant, but its targeting efficiency could be improved. The grants are generally progressive in terms of their coverage and almost one-third of the population benefits from them. However, proxy means testing could significantly improve efficiency. The OAP tops other grants in coverage and it is progressively targeted. Children's grants are given to a relatively small portion of the population and they are generally well targeted. Veterans, foster care, and disability grants are generally small in terms of coverage, but they also show a progressive pattern. The targeting efficiency of the many transfers in Namibia could be significantly improved by the introduction of proxy means tested programs.

Although direct transfers are low in coverage and poor in efficiency, they matter 
for the poor. The OAP, the largest grant, is the clear "winner" in terms of impact, although this is probably because of its large coverage rather than its targeting. In a distant second place is the children's grant. With the exception of the OAP, which benefits about 17 percent of the population, coverage is low, benefits are small, and targeting is loose. Even with the OAP, the richest decile still captures 5 percent of the benefits.

In comparison to other countries, transfers in Namibia do not do much for inequality even though they are absolutely progressive in their allocation. Perhaps because of the many transfers in Namibia, only a few countries (Indonesia, Guatemala, Peru) spend noticeably less on direct transfers.

Subsidies are more progressively targeted in Namibia than other transfers, largely because of the water subsidy. In addition to water, the subsidies section analyzed the two housing programs, the BTP and the NHE. The subsidies are slightly progressive. However, this progressivity is largely driven by the water subsidy; it accounts for nearly three-quarters of all subsidy expenditures analyzed in the study, while BTP accounts for nearly one-quarter and NHE for about 2 percent.

Proxy means testing is recommended. By itself, PMT could provide better coverage at existing spending levels, providing a greater poverty and inequality impact. However, PMT requires large sunk costs and high maintenance/operational expenses (e.g. continuous updates of beneficiary registers). Consolidation could be helpful if it captures all current beneficiaries who receive at least one of the six transfers; in practice, though, that would mean higher expenditures because a larger benefit package has to be transferred to the same (cumulative) beneficiary population.

\section{In-kind transfers in health and education}

In-kind transfers in health and education are weakly progressive. Their impact is driven almost entirely by primary education spending. For example, 78 percent of the 0.206 Gini point reduction from market to final income is due to the marginal impact of in-kind transfers. Two-thirds of that is due to primary education spending. The remaining third comes from secondary and tertiary education and inpatient and outpatient healthcare spending.

Primary education is the most progressively distributed in-kind transfer. This is largely because enrollment is nearly universal and poorer households have more children. Secondary education is approximately neutral because enrollment at this level starts to skew towards richer households; tertiary education is regressive. This pattern can be seen clearly in both the concentration curves and the marginal contributions to inequality.

Primary education's marginal contribution is 10 Gini points, which is the largest single factor in inequality reduction of the expenditures and revenues in the study. The single contribution from primary education accounts for nearly 70 percent of the overall contribution of in-kind transfers and about 50 percent of the total Gini reduction from market to final income.

Secondary education's marginal contribution - at 1.6 Gini points - is similar to the marginal contribution from the Old Age Pension. The old-age grant covers about 17 percent of the population, and public secondary education covers about 34 percent. Hence, secondary education is slightly propoor relative to market income but not as pro-poor as the OAP. Tertiary education is regressively allocated - its concentration coefficient is larger than the market income Gini. 


\section{E. Impact on poverty and inequality}

Public social spending reduces poverty and inequality, but the impacts of the components differ. Social spending is weighted heavily toward in-kind spending, which in turn is weighted heavily toward primary education, which turns out to be the most inequalityreducing benefit. If there were no in-kind spending, for example, the reduction in inequality would only be 0.045 Gini points, while actual social spending, including inkind transfers, yields a reduction of 0.206
Gini points. The inequality-reducing impact of in-kind social spending can be attributed to access (enrollment) as well as demographics.

The poverty-reducing impact is associated primarily with the direct transfers - low spending leading to low coverage and/or small transfer magnitudes. Social spending is progressively distributed and reduces inequality, but its impact would be much more significant with better targeting efficiency of direct transfers. Poverty and inequality could be much lower if targeting of direct transfers improved. 


\section{Annex 1: What is Fiscal Incidence Analysis}

This appendix presents additional details on the methodology and data as well as the revenue and expenditure components that make up CEQ income concepts. The CEQ framework and the results discussed in this report measure any income redistribution achieved by the application of fiscal policy's revenue and expenditure components. ${ }^{54}$

Fiscal incidence analysis consists of allocating taxes and public spending to households or individuals so that incomes before taxes and transfers can be compared with incomes after taxes and transfers, where the latter may include the monetized value or consumption of free public services. CEQ methodology makes these allocations in household level micro-data, so the CEQ analysis can (in principle) generate the impact of taxes and transfers disaggregated by any characteristics or profiles observed in the micro-data - for example, gender, ethnicity, or location.

The most common type of fiscal incidence analysis, the one used in this report, is the accounting approach, which takes place in a post-hoc, static setting. This approach begins from a "before" or "pre-fiscal" income and allocates the proper amount of a tax or a transfer to each household or individual. If the fiscal intervention is a direct tax (transfer), the post-tax (post-transfer) income is calculated by subtracting (adding) the tax paid (transfer received). In the accounting approach, behavioral responses that taxes and public spending may trigger in individuals or households are not taken into account.

More formally, define a "before taxes and transfers" income of unit $h$ (typically an individual or a household) as $I_{h}$, and net taxes of type $i$ as $T_{i}$. Let us define the "allocator" of tax $i$ to unit $h$ as $S_{i h}$ (or the share of net tax $i$ borne by unit $h$ ). Then post-tax income of unit $h$ can be defined as: $Y_{h}=I_{h}-\sum_{i} T_{i} S_{i}$. Complications in the accounting approach arise when actual incidence in the micro-data differs from statutory incidence (or incidence according to policies and their implementing regulations).

Partial fiscal incidence analysis assesses the impact of one or several fiscal policy interventions - for example, income taxes or the use of public education and health services. Comprehensive fiscal incidence analysis assesses the impact of the revenue and spending sides simultaneously; namely, the impact of direct and indirect taxes, cash and in-kind transfers, and indirect subsidies. In addition, there is point-in-time versus lifetime fiscal incidence analysis, which can assess a current system or estimate the potential or actual effects of particular reforms. It can make different assumptions about tax shifting and the value of in-kind benefits. The analysis can assess the average incidence of a tax or benefit or it can assess the incidence on the margin; e.g., the distribution of an increase in the spending of public education.

In this study, we assess the current fiscal system on partial and comprehensive bases. We estimate actual average incidence and effective average rates (i.e., we use average tax collection rates including possible tax evasion) and we value in-kind benefits according to the government cost approach.

Incidence studies use micro-data from 
household surveys or rely on incidence indicators from secondary sources (usually micro-data sets themselves). In practice, surveys will not include information on every tax paid or transfer received (or the information if it exists may be inaccurate), so that information must be generated in a consistent and methodologically solid way. Frequently, the information will have to be generated using more than one method to check the sensitivity of the results to assumptions that cannot be externally validated.

Indicators that can be generated by incidence analysis include measures of progressivity, such as incidence - i.e., the share of taxes (transfers) paid (received) as a proportion of the pre-tax (pre-transfer) income - and concentration coefficients, which measure the share (by decile or quintile) of specific or overall taxes and transfers. In addition, fiscal incidence studies report inequality and poverty indicators such as headcount ratios and Gini coefficients - before and after taxes and transfers. Some studies include indicators of horizontal equity to capture how policies impact individuals who are equal before fiscal intervention. 


\section{Annex 2: Classifying Targeting Methods $^{55}$}

Individual/household assessment is a method in which an official (usually a government employee) directly assesses, household by household or individual by individual, whether the applicant is eligible for the program. It is the most laborious of targeting methods. The gold standard of targeting is a verified means test that collects (nearly) complete information on a household's income and/or wealth and verifies the information collected against independent sources such as pay stubs or income and property tax records. This requires the existence of such verifiable records in the target population, as well as the administrative capacity to process this information and to continually update it in a timely fashion. For these reasons, verified means tests are extremely rare in developing countries where the poorest households receive income from a myriad of diverse sources and formal record keeping is nonexistent. Other individual assessment mechanisms are used in the absence of the capacity for a verified means test. Three common ones are simple means tests, proxy means tests, and communitybased targeting.

Simple means tests, with no independent verification of income, are not uncommon. A visit to the household by a program social worker may help to verify in a qualitative way that visible standards of living (which reflect income or wealth) are more or less consistent with the figures reported. Alternatively, the social workers' assessment may be wholly qualitative, taking into account many factors about the household's needs and means but not having to quantify them. These types of simple means tests are used for both direct transfer programs and for fee-wavering programs, with or without the visit to the household.

Proxy means tests, while relatively rare, are being instituted in a growing number of countries. We use the term to denote a system that generates a score for applicant households based on fairly easy to observe characteristics of the household such as the location and quality of the dwelling, ownership of durable goods, demographic structure of the household, and the education and possibly, occupations of adult members. The indicators used in calculating this score and their weights are derived from statistical analysis (usually regression analysis or principal components) of data from detailed household surveys of a sort, too costly to be carried out for all applicants to large programs. The information provided by the applicant is usually partially verified by either collecting the information on a visit to the home by a program official.

Community based-targeting uses a group of community members or a community leader whose principal functions in the community are not related to the transfer program to decide who in the community should benefit. School officials or the parentteacher association may determine entry to a school-linked program. A group of village elders may determine who receives grain provided for drought relief, or special committees composed of common community members or a mix of community members and local officials may be specially formed to determine eligibility for a program. 
The idea is that local knowledge of families' living conditions may be more accurate than the results of a means test conducted by a government social worker or a proxy means test.

Categorical targeting refers to a method in which all individuals in a specified category - for example, a particular age group or region — are eligible to receive benefits. This method is also referred to as statistical targeting, tagging, or group targeting. It involves defining eligibility in terms of individual or household characteristics that are fairly easy to observe, hard to falsely manipulate, and correlated with poverty.
Age, gender, ethnicity, land ownership, demographic composition, or geographical location are common examples that are fairly easy to verify. Age is a commonly used category, with cash child allowances predominant in transition countries, supplemental feeding programs for children under five common in poor countries, and non-contributory pensions for the elderly common in many places. Geographic targeting is even more common, often used in combination with other methods. Unemployment or disability status is somewhat harder to verify, but cash assistance to these groups may be categorically targeted as well. 
1 Source: http://www.commitmentoequity. org/.The Commitment to Equity (CEQ) was designed to analyze the impact of taxation and social spending on inequality and poverty in individual countries and provide a roadmap for governments, multilateral institutions, and nongovernmental organizations in their efforts to build more equitable societies. As of June 2016, the CEQ analysis has been completed in 20 countries and carried out in 15 countries.

2 The Namibia Statistics Agency (NSA) uses three national poverty lines (NSA, 2012). These include the food, lower bound and upper bound poverty lines which were set at $\mathrm{N} \$ 204.05, \mathrm{~N} \$ 277.54$, and $\mathrm{N} \$ 377.96$ per month, respectively, in $2009 / 10$ prices. The food poverty line recognizes that all human beings have a basic minimum nutritional requirement. The lower bound poverty line is based on households that sacrifice some of their basic food requirements in order to meet their non-food needs. Therefore, the minimum amount set on non-food basic needs is added to the food line. The upper bound poverty line is based on households whose food expenditure is very close to the food line. For these households, in addition to the basic food requirements that are measured by the food poverty line, there are certain basic non-food items that they need. The terminology used in this report is consistent with that used by NSA which considers the proportion of the population below the upper bound poverty as poor while those below the lower bound poverty line are considered to be severely poor. Severe poverty and extreme poverty are used interchangeably in this report.
3 The formulation process for National Development Plan V (NDP5) was launched in June 2016.

4 The poverty headcount in this target is measured at the national poverty line of $\mathrm{N} \$ 277.54$ in 2009/10.

5 See ILO (2014) for complete descriptions of these and other social programs.

6 See http://www.op.gov.na/ documents/84084/264431/

SONA+2016,+final.pdf/c57aa559-673f4618-8a49-37aeddc3f919

7 Total tax collections are taken to exclude Southern Africa Customs Union (SACU) receipts, which are not paid by Namibian households. SACU receipts are revenue for the Government but not part of its "tax collections."

8 Taxable income refers to gross income less exemptions and allowable deductions. Individual incomes could be salary/ wages, pension/annuity payments and investment income (interest and dividends).

9 Other zero-rate items include: petrol, diesel and paraffin; direct export of goods and services; international transport; sale of a going concern; sale of land and buildings for residential purposes and erection of residential buildings; supply of municipal services to residential accounts; supply of agricultural land to be used for resettlement purposes; supplies made in respect of guarantees; supply of undertaking services for funerals; supply of services physically rendered outside Namibia; postage stamps (but not postage stamps for collectors); telecommunication services to residential accounts; supplies by charitable organizations and similar 
institutions; supply of livestock (on the hoof); supply and repair of goods to be used as aids by physically handicapped persons who are blind, deaf, crippled or a chronic invalid; services for any adjustment or modification in respect of a vehicle used for these purposes.

Exemptions are applicable on the following supplies: financial services; medical services and services provided by hospitals; group finance/management companies and inter-company loans; residential leases and fringe-benefit accommodations; public transport services; educational services; management of group housing and commercial premises; employee organizations; local authorities; fringe benefits; supplies to foreign heads of state.

10 It is important to acknowledge other criterion besides equity for evaluating a tax system, including the impact on economic growth.

11 The classification into these categories is purely for the purposes of this study. The study acknowledges that most of the government's budget is allocated to sectors other than "social".

12 At 14.9 percent of GDP in 2009/10, total general government spending in Namibia was relatively low compared to the middle-income country average. The corresponding values for comparable middle-income countries are: South Africa at 34.8 percent; Indonesia at 17.5 percent, and Peru at 25.5 percent.

13 See ILO (2014) for details on the coverage of different types of social assistance programs.

14 This meant that parents were no longer required to pay fees toward the School Development Fund.

15 The Namibian education system is structured as follows: pre-school (early childhood development, care, and education) is typically for children up to age 6; this is followed by seven years of primary school, made up of lower primary (grades 1-4) and upper primary (grades 5-7); secondary school constitutes junior secondary (grades 8-10) and senior secondary (grades 11-12); tertiary/higher education is then offered at teacher education colleges, agricultural colleges, the University of Namibia, and the Polytechnic of Namibia. According to Fischer (2010), the private sector runs pre-schools and kindergartens, while the state runs other schools.

16 For more details on the approaches to fiscal incidence analysis see, for example, Adema and Ladaique (2005), Alleyne et al. (2004), Atkinson (1983), Barr (2004), Bergh (2005), Birdsall et al. (2008), Bourguignon and Pereira da Silva (2003), Breceda et al. (2008), Coady (2006), Ferreira and Robalino (2010), Fiszbein et al. (2009), Fullerton and Metcalf (2002), Goñi et al. (2011), Grosh et al. (2008), Kakwani (1977), Lambert (2002), Lora (2006), Lustig and Higgins (2013), Morra et al. (2009), O'Donnell et al. (2008), Shah (2003), Suits (1977), van de Walle and Nead (1995), and World Bank (2000/2001, 2006, 2009).

17 We do not provide an assessment of the drivers or causes of poverty or inequality, nor do we estimate how welfare might change if fiscal policy were changed; the analysis only describes the level of poverty or inequality that exists before and after the government undertakes fiscal policy.

18 Complications in the accounting approach arise when actual incidence (in the microdata) differs from the statutory incidence (or incidence according to policies and their implementing regulations).

19 For more on the definitions of progressivity, see Lustig and Higgins (2013). 
20 See, for example, Duclos and Araar (2006), p. 136.

21 A progressive transfer (so defined) will be equalizing in the sense that inequality measured after receipt of the transfer will be lower than was before receipt of the transfer. See, for example, Lambert (1985).

22 To establish progressivity in the CEQ process, it is not necessary for transfers (taxes) to be progressive (either relatively or absolutely in the case of transfers) at every point (i.e., for every individual) in the distribution. Transfers (taxes) can be globally progressive, even if they are not everywhere progressive. See, for example Duclos and Araar (2006).

23 The 45-degree line indicates the cumulative share of the total population that an individual represents. It is the line of perfect equality.

24 See Lindert, Skoufias and Shapiro (2006), Scott (2011) and O'Donnell et al. (2008).

25 NHIES is enumerated once every five years; the 2015/16 survey was being enumerated and collected as this report was being prepared.

26 Even when the "event" of paying a tax or receiving a benefit can be identified directly, it is not always possible to determine the amounts paid or received. In cases where inference or imputation is needed to estimate a value of a tax or benefit for a directly identified payer or recipient, the CEQ Master Workbook provides the details on the algorithms used to estimate these values.

27 Often, a combination of these methods works best. For example, simulating distributions of benefits in the primary survey using empirical distributions estimated from other sources. Lustig and Higgins (2013) describe the methods to allocate taxes and transfers in detail.
28 Net national income is gross national income less depreciation and other payments to fixed capital. Total market income from all sources in the survey represents about 67 percent of average gross national income in 2009/10.

29 The main reason for the use of consumption instead of income for this analysis is the significant underreporting of incomes among richer households. Consumption data represents the actual welfare of the population much better and thus is used as a proxy for market income.

30 In other words, the derived market income measure not only compresses the distribution of welfare, it also changes the rank position of some households in the distribution.

31 Despite high level of revenues in Namibia in comparison to other developing countries, Namibian tax-to-GDP ratio is significantly lower than the OECD average (34 percent in 2009/10, based on the WDI data).

32 Direct tax payers are imputed. If a household recalls paying income taxes or having income taxes withheld, that household is a taxpayer. The amount paid is simulated, with the total amount paid by NHIES respondents as a percent of total disposable income equal to the total amount collected (reported in budget documents) as a percent of national accounts final consumption expenditures.

33 Two caveats should be kept in mind in interpreting this result. First, the profile of PIT payers - including their rank position in the income distribution can change significantly depending on the reference income used. For example, the poorest 20 percent of the observed market income distribution contains no taxpayers; however, the poorest 20 percent of the derived market income contains 
about 0.5 percent of all taxpayers. In the bottom 60 percent, the market income group contains approximately 3 percent of all taxpayers, compared with 7 percent for derived market income. Second, the number of (observed) taxpayers and tax revenue reported from NHIES households are far less than comparable data from budget reporting documents and secondary sources. For example, NHIES reports just over 71,000 PIT taxpayers in 2009/10; secondary sources indicate that the number of actual taxpayers was nearly double the NHIES number at 139,000. Secondary sources also indicate that the top 1 percent of taxpayers (ranked by PIT paid) contribute more than 50 percent of total PIT revenues; NHIES households with minimum taxable income equal to the top 1 percent of taxpayers contribute only 28 percent of PIT.

$34 \mathrm{We}$ view the incidence of indirect taxes (and subsidies) with respect to disposable income because households make consumption decisions over a household budget that includes cash transfers received, affording them a higher consumption level than market income alone would allow. In turn, this implies households would have paid less in indirect taxes (or received less in consumption subsidies), in the absence of these transfers.

35 The fuel levy is a much smaller source of public revenues than the VAT; in addition, we cannot determine from NHIES how much fuel was consumed for household use (i.e., not for vehicles/transport). For both reasons, VAT has a 98 percent share in total indirect tax collected from NHIES households. As a result, we discuss here the cumulative impact of both VAT and the fuel levy.

36 NHIES was used to assess performance of specific programs in Namibia. Disaggregated NHIES data was used to analyze program performance, as well as to provide estimates of coverage, targeting and generosity of social spending. Using household survey data has its limitations. While household surveys, unlike administrative data, allow estimating incidence of transfers for different socioeconomic groups, some social assistance transfers are captured by surveys, while others are not. Also the survey is not designed to capture some of the small transfers and the results should be interpreted with caution.

37 Coady, D., M. Grosh and J. Hoddinott. 2004. "Targeting of Transfers in Developing Countries: Review of Lessons and Experience", World Bank and IFPRI.

38 It is important to acknowledge the possibility that the relatively high generosity of transfers could create disincentives to work in the formal sector. An investigation of this is beyond the scope of this report.

39 We view the incidence of subsidies with respect to disposable income because households make consumption decisions over household budgets that include the cash transfers they receive, affording them higher consumption levels than what market incomes alone would allow. In turn, this implies that households would have received less in consumption subsidies in the absence of these transfers.

40 We caution that this approach does not address the average, marginal, or relative quality of the services provided, although public service provision quality does vary in Namibia.

41 Specifically, concentration shares will be proportional to shares of enrolled children. Poorer households in Namibia have more school-age children and a higher propensity to send them to public schools; both tendencies produce a larger share of children in public schools, if enrollment rates are equal across deciles. 
42 A "utilizing" household is one with at least one child enrolled in a public school. Utilization can be higher because of the greater frequency of school-age children in some households, the greater propensity to enroll a school-age child in the public system, or both.

43 For a single student, the tertiary education benefit is approximately 2.7 times larger than the primary benefit, and richer households account for virtually all public tertiary utilization. Nonetheless, total education expenditures are approximately neutrally distributed because of the great numbers of publicly enrolled primaryaged children from poor households.

44 From administrative and budget records, we determined the government's "unit cost" of a publicly-provided outpatient or inpatient healthcare visit. From the DHS, we determined shares of inpatient and outpatient visits accounted for by income-ranked population groups. The DHS also allowed us to determine a propensity to visit public providers (as opposed to private providers). We use the latter share and propensity estimates to allocate verified public healthcare visits (and attendant benefits) to representative households in the NHIES.

45 This is based on total verified visits to outpatient care facilities, total verified inpatient days, and shares of government expenditures on health going to facilities providing both types of services.

46 Similar to education, private healthcare facilitates are typically considered to be of better quality compared to public facilities.

47 The Kakwani index of tax (transfer) progressivity is twice the area between the market income Lorenz curve and the tax (transfer) concentration curve. If the tax (transfer) concentration curve is below (above) the Lorenz curve, the Kakwani index will be positive, which indicates that taxes (transfers) are progressive. If the tax (transfer) concentration curve is above (below) the Lorenz curve, the Kakwani index will be negative, which indicates that taxes (transfers) are regressive.

48 As Bibi and Duclos (2010) and Lustig (2014) explain, the potential impact of any individual intervention should not be calculated by taking the difference between consecutive pairs of income concepts. For example, taking the difference between the Gini coefficient for post-fiscal and disposable income is not equal to the contribution of indirect subsidies and indirect taxes to the decline of inequality from market to post-fiscal income. There is an error component to our estimates when they are arranged sequentially because (a) the contribution of each intervention is path dependent; (b) we are showing one possible path; and (c) the actual path is unobserved. We can compare, however, the impact of interventions on any indicator with respect to market income. This is what we do in this section. Perhaps a more precise way of stating our result is the following: Without the redistributive process set in motion (via taxes and transfers) by fiscal policy, measured inequality would be higher in Namibia (in a static setting).

49 The use of 'extreme poverty' is consistent with the terminology used by NSA which considers the proportion of the population below the lower bound poverty severely poor. Severe poverty and extreme poverty are used interchangeably in this report.

50 The official national extreme/severe poverty rate estimated at the lower bound poverty line of $\mathrm{N} \$ 277.54$ is 15.3 percent. However, the present CEQ calculations find a rate of 15.4 percent at the disposable income concept (reported in Figure 40, Table 5, and Table 7). The difference which is marginal - is statistical and due 
to households that were not included in the disposable income calculation because they did not record answers to all the other NHIES questions necessary to create the other income concepts.

51 One drawback of the marginal contribution method is that the sum of all the marginal contributions is not equal to the total redistributive effect because of the interaction between policies, limiting the accuracy of the magnitude of each contribution (Shorrocks, 2013).

52 Based on the World Bank's WDI databases (http://data.worldbank.org/indicator/ GC.TAX.TOTL.GD.ZS), Namibia is among the list of the top 30 percent of the countries in terms of the total tax revenue as a percentage of GDP.

53 We have not actually compared the PMT based distribution and the current distribution. The basis for thinking that PMT will improve the outcomes is based on cross-country experiences. It is also important to emphasize that a combination of measures should be considered as a long term solution for Namibia. A whole range of targeting mechanisms (community, PMT, selftargeting, etc.) should be considered. An additional research in this area should be undertaken, suggesting appropriate methods that will improve targeting efficiency of direct transfers in Namibia.

54 For more details, see Lustig, Nora and Sean Higgins. (2013). Commitment to Equity Assessment (CEQ): Estimating the Incidence of Social Spending, Subsidies and Taxes. Handbook. CEQ Working Paper No. 1, Center for Inter-American Policy and Research and Department of Economics, Tulane University and InterAmerican Dialogue, September.

55 This annex is based on (and generally taken from) Coady et al. (2004). 


\section{References}

Adema, Willem, and Maxime Ladaique. 2005. "Net Social Expenditure, 2005 Edition: More Comprehensive Measures of Social Support." OECD Social, Employment and Migration Working Papers 29.

Alleyne, Dillon, James Alm, Roy Bahl, and Sally Wallace. 2004. "Tax Burden in Jamaica." Georgia State University International Studies Program Working Paper 04-34.

Aristy-Escuder, Jaime, Maynor Cabrera, Blanca Moreno-Dodson, and Miguel Sánchez-Martín. 2016. "Fiscal policy and redistribution in the Dominican Republic." CEQ Working Paper No. 37, CEQ Institute.

Atkinson, Anthony B. 1983. Social Justice and Public Policy. MIT Press.

Barr, Nicholas. 2004. Economics of the Welfare State, Fourth Edition. New York: Oxford University Press.

Beneke, Margarita, Nora Lustig, and José Andrés Oliva. 2014. El impacto de los impuestos y el gasto social en la desigualdad y la pobreza en El Salvador. CEQ Working Paper No. 26, Center for Inter-American Policy and Research and Department of Economics, Tulane University and InterAmerican Dialogue.

Bergh, Andreas. 2005. "On the counterfactual problem of welfare state research: How can we measure redistribution?" European Sociological Review 21(4): 345-357.

Besley, Timothy, and Torsten Persson. 2013. "Taxation and Development," in Auerbach, Alan, Raj Chetty, Martin Feldstein, and Emmanuel Saez, eds., Handbook of Public Economics Volume 5, 2013.

Bibi, Sami, and Jean-Yves Duclos. 2010. "A Comparison of the Poverty Impact of
Transfers, Taxes and Market Income Across Five OECD Countries," Bulletin of Economic Research 62(4): 387-406.

Birdsall, Nancy, Augusto de la Torre, and Rachel Menezes. 2008. Fair Growth: Economic Policies for Latin America's Poor and Middle-Income Majority. Washington DC: Brookings Institution Press.

Bourguignon, François, and Luiz A. Pereira da Silva, eds. 2003. The Impact of Economic Poverty and Income Distribution. Washington DC: World Bank and Oxford University Press.

Breceda, Karla, Jamele Rigolini, and Jaime Saavedra. 2008. "Latin America and the Social Contract: Patterns of Social Spending and Taxation." Policy Research Working Paper 4604. World Bank, Latin American and Caribbean Region, Poverty Department, Poverty Reduction and Economic Management Division. Washington DC: World Bank.

Bucheli, Marisa, Nora Lustig, Máximo Rossi, and Florencia Amábile. 2014. "Social Spending, Taxes and Income Redistribution in Uruguay," in Lustig, Nora, Carola Pessino, and John Scott, eds., The Redistributive Impact of Taxes and Social Spending in Latin America, special issue. Public Finance Review 42(3).

Cabrera, Maynor, Nora Lustig, and Hilcias Moran. 2015. "Fiscal Policy, Inequality and the Ethnic Divide in Guatemala," World Development 76: 263-279.

Coady, David. 2006. "The distributional impacts of indirect tax and public pricing reforms," in Coudouel, Aline, and Stefano Paternostro, eds., Analyzing the Distributional Impact of Reforms: A Practitioner's Guide. World Bank: Washington DC. 
Coady, David, Margaret Grosh, and John Hoddinott. 2004. "Targeting of Transfers in Developing Countries: Review of Lessons and Experience." World Bank and IFPRI.

Duclos, Jean-Yves, and Abdelkrim Araar. 2006. Poverty and Equity: Measurement, Policy, and Estimation with DAD. New York: Springer and International Development Research Centre.

Ferreira, Francisco, and David Robalino. 2010. "Social Protection in Latin America: Achievements and Limitations." Policy Research Working Paper 5305. Washington DC: World Bank, Latin America and Caribbean Region, Office of the Chief Economist, and Human Development Network Social Protection and Labor Unit.

Fischer, Gereon. 2010. The Namibian educational system. Windhoek: FriedrichEbert-Stiftung.

Fiszbein, Ariel, Norbert Schady, Francisco Ferreira, Margaret Grosh, Nial Kelleher, Pedro Olinto, and Emmanuel Skoufias. 2009. Conditional Cash Transfers: Reducing Present and Future Poverty. Washington DC: World Bank.

Fullerton, Don, and Gilbert Metcalf. 2002. “Tax Incidence," NBER Working Paper 8829, March.

Goñi, Edwin, Humberto López, and Luis Servén. 2011. "Fiscal Redistribution and Income Inequality in Latin America," World Development 39(9): 1558-1569.

Government of the Republic of Namibia. 2004. Namibia Vision 2030: Policy Framework for Long-Term National Development. Office of the President, Windhoek. 2016. Harambee Prosperity Plan, 2016/17-2019/20: Namibian Government's Action Plan towards Prosperity for All. Office of the President, Windhoek.

Grosh, Margaret, Carlo del Ninno, Emil Tesliuc, and Azedine Ouerghi. 2008. For Protection and Promotion: The Design and Implementation of Effective Safety Nets.
Washington DC: World Bank.

Higgins, Sean and Claudiney Pereira. 2014. "The Effects of Brazil's Taxation and Social Spending on the Distribution of Household Income," in Lustig, Nora, Carola Pessino, and John Scott, eds., The Redistributive Impact of Taxes and Social Spending in Latin America, special issue, Public Finance Review 42(3).

Honorati, Maddalena, Ugo Gentilini, and Yemtsov Ruslan. 2015. The state of social safety nets 2015. Washington, D.C: World Bank Group.

Inchauste, Gabriela, Nora Lustig, Mashekwa Maboshe, Catriona, Purfield and Ingrid Woolard. 2015. The Distributional Impact of Fiscal Policy in South Africa. Policy Research Working Paper 7194. World Bank: Poverty Global Practice Group \& Macroeconomics and Fiscal Management Global Practice Group.

Inchauste, Gabriela, and Nora Lustig. The Distributional Impact of Fiscal Policy: Experience from Developing Countries, edited by. Washington, D.C: World Bank. Forthcoming.

International Labor Organization (ILO). 2014. Namibia Social Protection Floor Assessment. Geneva: ILO, 2014.

Jaramillo, Miguel. 2014. "The Incidence of Social Spending and Taxes in Peru," in Lustig, Nora, Carola Pessino, and John Scott, eds., The Redistributive Impact of Taxes and Social Spending in Latin America, special issue, Public Finance Review 42: (3).

Jellema, Jon, Matthew Wai-Poi, and Rythia Afkar. "The Distributional Impact of Fiscal Policy in Indonesia." World Bank. Forthcoming.

Kakwani, Nanak C. 1977. "Measurement of Tax Progressivity: An International Comparison," The Economic Journal 87(345): 71-80.

Lambert, Peter. 1985. "On the redistributive effect of taxes and benefits," 
Scottish Journal of Political Economy 32(1): 39-54. . 2002. The Distribution and Redistribution of Income, Third Edition. Manchester United Kingdom: Manchester University Press.

Lindert, Kathy, Emmanuel Skoufias, and Joseph Shapiro. 2006. "Redistributing Income to the Poor and Rich: Public Transfers in Latin America and the Caribbean." Social Protection Discussion Paper 0605. Washington, D.C: The World Bank.

Lora, Eduardo, ed. 2006. The State of State Reforms in Latin America. Washington DC: World Bank.

Lustig, Nora, and Sean Higgins. 2013. Commitment to Equity Assessment (CEQ): Estimating the Incidence of Social Spending, Subsidies and Taxes. Handbook. CEQ Working Paper No. 1, Center for Inter-American Policy and Research and Department of Economics, Tulane University and Inter-American Dialogue, September. 2014. "Taxes, Transfers, Inequality and the Poor in the Developing World. Round 1." CEQ Working Paper No. 23, Center for Inter-American Policy and Research and Department of Economics, Tulane University and Inter-American Dialogue.

Morra Imas, Linda G., and Ray C. Rist. 2009. The Road to Results: Designing and Conducting Effective Development Evaluations. Washington DC: World Bank.

Namibia Statistics Agency. 2012. Poverty Dynamics in Namibia: A comparative study using the 1993/94, 2003/04 and the 2009/10 NHIES surveys. Windhoek: Namibia Statistics Agency.

2014. Namibia Labor Force Survey 2014 Report. Windhoek: Namibia Statistics Agency.

O’Donnell, Owen, Eddy van Doorslaer, Adam Wagstaff, and Magnus Lindelow. 2008. Analyzing Health Equity Using
Household Survey Data: A Guide to Techniques and Their Implementation. Washington, D.C: The World Bank.

Paz Arauco, Verónica, George Gray Molina, Wilson Jiménez Pozo, and Ernesto Yáñez Aguilar. 2014. "Explaining Low Redistributive Impact in Bolivia," in Lustig, Nora, Carola Pessino, and John Scott, eds., The Redistributive Impact of Taxes and Social Spending in Latin America, special issue, Public Finance Review 42(3).

Sauma, Pablo, and Juan Diego Trejos. 2014. "Gasto Público, Social Impuestos, Redistribución del Ingreso y Pobreza en Costa Rica," CEQ Working Paper No. 18.

Scott, John. 2011. "Gasto Público y Desarrollo Humano en México: Análisis de Incidencia y Equidad." Working Paper for Informe sobre Desarrollo Humano México 2011. Mexico City: UNDP. . 2014. "Redistributive Impact and Efficiency of Mexico's Fiscal System," in Lustig, Nora, Carola Pessino and John Scott, eds., The Redistributive Impact of Taxes and Social Spending in Latin America, special issue, Public Finance Review 42(3).

Shah, Anwar, ed. 2003. Handbook on Public Sector Performance Reviews. Washington DC: The World Bank.

Shorrocks, A. 2013. "Decomposition procedures for distributional analysis: a unified framework based on the Shapley value," Journal of Economic Inequality 11(1): 99-126.

Suits, Daniel B. 1997. "Measure of Tax Progressivity," The American Economic Review 67(4): 747-752.

Van de Walle, Dominique, and Kimberly Nead, eds. 1995. Public Spending and the Poor: Theory and Evidence. Baltimore and London: Published for the World Bank by John Hopkins University Press.

Woldehanna, Tassew, Tsehaye Eyasu, Ruth Hill, Gabriela Inchauste, and Nora Lustig. 2014. "A Fiscal Incidence Analysis 
for Ethiopia.” Background Paper for World Bank Poverty Assessment. Forthcoming.

Work Bank. 2000/2001. "World Development Report 2000/2001: Attacking Poverty." Washington, DC and New York: Published for the World Bank by Oxford University Press.

2006. "Country Policy and Institutional Assessments." Operations Policy and Country Services. Washington, DC: World Bank

. 2009. "The World Bank's Country Policy and Institutional Assessment, An Evaluation." Independent Evaluation Group. Washington, DC: World Bank. 2009. "Levels and Patterns of Safety Net Spending in Developing and Transition Countries." Safety Net Primer, Washington DC: The World Bank. . 2014. South Africa Economic Update: Fiscal Policy and Redistribution in an Unequal Society. November. Washington, DC: World Bank.

Younger, Stephen, and Artsvi Khachatryan. 2014. "Fiscal Incidence in Armenia.” Background Paper for World Bank Armenia Public Expenditure Review (forthcoming).

Younger, Stephen, Eric Osei-Assibey, and Felix Oppong. 2015. "Fiscal Incidence in Ghana." CEQ Working Paper No. 35. Center for Inter-American Policy and Research and Department of Economics, Tulane University, Ithaca College, University of Ghana and World Bank. 
Notes: 
Does Fiscal Policy Benefit the Poor and Reduce Inequality in Namibia?

\section{Notes:}


